medRxiv preprint doi: https://doi.org/10.1101/2021.10.26.21265535; this version posted October 28, 2021. The copyright holder for this preprint

(which was not certified by peer review) is the author/funder, who has granted medRxiv a license to display the preprint in perpetuity.

It is made available under a CC-BY-NC 4.0 International license .

\title{
Water, Sanitation, and Women's Empowerment: A systematic review and qualitative metasynthesis
}

Bethany A. Caruso ${ }^{1,2}$, Amelia Conrad ${ }^{2}$, Madeleine Patrick ${ }^{2}$, Ajilé Owens ${ }^{3}$, Kari Kviten ${ }^{2}$, Olivia Zarella $^{1}$, Hannah Rogers ${ }^{4}$, Sheela S. Sinharoy ${ }^{1,2}$

${ }^{1}$ Hubert Department of Global Health, Rollins School of Public Health, Emory University, Atlanta, Georgia, United States of America

${ }^{2}$ Gangarosa Department of Environmental Health, Rollins School of Public Health, Emory University, Atlanta, Georgia, United States of America

${ }^{3}$ Department of Epidemiology, Rollins School of Public Health, Emory University, Atlanta, Georgia, United States of America

${ }^{4}$ Woodruff Health Sciences Center Library, Emory University, Atlanta, Georgia, United States of America 


\begin{abstract}
Background

Water and sanitation programs historically have focused on women's instrumental value in improving effectiveness and impact of programs, though focus is shifting to consider how programming and conditions may contribute to women's empowerment an gender equality. To date no systematic review has comprehensively assessed and synthesized evidence on water and sanitation and women and girls' empowerment. The primary aims of this review were to: a) identify empirical water and sanitation research that engaged empowerment and/or empowermentrelated domains from a pre-specified conceptual model; b) tabulate and report how empowermentrelated terminology was used, where and when research was conducted, what methods were leveraged, and if water and/or sanitation was the primary focus; c) synthesize findings by empowerment domain and water and/or sanitation focus.
\end{abstract}

\title{
Methods and Findings
}

The conceptual model of women's and girls' empowerment developed by van Eerdewijk et.al (2017) informed our search strategy and analysis. The model presents three interrelated domains (agency, resources, institutional structures) and 13 sub-domains of empowerment. We searched MEDLINE, EMBASE, CABI Global Health, PsycINFO, CINAHL and AGRICOLA for any peerreviewed sources presenting research related to water and/or sanitation and either empowerment and/or related terms from the conceptual model (4 May 2020). Systematic and ancestry and decendency searching identified 12,616 publications, of which 257 were included following screening, representing 1,600,348 participants. We assessed all studies using the Mixed-Method Appraisal Tool (MMAT). We followed the 'best-fit framework synthesis' approach for analysis, using the domains and sub-domains of the conceptual model as codes to assess all included sources. During coding, we inductively identified two additional sub-domains relevant to water and sanitation: privacy and freedom of movement. Thematic analysis guided synthesis of coded text by domain and sub-domain. The majority of research took place in Asia $(46 \% ; 117)$ or Africa $(40 \% ; 102)$, engaged adults $(69 \% ; 177)$, and were published since $2010 ;(82 \% ; 211)$. A greater proportion of studies focused on water $(45 \% ; 115)$ than sanitation $(22 \% ; 57)$ or both $(33 \% ; 85)$. Over half of articles use the term empowerment yet only 7\% (17) provided a clear definition or conceptualization. Agency was the least commonly engaged domain $(47 \% ; 122)$ while the Resources domain was dominant $(94 \% ; 241)$. Measures for assessing empowerment and related domains is limited. This review was limited by only including sources in English and only includes menstruation-focused research in the context of water and sanitation.

\section{Conclusions}

Water and sanitation research specifically engaging women's and girls' empowerment in a welldefined or conceptualized manner is limited. A substantial body of research examining domains and sub-domains of empowerment exists, as does research that illuminates myriad negative impacts of water and sanitation conditions and circumstances women's and girl's well-being . Available research should be used to develop and evaluate programs focused on improving the life outcomes of women and girls, which has only been minimally conducted to date. A more comprehensive 'transformative WASH' that includes gender-transformative approaches to challenge and reduce systemic constraints on women's and girls' resources and agency is not only warranted but long overdue. 


\section{Introduction}

Water, sanitation, and hygiene (WASH) access, behaviors, experiences, and physical and social environments have been shown to influence multiple outcomes, including diarrheal disease, soil transmitted helminth and protozoa infection, active trachoma and schistosomiasis, pneumonia, anaemia, mental health and general well-being, economic productivity, school absence, and child growth and cognitive development. ${ }^{1-14}$ This demonstrated importance of WASH underlies Sustainable Development Goal (SDG) 6, which aims to "Ensure availability and sustainable management of water and sanitation for all." 15 Still, water and sanitation access remain out of reach for large proportions of the global population: $29 \%$ of the global population lacks access to water that is available when needed and free from chemical and fecal contamination, and 55\% lacks access to household sanitation facilities that safely manage excreta. ${ }^{16}$ Furthermore, while SDG Target 6.2 emphasizes "paying special attention to the needs of women and girls," who are recognized as WASH duty-bearers globally, ${ }^{17-20}$ data often fail to reflect the gender-specific benefits and harms of WASH conditions, behaviors, and interventions. Despite recognition of WASH as on the pathway to gender equality, ${ }^{21}$ a full understanding of the gendered effects of WASH remains limited, prompting calls for improved gender measurement, data, and learning. ${ }^{19,22-25}$

Critical discourse on gender and WASH is evolving. While historically WASH programs focused on women's instrumental value in improving effectiveness and impact of programs, focus has been shifting to consider how WASH programming may contribute to women's empowerment ${ }^{26-29}$. Recent reviews examining WASH and gender further demonstrate this shift in focus. ${ }^{30-32}$ In their scoping review, Dery et al. (2020) explored how empowerment was used in WASH; five interrelated dimensions of empowerment were identified among the 13 included articles: access to information, participation, capacity building, leadership and accountability, and decisionmaking. ${ }^{30}$ MacArthur and colleagues (2020) conducted a critical review of WASH-gender literature from 2008-2018 to understand how WASH studies engaged gender equality. Their distant-reading analysis of the 155 included articles, which focused only on assessment of titles and abstracts, revealed that few engaged with gender transformational-aspects of gender equality. ${ }^{31}$

To date there have been no rigorous systematic reviews to assess and synthesize evidence on WASH and women and girls' empowerment. The primary aims of this literature review were to: a) identify empirical water and sanitation research that engaged empowerment and/or empowerment-related domains; b) tabulate and report how empowerment-related terms were used, where and when research was conducted, what methods were leveraged, and if water and/or sanitation was the primary focus; c) synthesize findings by empowerment domain and water and/or sanitation focus.

\section{Methods}

We report our review using Preferred Reporting Items for Systematic Reviews and Meta-Analyses (PRISMA) criteria (see Supplemental Table 1).

\section{Search Strategy}

Our search strategy aimed to identify studies that engaged with and reported on water, sanitation, and empowerment, including associated domains and sub-domains of empowerment. The conceptual model of empowerment outlined by Van Eerdewijk et al. (2017), ${ }^{33}$ which extended 
work by Naila Kabeer, ${ }^{34}$ the World Bank, ${ }^{35}$ and CARE, ${ }^{36}$ guided our search and subsequent analyses. Table 1 provides definitions of empowerment, and the three domains (agency, resources, institutional structures) and 13 subdomains included in the model.

We completed our search on 4 May 2020 for articles published in English in peer-reviewed sources on any date in the following databases: MEDLINE (PubMed), EMBASE, CABI Global Health, PsycINFO (EBSCOhost), CINAHL (EBSCOhost) and AGRICOLA (EBSCOhost) (Supplemental Table 2 for terms). One co-author (AC) identified additional articles by reviewing the reference lists of each included article (ancestry search) and by using Google Scholar to identify articles that cited each included article (descendancy search). Finally, additional articles identified by BC and SS not captured in the search were included.

\section{Study Eligibility}

Any peer-reviewed article presenting primary or secondary research related to water and/or sanitation and either empowerment and/or one of the domains of empowerment from the conceptual model was eligible for inclusion. We included all countries, settings, human populations, and study designs; we excluded articles not in English.

To determine inclusion, one team member independently reviewed all titles and abstracts from the database search. Three other team members then split all titles and abstracts to complete a second review. When a consensus decision could not be made from the title and abstract, the full article was reviewed by two reviewers. When reviewers disagreed on eligibility, six members of the broader study team met to reach consensus on inclusion or exclusion.

\section{Analysis}

One team member (MP) extracted and collated study design, setting, population, and relevant water and sanitation information from each study.

To assess if papers engaged 'empowerment' and like terms, we conducted a word search on all papers for 'empow,' which enabled identification of 'empowerment' and similar terms (e.g. empower, disempowered). We then classified how papers engaged empowerment-related terms using a four-tier classification tool we created; see Figure 1 for tier classifications. 
Table 1. Definitions of empowerment and related domains and sub-domains from Van Eerdewijk et al. (2017)

\begin{tabular}{|c|c|}
\hline Term & Definition \\
\hline Empowerment & $\begin{array}{l}\text { The expansion of choice and strengthening of voice through the transformation of } \\
\text { power relations so women and girls have more control over their lives and futures. }\end{array}$ \\
\hline Disempowerment & $\begin{array}{l}\text { Unequal distribution of resources and women and girls' lack of control over their } \\
\text { bodies and low self-esteem, combined with biased laws and policies and } \\
\text { discriminatory gender norms and practices. }\end{array}$ \\
\hline 1. Agency & $\begin{array}{l}\text { Women and girls pursuing goals, expressing voice and influencing and making } \\
\text { decisions free from violence and retribution }\end{array}$ \\
\hline a. Decision-Making & $\begin{array}{l}\text { Women and girls influencing and making decisions, and establishing and acting on } \\
\text { goals }\end{array}$ \\
\hline b. Leadership & $\begin{array}{l}\text { Women and girls leading, inspiring social change and effectively participating in } \\
\text { governance }\end{array}$ \\
\hline c. Collective Action & $\begin{array}{l}\text { Women and girls gaining solidarity and taking action collectively on their interests to } \\
\text { enhance their position and expand the realm of what is possible }\end{array}$ \\
\hline 2. Resources & $\begin{array}{l}\text { The tangible and intangible capital and sources of power that women and girls have, } \\
\text { own or use, individually or collectively, in the exercise of agency }\end{array}$ \\
\hline a. Bodily Integrity & $\begin{array}{l}\text { Women and girls' security and control over their bodies, and physical and mental } \\
\text { well-being }\end{array}$ \\
\hline i. Safety \& Security ${ }^{1}$ & Women and girls' freedom from acts or threats of violence, coercion or force \\
\hline ii. Health & $\begin{array}{l}\text { Women and girls' complete physical, mental and social well-being and not merely } \\
\text { the absence of disease or infirmity }\end{array}$ \\
\hline b. Critical Consciousness & $\begin{array}{l}\text { Women and girls identifying and questioning how inequalities in power operate in } \\
\text { their lives, and asserting and affirming their sense of self and their entitlement } \\
\text { ('power-within') }\end{array}$ \\
\hline c. Assets & $\begin{array}{l}\text { Women and girls' control over tangible or intangible economic, social or productive } \\
\text { resources that include (1) financial and productive assets, (2) knowledge and skills, } \\
\text { (3) time and (4) social capital }\end{array}$ \\
\hline i. Financial \& Productive Assets & $\begin{array}{l}\text { Women and girls' control over economic resources such as income, credit or savings, } \\
\text { as well as long-term stocks of value like land, equipment, housing or livestock that } \\
\text { can be owned, controlled or used by a person }\end{array}$ \\
\hline ii. Knowledge \& Skills & $\begin{array}{l}\text { Women and girls' knowledge and skills (including life skills), and their abilities to } \\
\text { apply knowledge to situations, obtained through high-quality formal or informal } \\
\text { education, training or information }\end{array}$ \\
\hline iii. Social Capital & $\begin{array}{l}\text { Women and girls' relations and social networks that provide tangible and intangible } \\
\text { value and support }\end{array}$ \\
\hline iv. Time & $\begin{array}{l}\text { Women and girls' control over their time and labor, which is key to time poverty and } \\
\text { work burden }\end{array}$ \\
\hline 3. Institutional Structures & $\begin{array}{l}\text { The social arrangements of formal and informal rules and practices that enable and } \\
\text { constrain the agency of women and girls, and govern the distribution of resources }\end{array}$ \\
\hline a. Formal Laws \& Policies & $\begin{array}{l}\text { Formally recognized rules of conduct or procedures established by nation states, } \\
\text { international treaties and conventions, or local governance authorities that govern the } \\
\text { rights and entitlements of women and girls }\end{array}$ \\
\hline b. Norms & $\begin{array}{l}\text { Collectively held expectations and beliefs of how women, men, girls, and boys } \\
\text { should behave and interact in specific social settings and during different stages of } \\
\text { their lives }\end{array}$ \\
\hline c. Relations & $\begin{array}{l}\text { The interactions and relations with key actors that women and girls experience in } \\
\text { their daily lives }\end{array}$ \\
\hline \multicolumn{2}{|c|}{$\begin{array}{l}\text { 1. In our analysis, we use the definition of sexual violence used by Van Eerdewijk et al. (2017) which comes from Krug et al. } \\
\text { (2002): "any sexual act, attempt to obtain a sexual act, unwanted sexual comments or advances, or acts to traffic, or otherwise } \\
\text { directed, against a person's sexuality using coercion, by any person regardless of their relationship to the victim, in any } \\
\text { setting, including but not limited to home and work" (p. 149). }{ }^{37} \text { Forms of sexual violence included in this definition include: } \\
\text { rape within marriage or relationships; rape by strangers; systematic rape during armed conflict; unwanted sexual advances or } \\
\text { sexual harassment; sexual abuse of mentally or physically disabled people; sexual abuse of children; forced marriage or } \\
\text { cohabitation including child marriage; denial of the right to use contraception or to adopt other measures to protect against } \\
\text { sexually transmitted diseases; forced abortion; female genital mutilation and obligatory inspections for virginity; forced } \\
\text { prostitution and trafficking of people for the purpose of sexual exploitation. }\end{array}$} \\
\hline
\end{tabular}


Figure 1: Four Tier Classification Schema for Article Engagement of 'Empowerment'

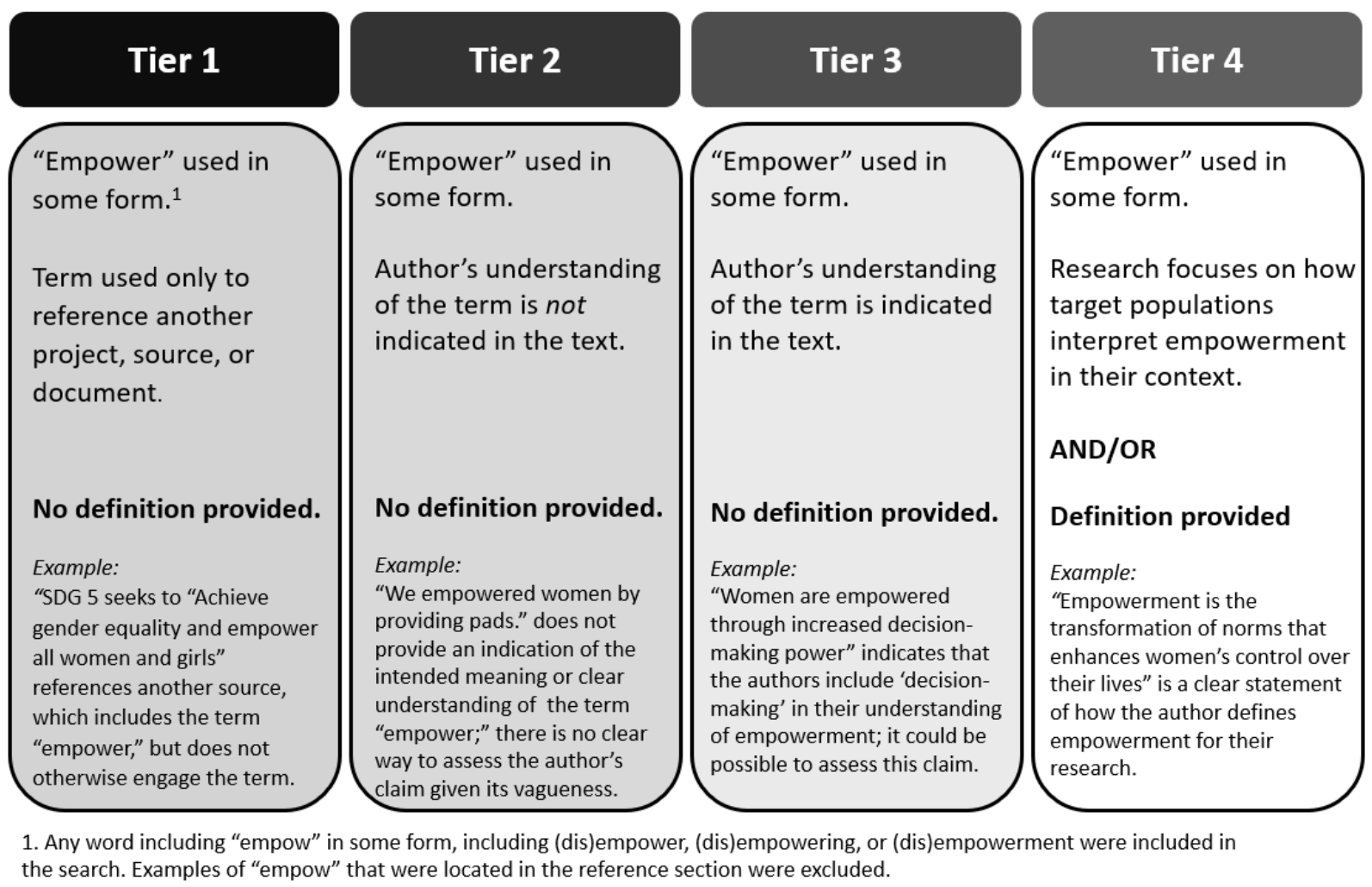

To classify and synthesize evidence on water, sanitation, and empowerment, we used the 'best-fit framework synthesis' approach. ${ }^{38}$ Using this method, themes are identified to use as codes a priori from pre-existing, guiding frameworks or models. This synthesis approach allows for the guiding framework or conceptual model to be modified as themes emerge inductively from the data.

We created and defined codes based on the empowerment subdomains in the conceptual model by Van Eerdewijk et al. ${ }^{33}$ (Table 1), including two additional empowerment-related subdomains identified iteratively through analysis, thus expanding the existing model: Privacy and Freedom of Movement (Figure 2). Other codes included water, sanitation, and menstruation to identify the broad topics engaged.

All eligible papers were imported into MaxQDA (version 12$)^{39}$ qualitative analysis software. Lineby-line coding of the results sections of eligible papers was carried out independently by two team members, who first coded two papers independently and compared to assess inter-coder agreement.

Using thematic analysis, two team members generated descriptive themes for each empowerment code based on the relevant coded texts. All coded segments containing both an empowermentrelated code and a sanitation/water code (e.g. 'safety' and 'sanitation') were exported into an Excel file and analyzed further. Each subdomain of empowerment (e.g. 'safety,' 'privacy') was analyzed separately. Themes were refined into a smaller set of descriptive themes that outlined how experiences with water and sanitation related to the various subdomains of empowerment. 
medRxiv preprint doi: https://doi.org/10.1101/2021.10.26.21265535; this version posted October 28, 2021. The copyright holder for this preprint (which was not certified by peer review) is the author/funder, who has granted medRxiv a license to display the preprint in perpetuity.

It is made available under a CC-BY-NC 4.0 International license .

Descriptive themes were then used to describe how each domain/subdomain of empowerment has been researched in the literature.

Figure 2: Domains and Sub-Domains of Women's and Girls' Water and Sanitation-Related Empowerment (Adapted from Van Eerdewijk et al. (2017)

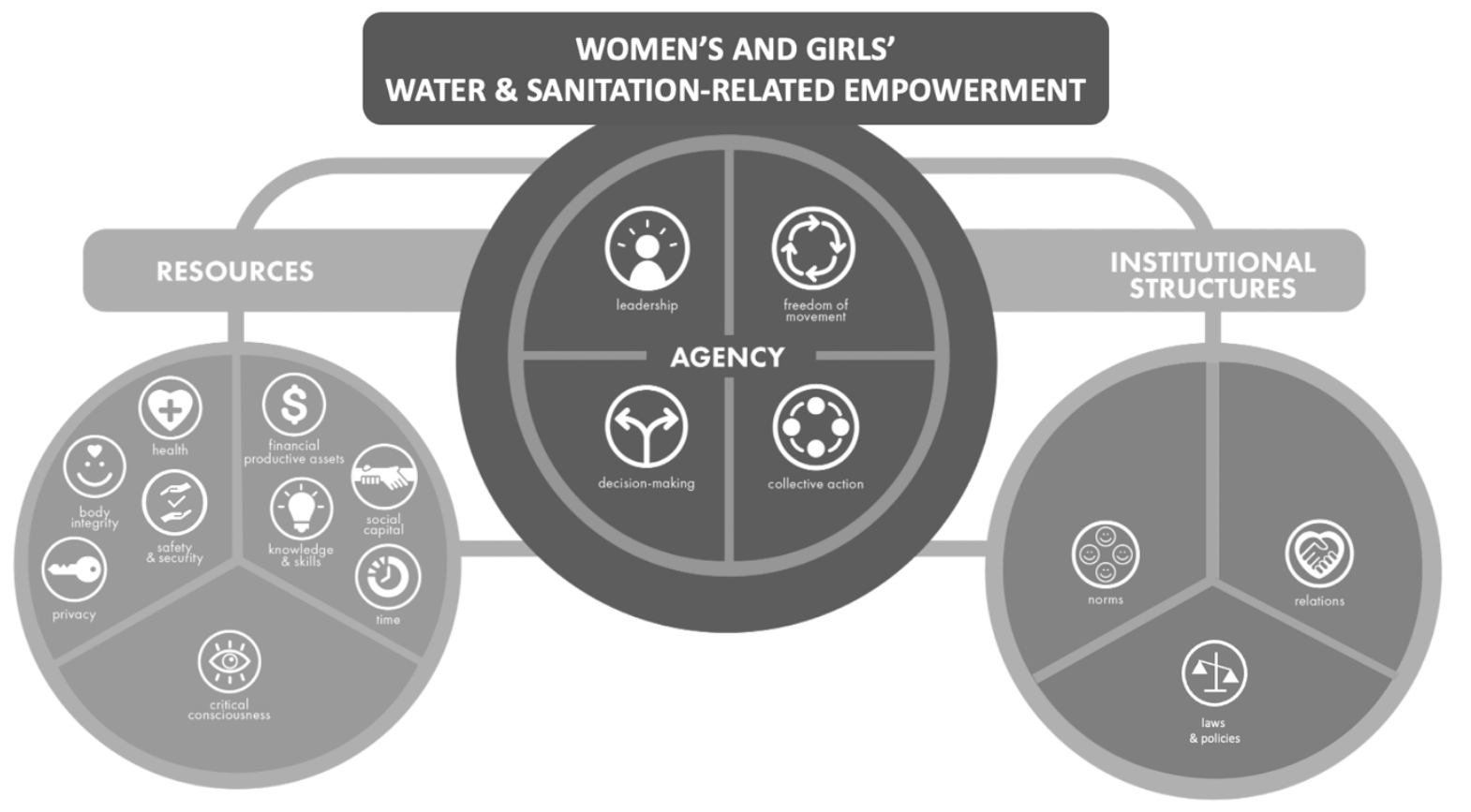

Study Quality Appraisal

We assessed all studies using the Mixed-Method Appraisal Tool (MMAT) 2018 developed by Pluye et al. ${ }^{40}$ and updated in $2018^{41}$ for the appraisal of qualitative, quantitative, and mixedmethods studies. One team member performed quality appraisals of all studies and a second team member performed a quality appraisal agreement check on $10 \%$ of studies. Qualitative and most quantitative studies were assessed using the five-criteria questionnaire; one criterion was dropped for randomized control trials because we did not consider it indicative of quality ('Did participants adhere to the assigned intervention?'). Mixed-methods studies were assessed using the relevant independent questionnaires for qualitative and quantitative work and a five-criteria questionnaire for mixed-methods; the lowest of the three scores was used as the quality score. Possible scores were $0-5$ across study types ( 5 is the best). Because the primary aim of this work is to understand if and how research engaged water and sanitation and empowerment themes, all studies were retained regardless of scores.

In their meta-synthesis of sanitation and well-being, Sclar et al. (2018) ${ }^{14}$ note that qualitative research is explicitly unblinded, subjective, and self-reported, and thus likely to produce poor scores from bias assessment tools. Because this review is exploratory, we excluded bias assessment, reasoning that qualitative studies would have low bias scores by default (despite rich insights), and therefore the activity would introduce bias. 
medRxiv preprint doi: https://doi.org/10.1101/2021.10.26.21265535; this version posted October 28, 2021. The copyright holder for this preprint (which was not certified by peer review) is the author/funder, who has granted medRxiv a license to display the preprint in perpetuity. It is made available under a CC-BY-NC 4.0 International license.

\section{Results}

Figure 3 shows the review strategy, including reasons for exclusion. We included 257 articles129 qualitative, 54 quantitative, and 74 mixed methods - representing an estimated 1,600,348 participants (Supplemental Table 3 describes all included studies). Articles largely featured research from Asia (48\%) and Africa (42\%), and focused on adult participants (69\%) (Table 2). The earliest paper was published in 1989; 82\% (211) of articles were published since 2010 and 60\% (153) since 2015 (Figure 4).

Figure 3: PRISMA flow diagram of publications considered for the review

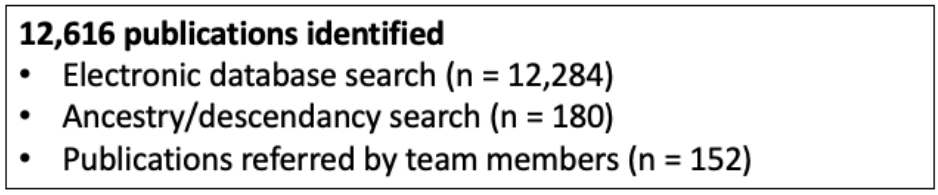

\begin{tabular}{|c|c|}
\hline & $\begin{array}{l}\text { 12,270 articles excluded based on title and abstract } \\
\text { - Irrelevant title/abstract }(n=9,660) \\
\text { - Duplicate publication }(n=2,489) \\
\text { - Ineligible language }(n=22) \\
\text { - Not peer-reviewed research publications }(n=99)\end{array}$ \\
\hline \multicolumn{2}{|l|}{346 full-texts assessed for eligibility } \\
\hline & $\begin{array}{l}89 \text { articles excluded based on full-text } \\
\text { - Insufficient engagement with empowerment domains } \\
\text { and/or water/sanitation }(n=89)\end{array}$ \\
\hline
\end{tabular}

257 articles included in this literature review

- 54 quantitative studies

- 129 qualitative studies

- 74 mixed methods studies 
Table 2. Summary Information about Included Sources ( $\mathbf{N = 2 5 7 )}$

\begin{tabular}{|c|c|c|c|c|c|c|c|c|}
\hline \multirow{2}{*}{ Total Number of Articles } & \multicolumn{2}{|c|}{ Total } & \multicolumn{2}{|c|}{ Qualitative } & \multicolumn{2}{|c|}{ Quantitative } & \multicolumn{2}{|c|}{$\begin{array}{c}\text { Mixed } \\
\text { Methods }\end{array}$} \\
\hline & 257 & & 129 & $50 \%$ & 54 & $21 \%$ & 74 & $29 \%$ \\
\hline \multicolumn{9}{|l|}{ Region } \\
\hline Africa & 102 & $40 \%$ & 44 & $34 \%$ & 26 & $48 \%$ & 32 & $43 \%$ \\
\hline Asia & 117 & $46 \%$ & 64 & $50 \%$ & 20 & $37 \%$ & 33 & $45 \%$ \\
\hline Europe & 3 & $1 \%$ & 2 & $2 \%$ & 0 & $0 \%$ & 1 & $1 \%$ \\
\hline Latin America/Caribbean & 9 & $4 \%$ & 5 & $4 \%$ & 0 & $0 \%$ & 4 & $5 \%$ \\
\hline Middle East & 0 & $0 \%$ & 0 & $0 \%$ & 0 & $0 \%$ & 0 & $0 \%$ \\
\hline North America & 11 & $4 \%$ & 10 & $8 \%$ & 1 & $2 \%$ & 0 & $0 \%$ \\
\hline Oceania & 5 & $2 \%$ & 2 & $2 \%$ & 1 & $2 \%$ & 2 & $3 \%$ \\
\hline Multiple Regions & 10 & $4 \%$ & 2 & $2 \%$ & 6 & $11 \%$ & 2 & $3 \%$ \\
\hline Unspecified & 0 & $0 \%$ & 0 & $0 \%$ & 0 & $0 \%$ & 0 & $0 \%$ \\
\hline \multicolumn{9}{|l|}{ Location within Country } \\
\hline Urban & 69 & $27 \%$ & 32 & $25 \%$ & 18 & $33 \%$ & 19 & $26 \%$ \\
\hline Peri-Urban & 7 & $3 \%$ & 6 & $5 \%$ & 0 & $0 \%$ & 1 & $1 \%$ \\
\hline Rural & 131 & $51 \%$ & 67 & $52 \%$ & 20 & $37 \%$ & 44 & $59 \%$ \\
\hline Refugee camps & 1 & $0 \%$ & 0 & $0 \%$ & 0 & $0 \%$ & 1 & $1 \%$ \\
\hline Multiple Locations & 39 & $15 \%$ & 19 & $15 \%$ & 15 & $28 \%$ & 5 & $7 \%$ \\
\hline Unspecified & 10 & $4 \%$ & 5 & $4 \%$ & 1 & $2 \%$ & 4 & $5 \%$ \\
\hline \multicolumn{9}{|l|}{ Sex of Primary Research Population } \\
\hline Female & 103 & $40 \%$ & 47 & $36 \%$ & 31 & $57 \%$ & 25 & $34 \%$ \\
\hline Male & 0 & $0 \%$ & 0 & $0 \%$ & 0 & $0 \%$ & 0 & $0 \%$ \\
\hline Both Male and Female & 140 & $54 \%$ & 75 & $58 \%$ & 21 & $39 \%$ & 44 & $59 \%$ \\
\hline Non-Binary/Transgender/Other & 0 & $0 \%$ & 0 & $0 \%$ & 0 & $0 \%$ & 0 & $0 \%$ \\
\hline Unspecified & 14 & $5 \%$ & 7 & $5 \%$ & 2 & $4 \%$ & 5 & $7 \%$ \\
\hline \multicolumn{9}{|l|}{ Life Stage of Primary Research Population } \\
\hline Children (0-9) & 0 & $0 \%$ & 0 & $0 \%$ & 0 & $0 \%$ & 0 & $0 \%$ \\
\hline Adolescents (10-19) & 14 & $5 \%$ & 6 & $5 \%$ & 5 & $9 \%$ & 3 & $4 \%$ \\
\hline Adults (20-59) & 177 & $69 \%$ & 90 & $70 \%$ & 33 & $61 \%$ & 54 & $73 \%$ \\
\hline Elderly $(60+)$ & 0 & $0 \%$ & 0 & $0 \%$ & 0 & $0 \%$ & 0 & $0 \%$ \\
\hline Multiple Populations & 56 & $22 \%$ & 26 & $20 \%$ & 14 & $26 \%$ & 16 & $22 \%$ \\
\hline Unspecified & 10 & $4 \%$ & 7 & $5 \%$ & 2 & $4 \%$ & 1 & $1 \%$ \\
\hline \multicolumn{9}{|l|}{ Primary Research Focus } \\
\hline Sanitation & 57 & $22 \%$ & 28 & $22 \%$ & 15 & $28 \%$ & 14 & $19 \%$ \\
\hline Water & 115 & $45 \%$ & 54 & $42 \%$ & 27 & $50 \%$ & 34 & $46 \%$ \\
\hline Sanitation and Water & 85 & $33 \%$ & 47 & $36 \%$ & 12 & $22 \%$ & 26 & $35 \%$ \\
\hline \multicolumn{9}{|c|}{ Articles Engaging Menstruation by Research Focus } \\
\hline All & 34 & $13 \%$ & 21 & $16 \%$ & 3 & $6 \%$ & 10 & $14 \%$ \\
\hline Sanitation & 9 & $4 \%$ & 6 & $5 \%$ & 2 & $4 \%$ & 1 & $1 \%$ \\
\hline Water & 2 & $1 \%$ & 0 & $0 \%$ & 1 & $2 \%$ & 1 & $1 \%$ \\
\hline Sanitation and Water & 23 & $9 \%$ & 15 & $12 \%$ & 0 & $0 \%$ & 8 & $11 \%$ \\
\hline Study Quality: Mean Score (Range) ${ }^{2}$ & 4.2 & $(1-5)$ & 4.8 & $(2-5)$ & 4.1 & $(2-5)$ & 3.3 & $(1-5)$ \\
\hline \multicolumn{9}{|l|}{ Article Engagement of Empowerment ${ }^{1}$ by Tier } \\
\hline No Engagement of Empowerment Terms & 124 & $48 \%$ & & & & & & \\
\hline Tier 1 & 20 & $8 \%$ & & & & & & \\
\hline Tier 2 & 65 & $25 \%$ & & & & & & \\
\hline Tier 3 & 31 & $12 \%$ & & & & & & \\
\hline Tier 4 & 17 & $7 \%$ & & & & & & \\
\hline
\end{tabular}


medRxiv preprint doi: https://doi.org/10.1101/2021.10.26.21265535; this version posted October 28, 2021. The copyright holder for this preprint (which was not certified by peer review) is the author/funder, who has granted medRxiv a license to display the preprint in perpetuity.

Figure 4: Number of Articles Included in Search by Date of Publication, through 4 May 2020 $(\mathrm{N}=\mathbf{2 5 7})$

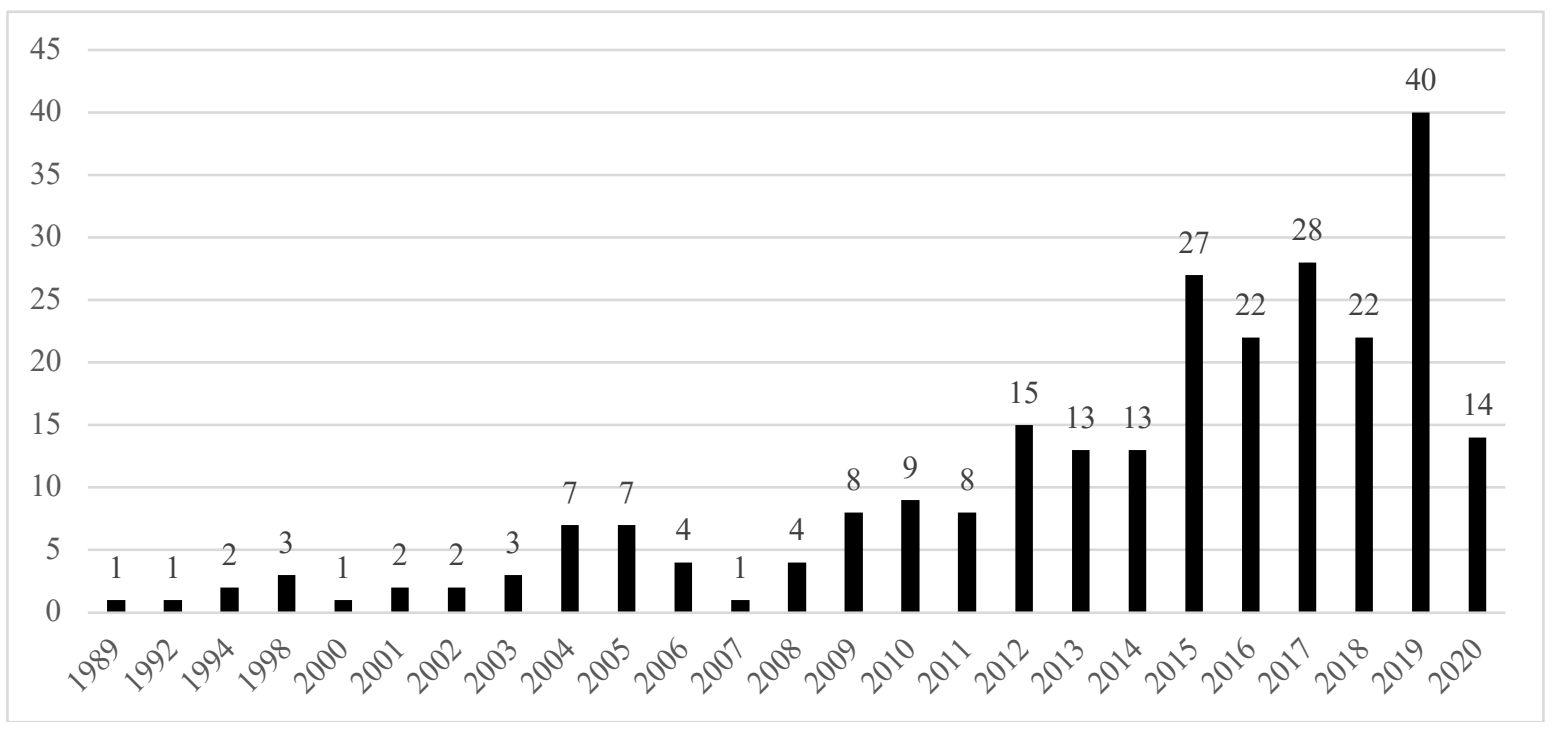

\section{Study Quality}

Supplemental Table 4 presents study quality scores for each included article. Mean study quality was 4.2 overall indicating good quality, 4.8 for qualitative studies, 4.1 for quantitative studies, and 3.3 for mixed methods studies (5 is maximum). (Table 2).

\section{Water and Sanitation Research Engaging Empowerment and Associated Domains}

The terms "empower," "empowerment," "empowering," "disempowerment," or "disempowering" featured in the text of $133(52 \%)$ articles. Only 17 (7\%) articles included a specific definition or conceptualization of empowerment to inform their research (see Table 2; Supplemental Table 5 for specific definitions used) ${ }^{29,42-57} 12(5 \%)$ had a specific aim or research question focused broadly on empowerment. ${ }^{29,42,43,45,50,52,54,56,58-61}$

One hundred fifteen (45\%) articles focused on water, $57(22 \%)$ on sanitation, $85(33 \%)$ on both; $34(13 \%)$ engaged menstruation. Table 3 summarizes which studies contributed to each domain or subdomain; Supplemental Table 6 collates all menstruation-related articles by domain and subdomain. Of the domains of empowerment, the resources domain was the most represented (241 articles; 94\%) (Supplemental Figure 1). 181 (70\%) articles engaged at least two of the empowerment domains; 113 (44\%) engaged all three (Supplemental Figure 1). 
Table 3. Summary of studies that engage water and/or sanitation by Sub-domains of empowerment. ( $N=257)$

\begin{tabular}{|c|c|c|c|}
\hline \multirow{2}{*}{$\begin{array}{c}\text { Domains \& } \\
\text { Sub-Domains }\end{array}$} & \multicolumn{3}{|c|}{ Articles that Engage the Domain/Sub-Domain } \\
\hline & $\begin{array}{c}\text { Water } \\
(\mathrm{N}=116)\end{array}$ & $\begin{array}{l}\text { Water and Sanitation } \\
\qquad(\mathbf{N}=\mathbf{8 3})\end{array}$ & $\begin{array}{c}\text { Sanitation } \\
(N=58)\end{array}$ \\
\hline $\begin{array}{l}\text { 1. AGENCY } \\
(\mathrm{N}=137)\end{array}$ & $(n=76)$ & $(n=24)$ & $(n=37)$ \\
\hline $\begin{array}{l}\text { 1.a } \\
\text { Decision-making } \\
(\mathrm{N}=90)\end{array}$ & 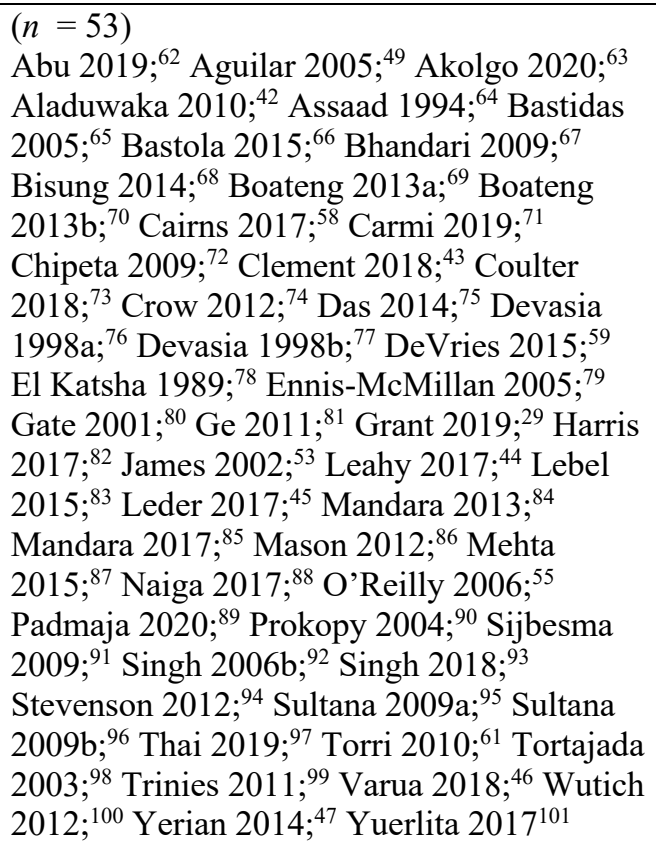 & 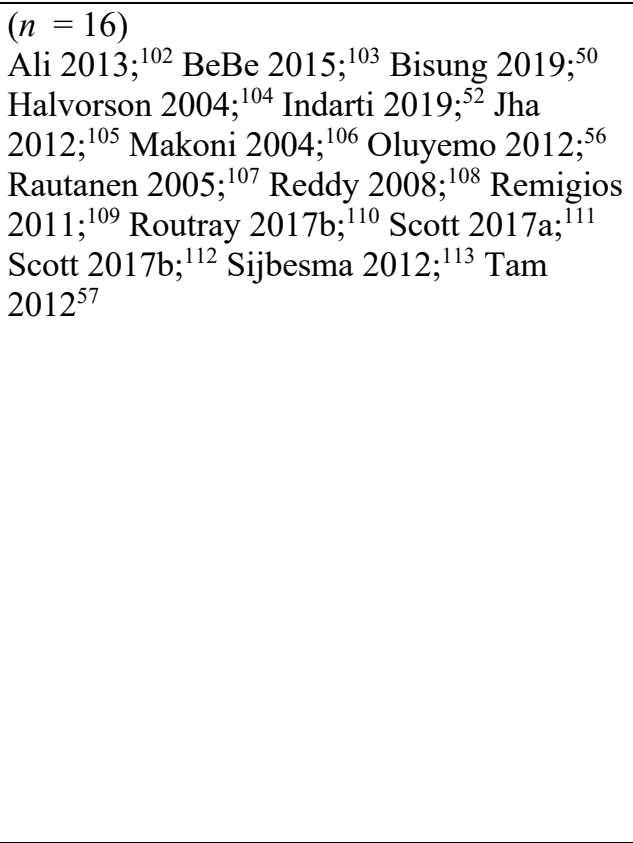 & 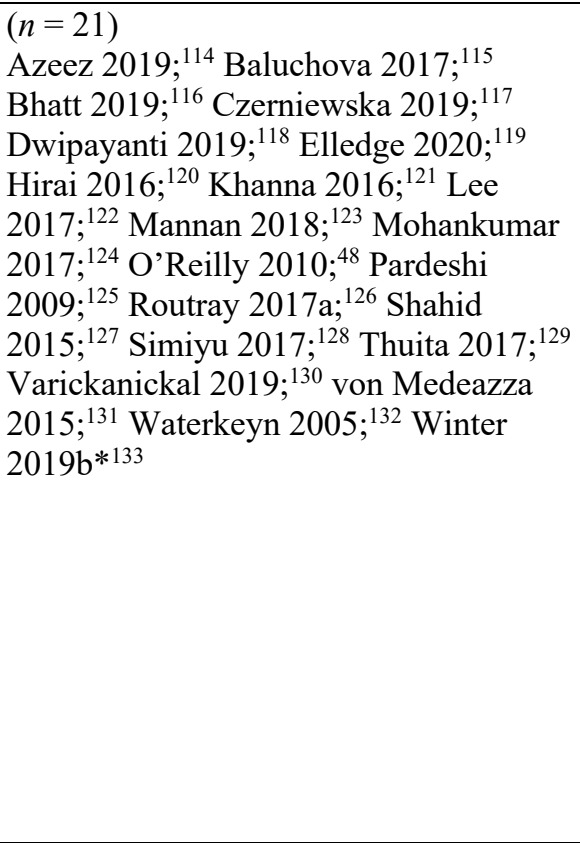 \\
\hline $\begin{array}{l}\text { 1.b } \\
\text { Leadership } \\
(N=56)\end{array}$ & 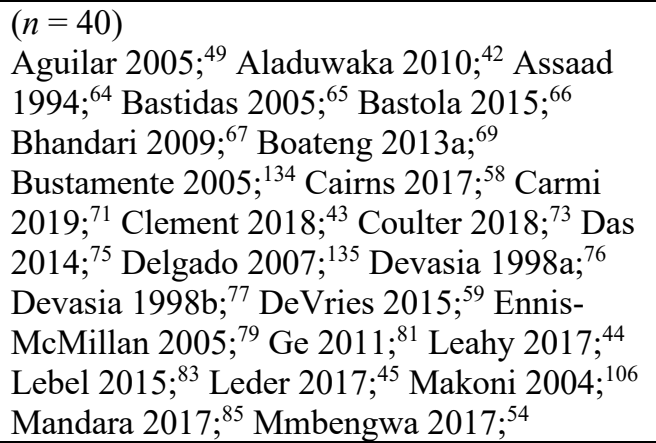 & $\begin{array}{l}(n=7) \\
\text { Bisung } 2019 ;{ }^{50} \text { Indarti } 2019 ; 52 \text { Jha } 2012 ;{ }^{105} \\
\text { O'Reilly } 2014 ;{ }^{140} \text { Scott } 2017 \mathrm{a} ;{ }^{111} \mathrm{Scott} \\
\text { 2017b; }{ }^{112} \text { Sijbesma } 2012^{113}\end{array}$ & $\begin{array}{l}(n=9) \\
\text { Elledge } 2020 ;{ }^{119} \text { Hoque } 1994 ;^{141} \\
\text { Pardeshi } 2008 ;{ }^{142} \text { Pardeshi } 2009 ;{ }^{125} \\
\text { Smith } 2004 ;{ }^{143} \text { Thuita } 2017 ;^{129} \text { von } \\
\text { Medeazza } 2015 ;{ }^{131} \text { Waterkeyn } 2005 ;{ }^{132} \\
\text { Winter } 2019 b^{* 133}\end{array}$ \\
\hline
\end{tabular}




\begin{tabular}{|c|c|c|c|}
\hline & 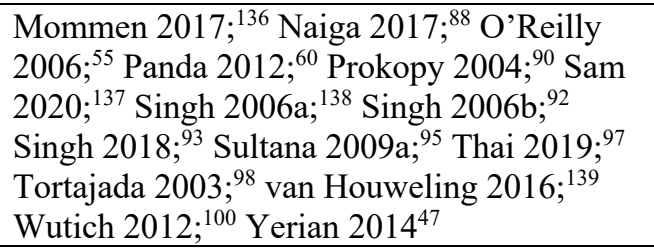 & & \\
\hline $\begin{array}{l}\text { 1.c } \\
\text { Collective Action } \\
(\mathrm{N}=55)\end{array}$ & 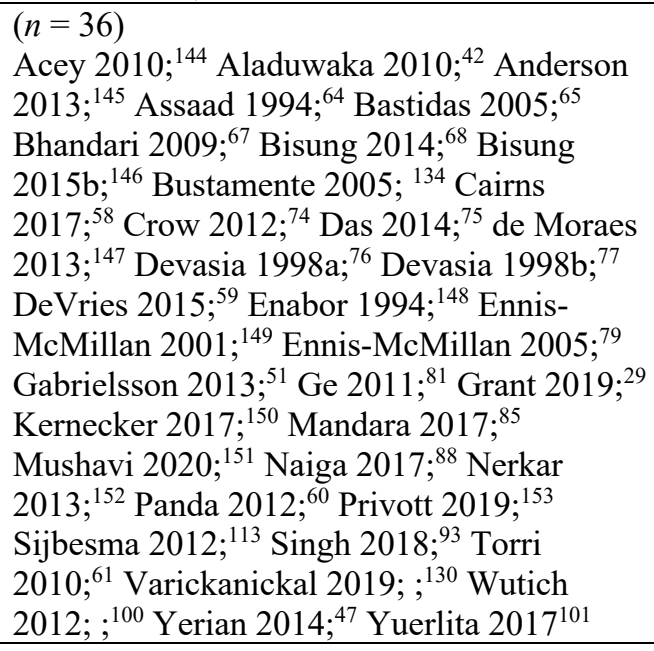 & $\begin{array}{l}(n=6) \\
\text { Bapat 2003; } ;{ }^{154} \text { Bisung 2015a; }{ }^{155} \text { Bisung } \\
\text { 2016; } ; 156 \text { Gate 2001; } ; 0 \text { Rautanen 2005; }{ }^{107} \text { Tam } \\
\text { 2012 }\end{array}$ & 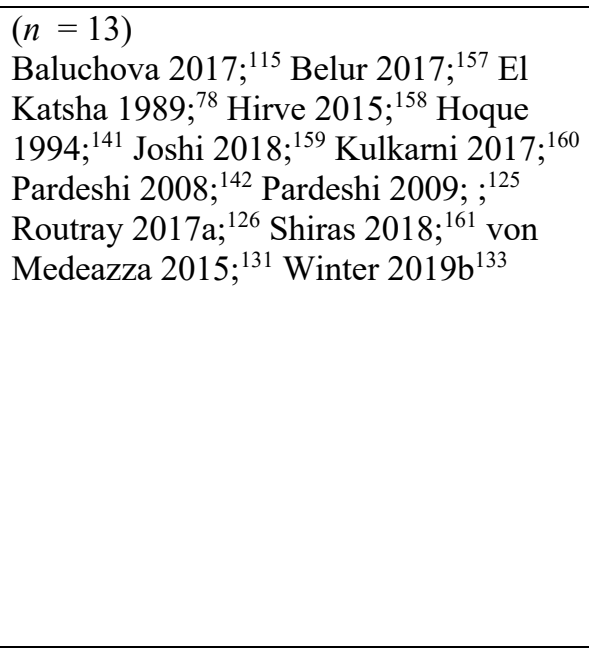 \\
\hline $\begin{array}{l}\text { 1.d } \\
\text { Freedom of } \\
\text { Movement } \\
(\mathrm{N}=48)\end{array}$ & 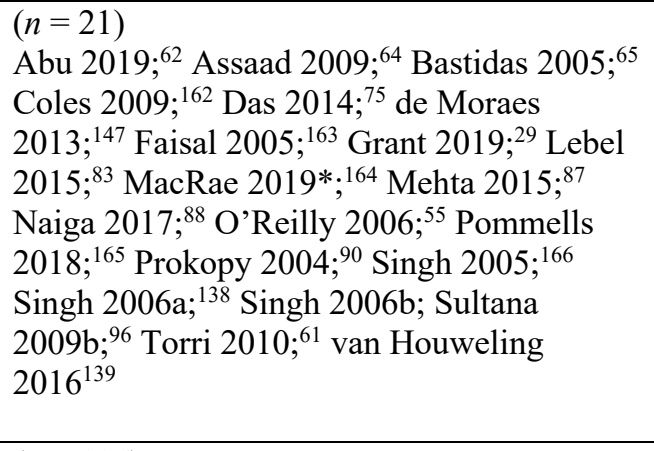 & $\begin{array}{l}(n=7) \\
\text { Halvorson } 2004 ;{ }^{104} \text { Hulland } 2015 ;{ }^{167} \text { Indarti } \\
\text { 2019; }{ }^{52} \text { Rautanen } 2005 ;{ }^{107} \text { Routray } 2015 ; ;^{168} \\
\text { Scott } 2017 b ;{ }^{112} \text { Sommer } 2018^{169}\end{array}$ & 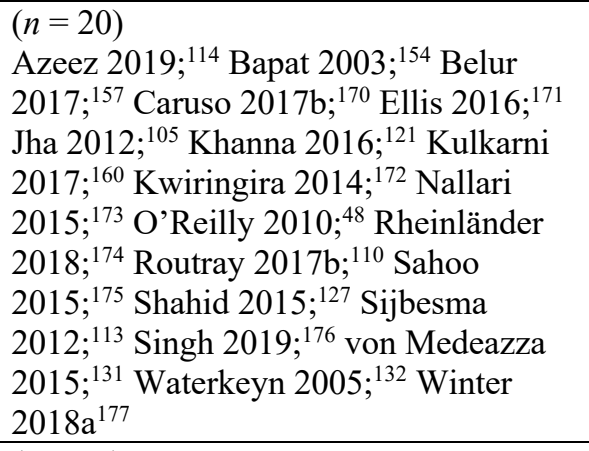 \\
\hline $\begin{array}{l}\text { 2. RESOURCES } \\
(\mathrm{N}=\mathbf{2 4 0})\end{array}$ & $(n=106)$ & $(n=77)$ & $(n=57)$ \\
\hline $\begin{array}{l}\text { 2.a } \\
\text { Bodily Integrity } \\
(\mathrm{N}=114)\end{array}$ & $\begin{array}{l}(n=38) \\
\text { Aguilar 2005; }{ }^{49} \text { Aihara 2016; } ;{ }^{178} \text { Andajani- } \\
\text { Sutahjo 2015; }{ }^{179} \text { Arku 2010b; }{ }^{180} \text { Assaad } \\
\text { 1994; } ;{ }^{64} \text { Baker 2017; } ; 181 \text { Bisung } 2018 ; ;^{182} \text { Chew } \\
\text { 2019;183 Chipeta 2009; } ;{ }^{72} \text { Collins 2018; } ;{ }^{184}\end{array}$ & 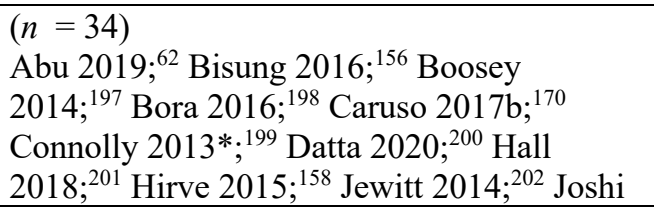 & $\begin{array}{l}(n=42) \\
\text { Abrahams 2006; } ; 19 \text { Alam 2017*.220 } \\
\text { Anyarayor 2019;221 Bapat 2003; }{ }^{154} \text { Belur } \\
2017 *, 157 \text { Bhatt } 2019 ; 116 \text { Camenga } \\
2019 ;{ }^{222} \text { Carolini } 2012 ;{ }^{223} \text { Caruso }\end{array}$ \\
\hline
\end{tabular}




\begin{tabular}{|c|c|c|c|}
\hline & 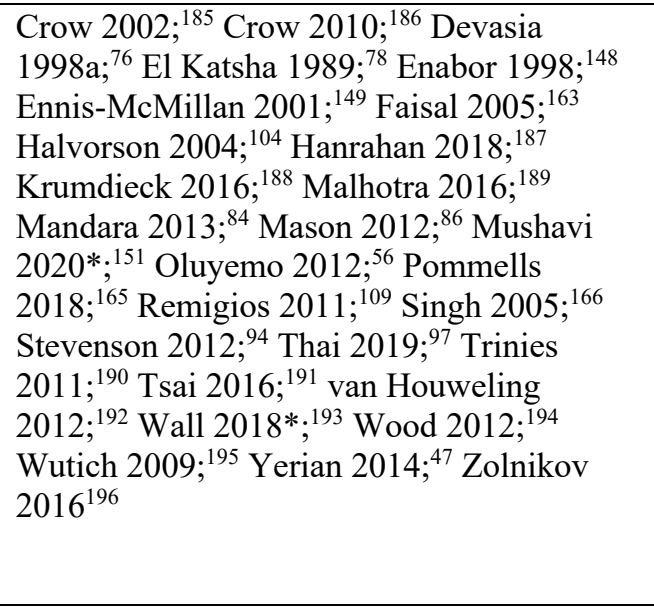 & 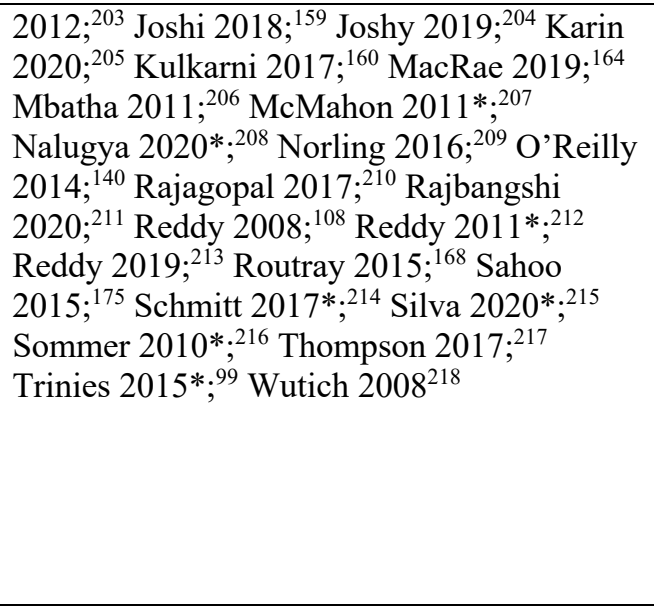 & 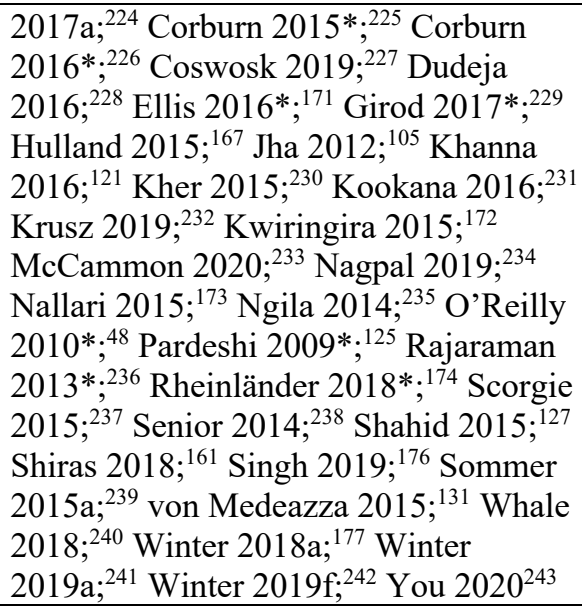 \\
\hline $\begin{array}{l}\text { 2.a.i } \\
\text { Safety and Security } \\
(N=82)\end{array}$ & 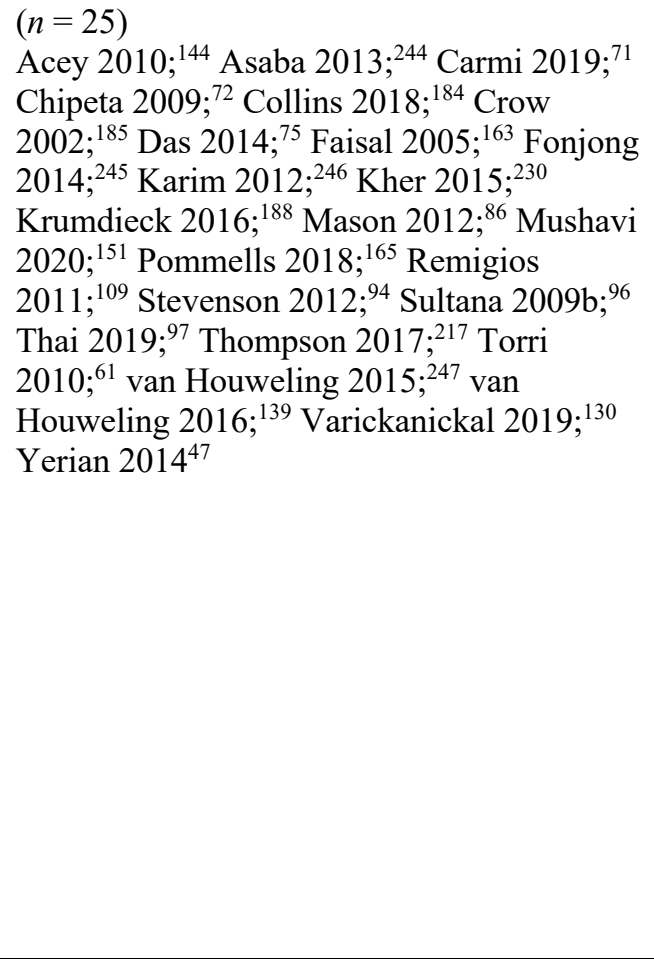 & $\begin{array}{l}(n=4) \\
\text { Abu 2019;62 Barchi 2020; }{ }^{248} \text { Norling 2016; }{ }^{209} \\
\text { Sommer } 2018^{169}\end{array}$ & 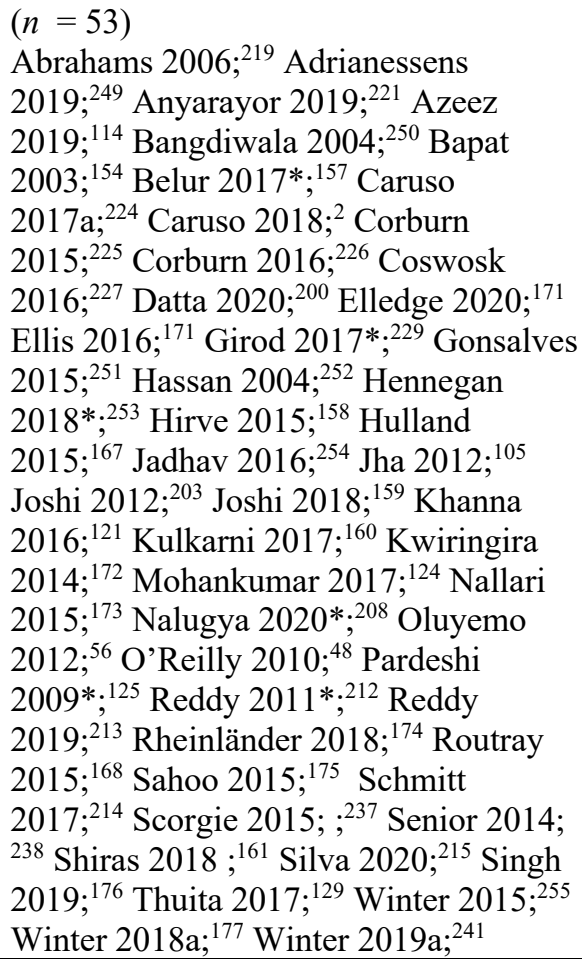 \\
\hline
\end{tabular}




\begin{tabular}{|c|c|c|c|}
\hline & & & $\begin{array}{l}\text { Winter 2019b; ;33 Winter 2019c; }{ }^{256} \\
\text { Winter 2019f; }{ }^{242} \text { You } 2020^{243}\end{array}$ \\
\hline $\begin{array}{l}\text { 2.a.ii } \\
\text { Health } \\
(N=116)\end{array}$ & 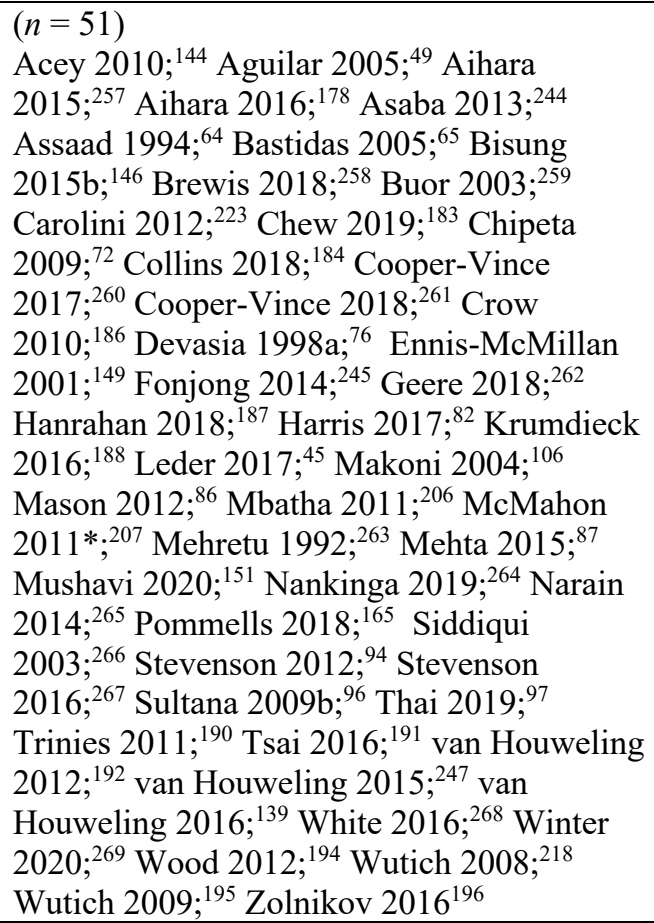 & 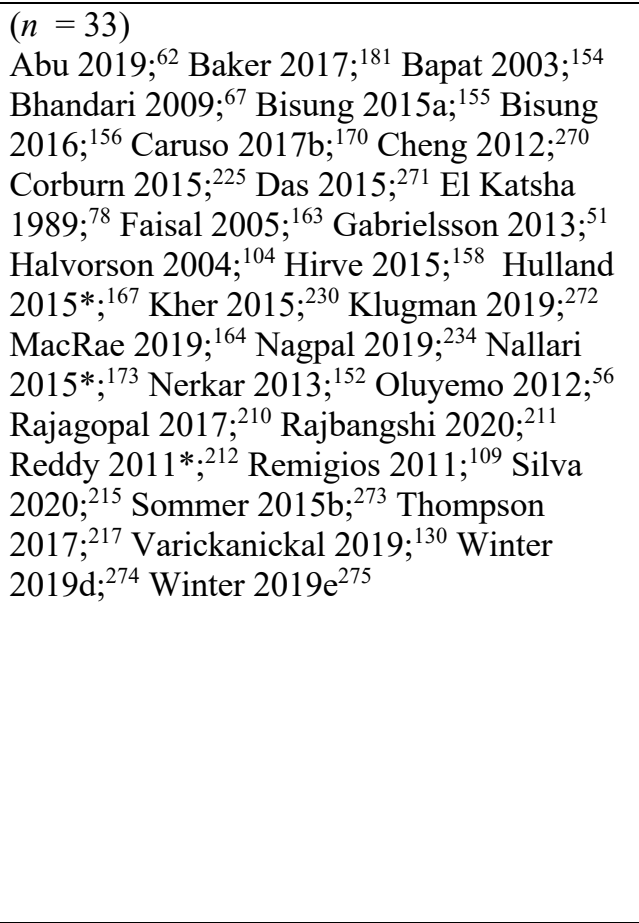 & 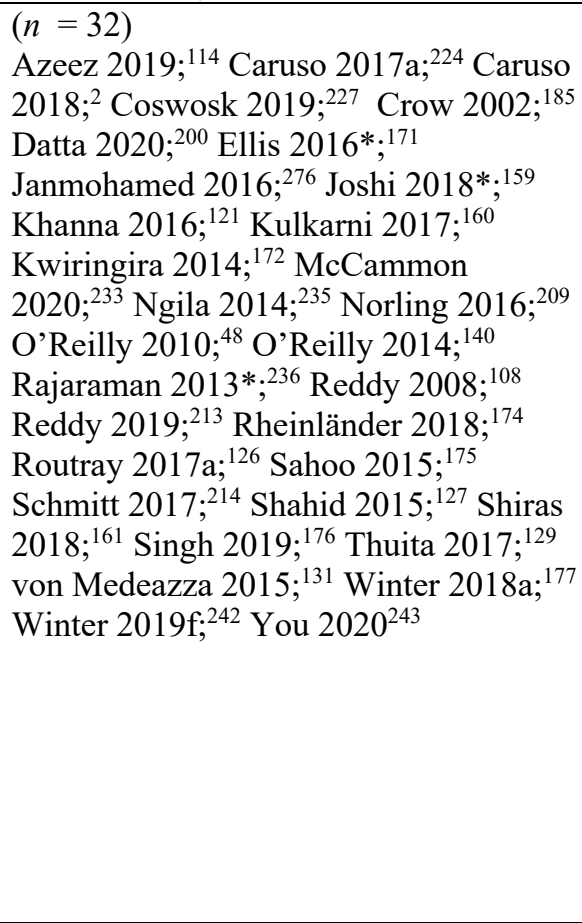 \\
\hline $\begin{array}{l}\text { 2.a.iii } \\
\text { Privacy } \\
(N=71)\end{array}$ & $\begin{array}{l}(n=7) \\
\text { Bhandari } 2009 * 66 \text { Das } 2014 ; ;^{75} \text { Girod } \\
2017 * ; 229 \text { O'Reilly 2006;55 Sultana 2009b; }{ }^{96} \\
\text { van Houweling 2016; } ;{ }^{139} \text { Yuerlita } 2017^{101}\end{array}$ & 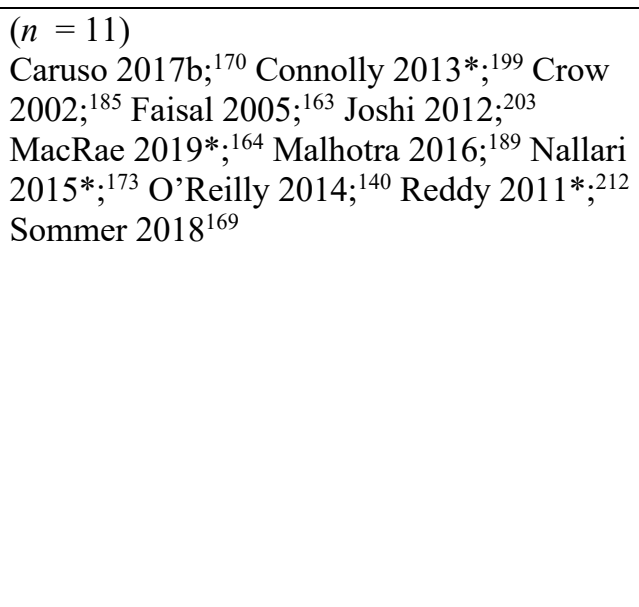 & 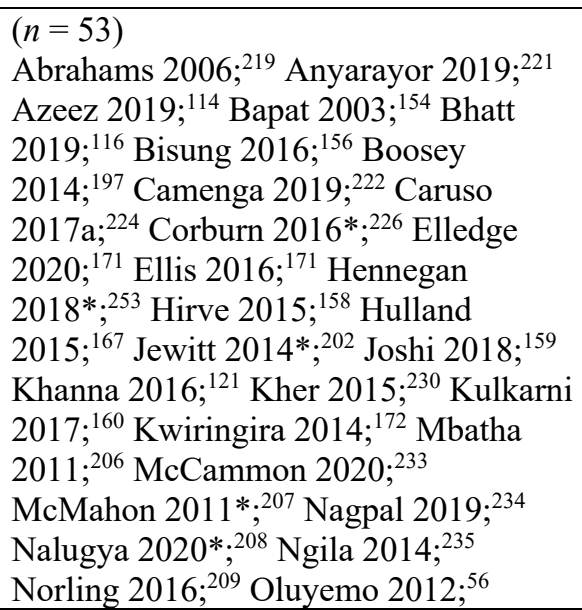 \\
\hline
\end{tabular}




\begin{tabular}{|c|c|c|c|}
\hline & & & 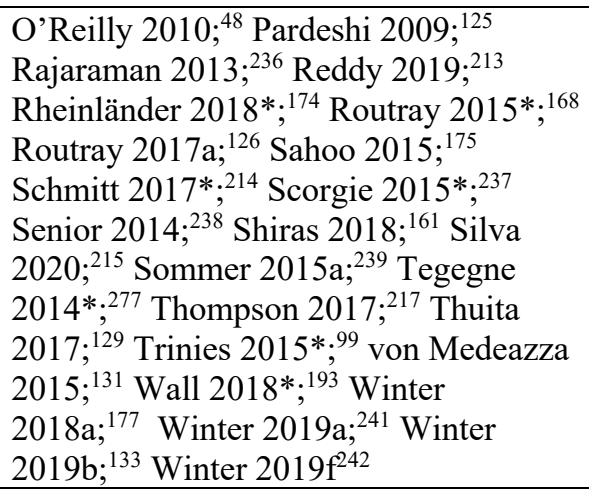 \\
\hline $\begin{array}{l}2 . b . \\
\text { Critical } \\
\text { Consciousness } \\
(\mathrm{N}=44)\end{array}$ & 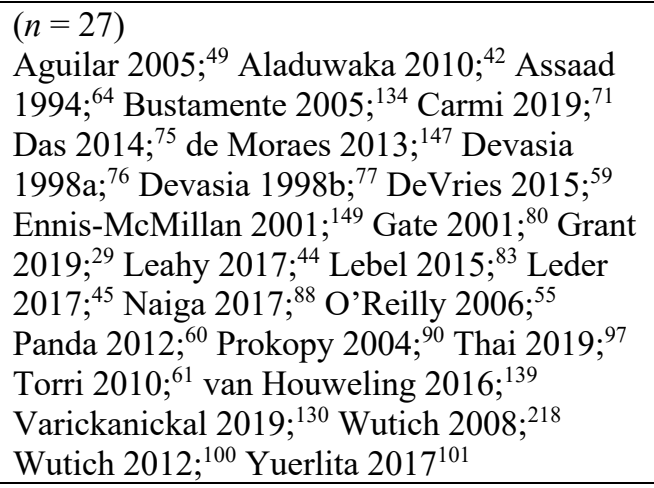 & $\begin{array}{l}(n=4) \\
\text { Indarti } 2019 ;{ }^{52} \text { Nerkar } 2013 ;{ }^{152} \text { Rautanen } \\
2005 ;{ }^{107} \text { Remigios } 2011^{109}\end{array}$ & $\begin{array}{l}(n=13) \\
\text { Baluchova 2017; }{ }^{115} \text { Bhatt 2019; }{ }^{116} \\
\text { Camenga 2019;222 El Katsha 1989; }{ }^{78} \\
\text { Kwiringira 2014; }{ }^{172} \text { Malhotra 201; }{ }^{189} \\
\text { Norling 2016; }{ }^{209} \text { Routray 2017b; } ;^{110} \\
\text { Shahid 2015;127 Thompson 2017;:217 } \\
\text { Thuita 2017; } ; 29 \text { Waterkeyn 2005; }{ }^{132} \\
\text { Winter 2019b*133 }\end{array}$ \\
\hline $\begin{array}{l}\text { 2.c } \\
\text { Assets } \\
(\mathrm{N}=186)\end{array}$ & $(n=111)$ & $(n=26)$ & $(n=49)$ \\
\hline $\begin{array}{l}\text { 2.c.i } \\
\text { Financial and } \\
\text { Productive Assets } \\
(N=118)\end{array}$ & 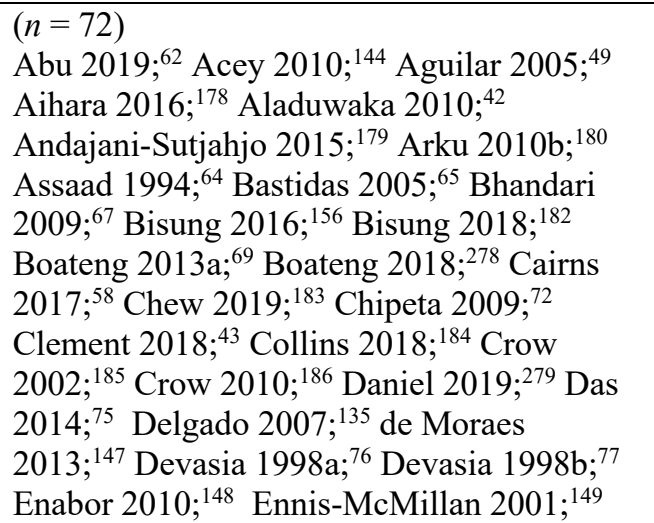 & 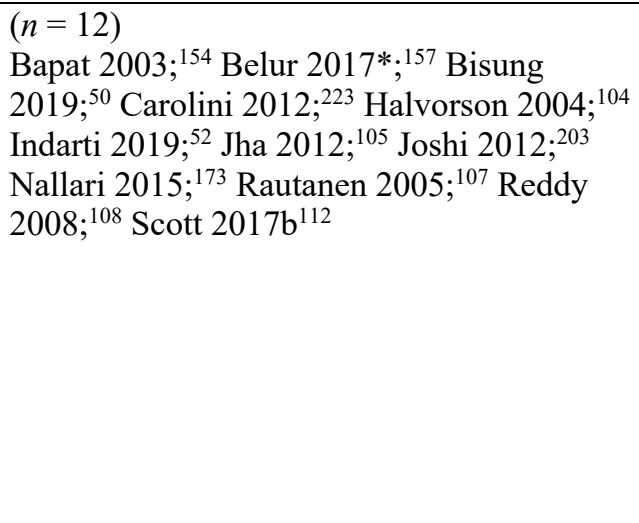 & 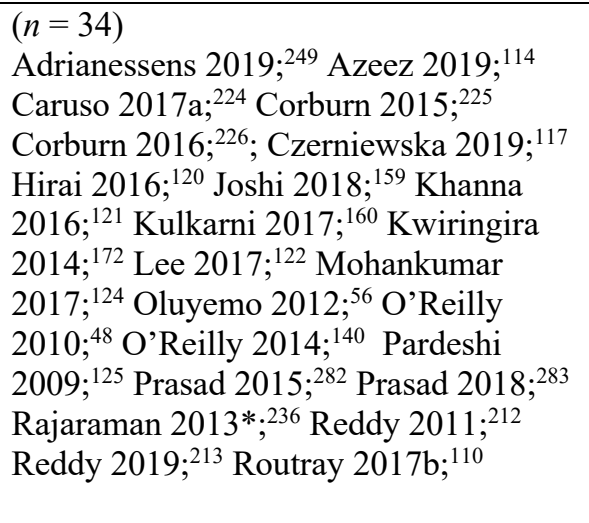 \\
\hline
\end{tabular}




\begin{tabular}{|c|c|c|c|}
\hline & 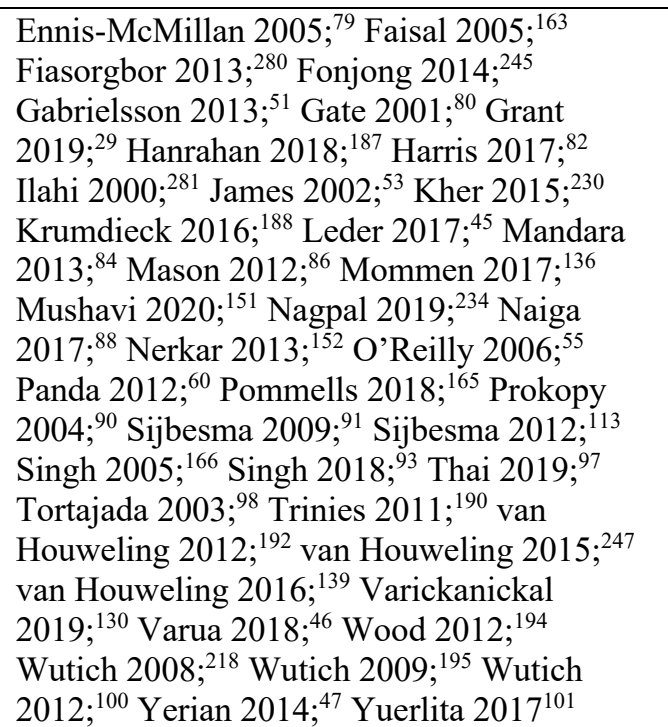 & & $\begin{array}{l}\text { Shahid 2015; } ;^{127} \text { Shiras 2018; } ;^{161} \text { Singh } \\
\text { 2019; }{ }^{176} \text { Smith 2004; } ;^{143} \text { Thuita } 2017 ; ;^{129} \\
\text { von Medeazza 2015; } ;^{131} \text { Winter } \\
\text { 2018a; } ; 177 \text { Winter 2019b; } 1133 \text { Winter } \\
\text { 2019c; } ;{ }^{256} \text { Winter 2019f; } ;{ }^{242} \text { You } 2020^{243}\end{array}$ \\
\hline $\begin{array}{l}\text { 2.c.ii } \\
\text { Knowledge \& Skills } \\
(N=95)\end{array}$ & 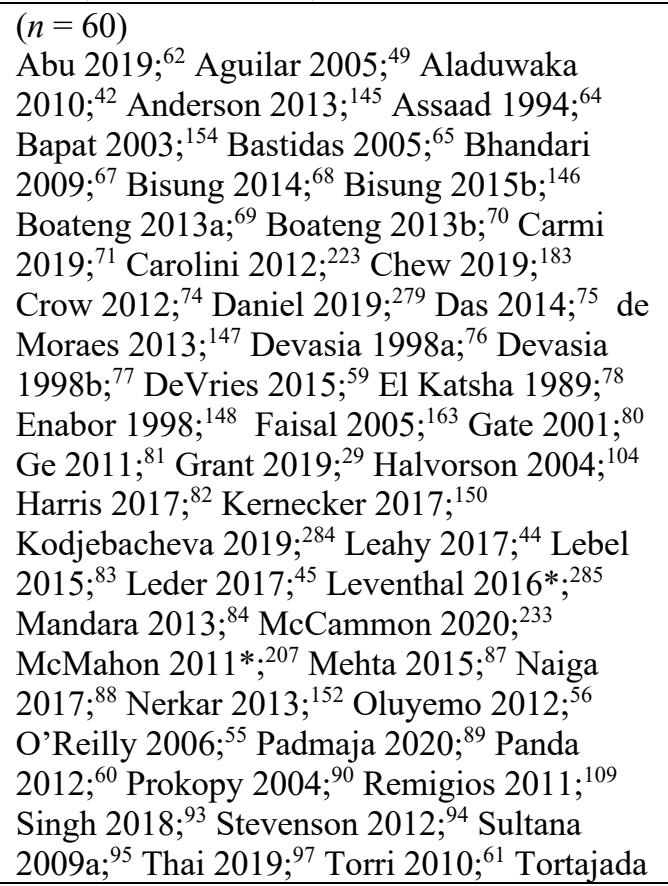 & $\begin{array}{l}(n=11) \\
\text { Bisung 2015a; }{ }^{155} \text { Bisung 2019; }{ }^{50} \text { Dreibelbis } \\
\text { 2013; } ; 86 \text { Indarti } 2019 ;{ }^{52} \text { Jha } 2012 ;{ }^{105} \text { Nallari } \\
\text { 2015; }{ }^{173} \text { O'Reilly 2014; }{ }^{140} \text { Rautanen 2005; }{ }^{107} \\
\text { Sijbesma 2012; }{ }^{113} \text { Tam 2012; }{ }^{57} \text { Tegegne } \\
\text { 2014*277 }\end{array}$ & 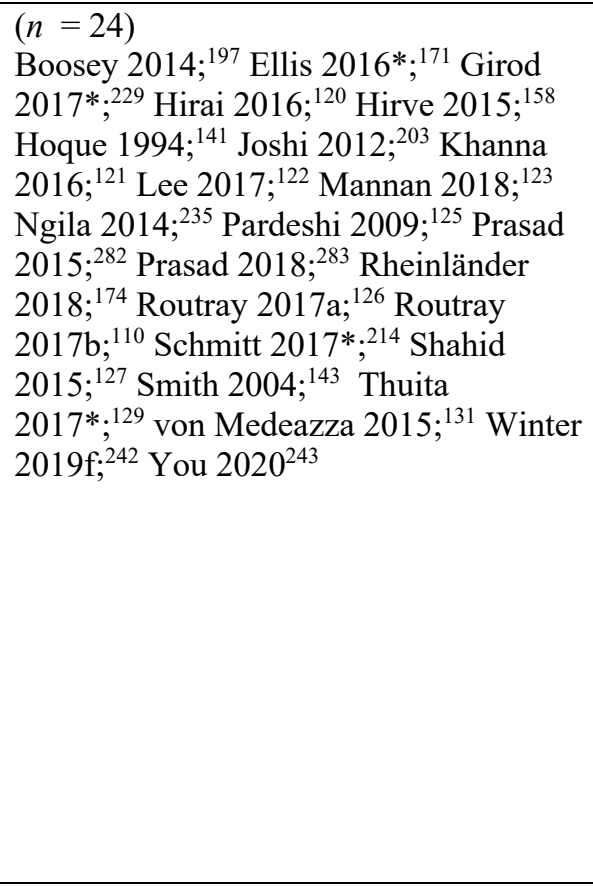 \\
\hline
\end{tabular}




\begin{tabular}{|c|c|c|c|}
\hline & $\begin{array}{l}2003 ;^{98} \text { Trinies } 2011 ;^{190} \text { Winter } 2019 d ; ;^{274} \\
\text { Wood 2012:194 Wutich } 2012 ; 100 \text { Yuerlita } \\
\text { 2017; }{ }^{101} \text { Zolnikov } 2016^{196}\end{array}$ & & \\
\hline $\begin{array}{l}\text { 2.c.iii } \\
\text { Social Capital } \\
(N=64)\end{array}$ & 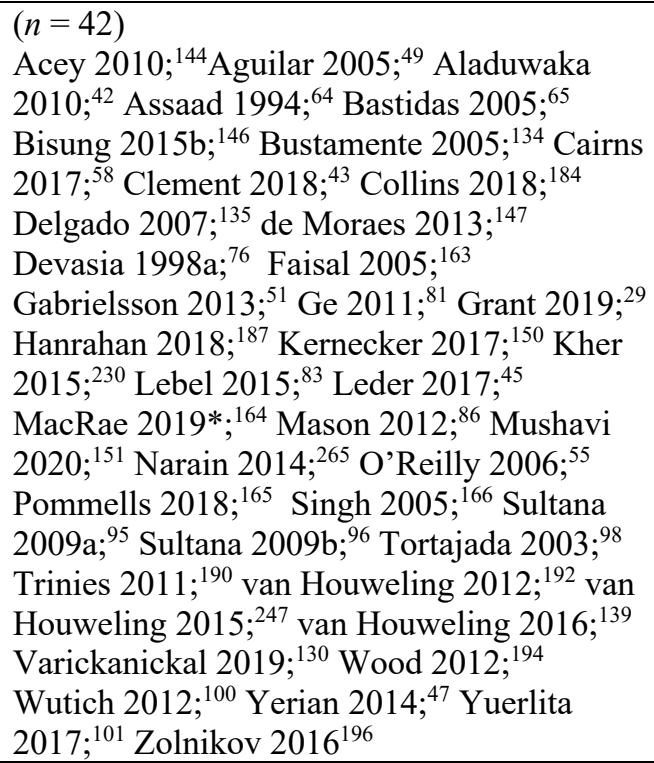 & $\begin{array}{l}(n=7) \\
\text { Indarti } 2019 ; 5^{.2} \text { Nerkar } 2013 ;{ }^{152} \text { Rautanen } \\
\text { 2008; }{ }^{107} \text { Reddy } 2008 ;{ }^{108} \text { Reddy } 2011 ; ;^{212} \\
\text { Scott } 2017 \mathrm{a} ;{ }^{111} \text { Scott } 2017 \mathrm{~b}^{112}\end{array}$ & 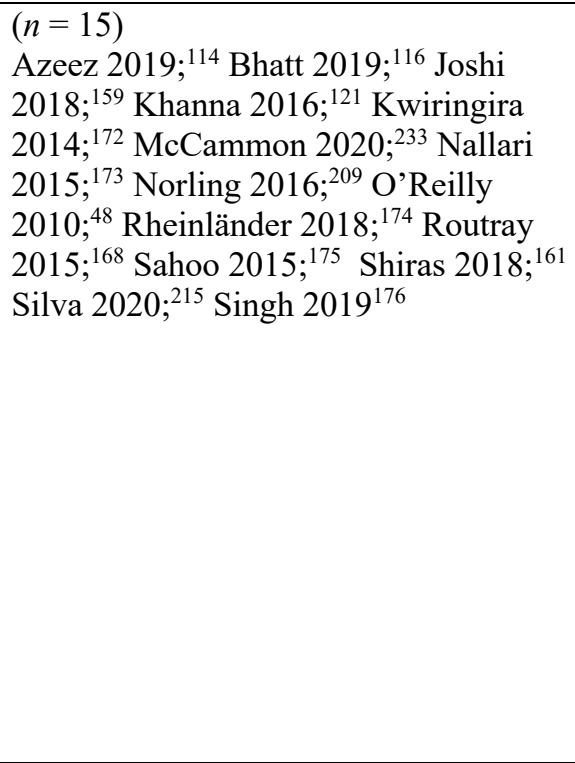 \\
\hline $\begin{array}{l}\text { 2.c. iv } \\
\text { Time } \\
(N=122)\end{array}$ & 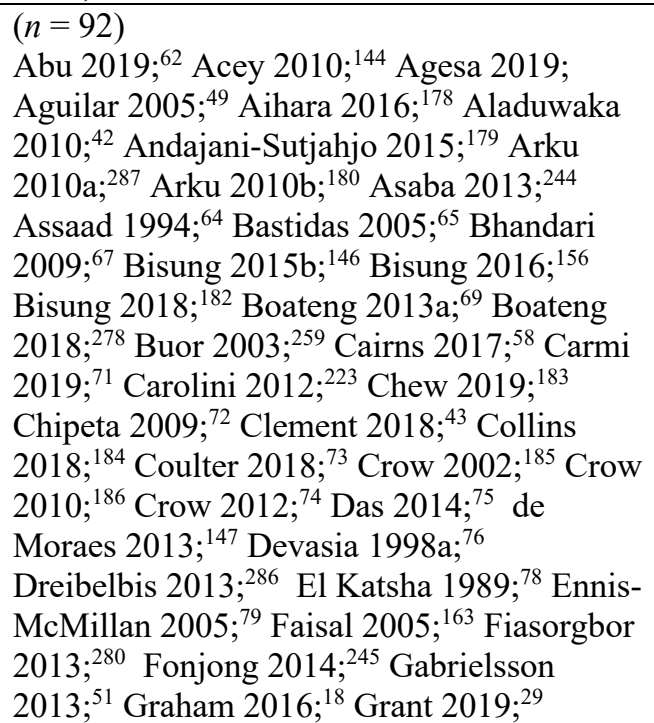 & $\begin{array}{l}(n=13) \\
\text { Baker 2017; }{ }^{181} \text { Bapat } 2003 ;{ }^{154} \text { Bisung } \\
\text { 2019;50 Caruso 2017b*:170 Corburn 2015; } ;^{225} \\
\text { Corburn 2016; } ;^{226} \text { Indarti } 2019 ; ;^{52} \text { Nagpal } \\
\text { 2019; } ;^{234} \text { Rautanen 2005;107 Reddy 2008; }{ }^{108} \\
\text { Routray 2015;168 Scott } 2017 a ; ;^{111} \text { Sijbesma } \\
2012^{113}\end{array}$ & 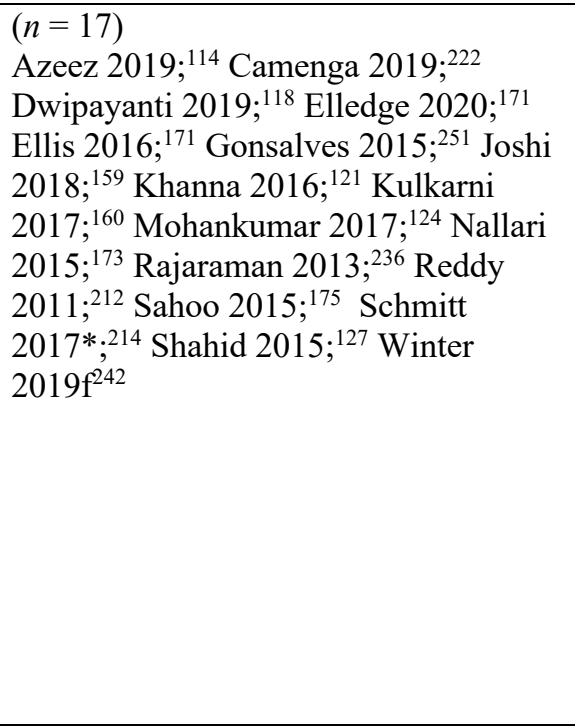 \\
\hline
\end{tabular}




\begin{tabular}{|c|c|c|c|}
\hline & 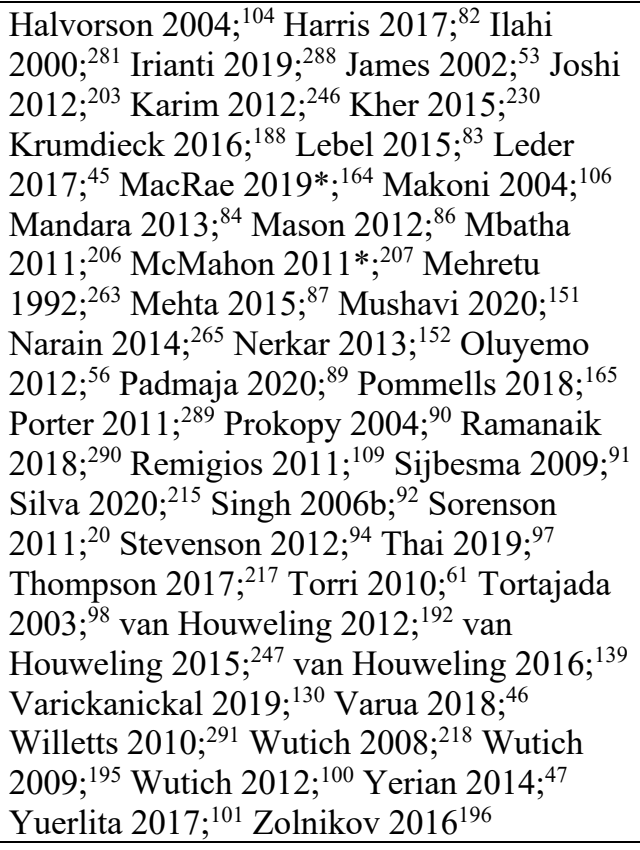 & & \\
\hline $\begin{array}{l}\text { 3, } \\
\text { INSTITUTIONAL } \\
\text { STRUCTURES } \\
(\mathbf{N}=\mathbf{1 7 3}) \\
\end{array}$ & $(n=104)$ & $(n=27)$ & $(n=42)$ \\
\hline $\begin{array}{l}\text { 3.a } \\
\text { Formal Laws \& } \\
\text { Policies } \\
(\mathbf{N}=21)\end{array}$ & 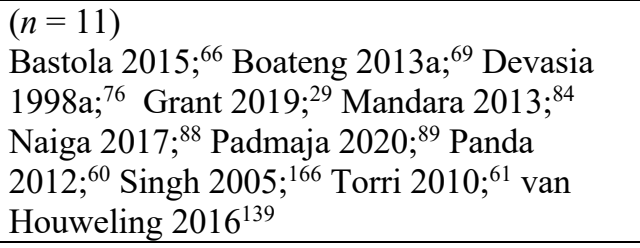 & $\begin{array}{l}(n=4) \\
\text { Bapat } 2003 ;{ }^{154} \text { Bisung } 2019 ;{ }^{.0} \text { Remigios } \\
2011 ;{ }^{109} \text { Scott } 2017 b^{112}\end{array}$ & $\begin{array}{l}(n=6) \\
\text { Belur 2017; } ;^{157} \text { Mannan 2018; }{ }^{123} \\
\text { O'Reilly 2014:140 Prasad 2015; }{ }^{282} \\
\text { Shahid 2015; }{ }^{127} \text { von Medeazza } 2015^{131}\end{array}$ \\
\hline $\begin{array}{l}\text { 3.b } \\
\text { Norms } \\
(\mathrm{N}=140)\end{array}$ & 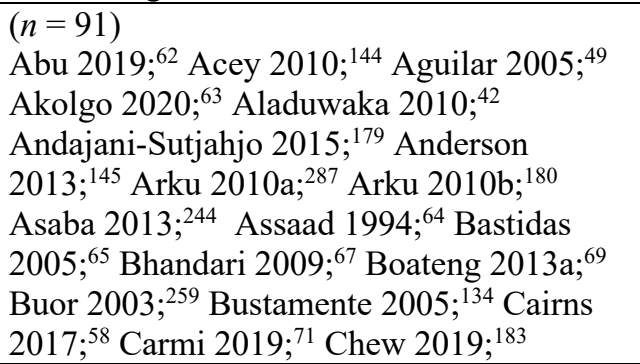 & 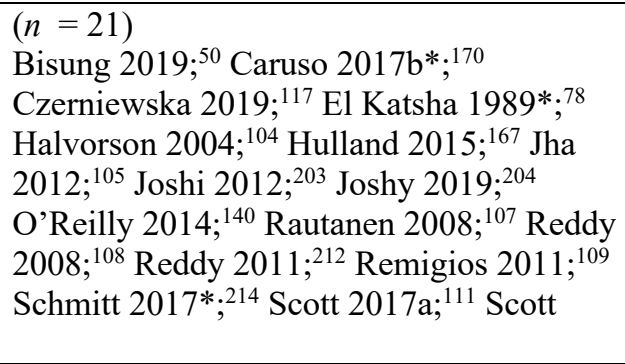 & 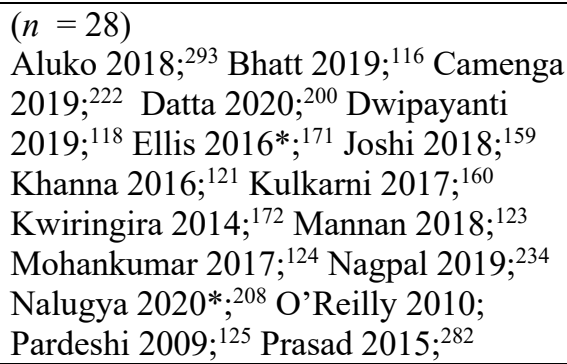 \\
\hline
\end{tabular}




\begin{tabular}{|c|c|c|c|}
\hline & 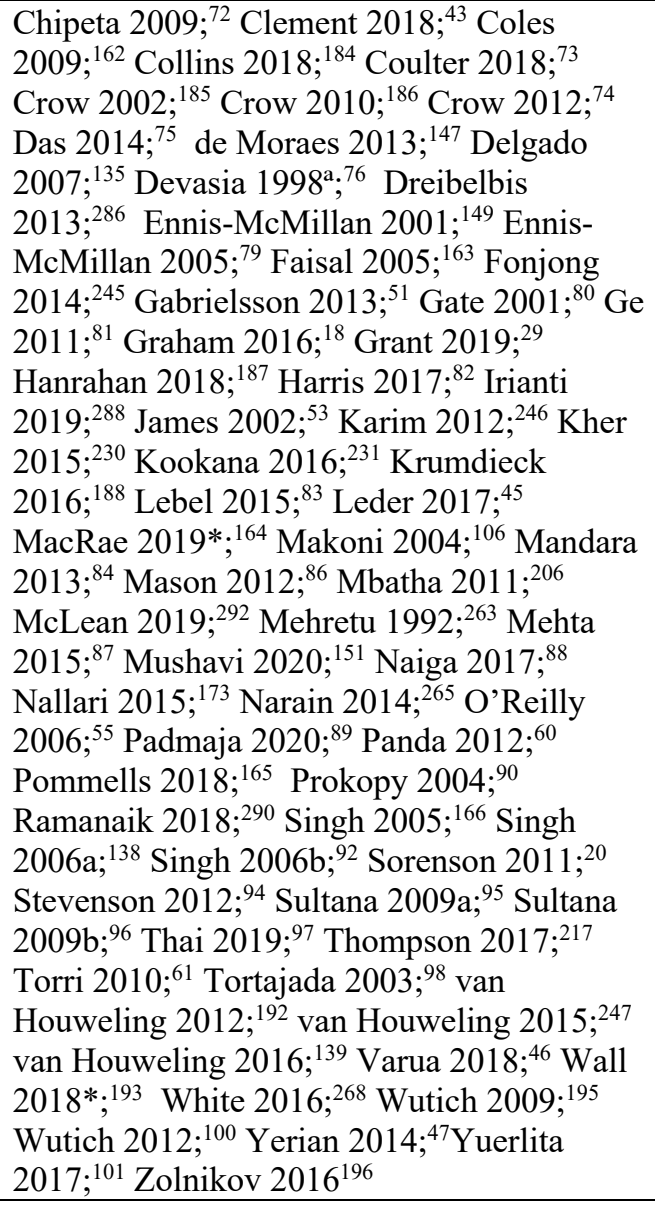 & $\begin{array}{l}\text { 2017b; }{ }^{112} \text { Sijbesma } 2012 ; ;^{113} \text { Silva } 2020 ; ;^{215} \\
\text { Sommer } 2018 ;{ }^{169} \text { Tam } 2012^{57}\end{array}$ & 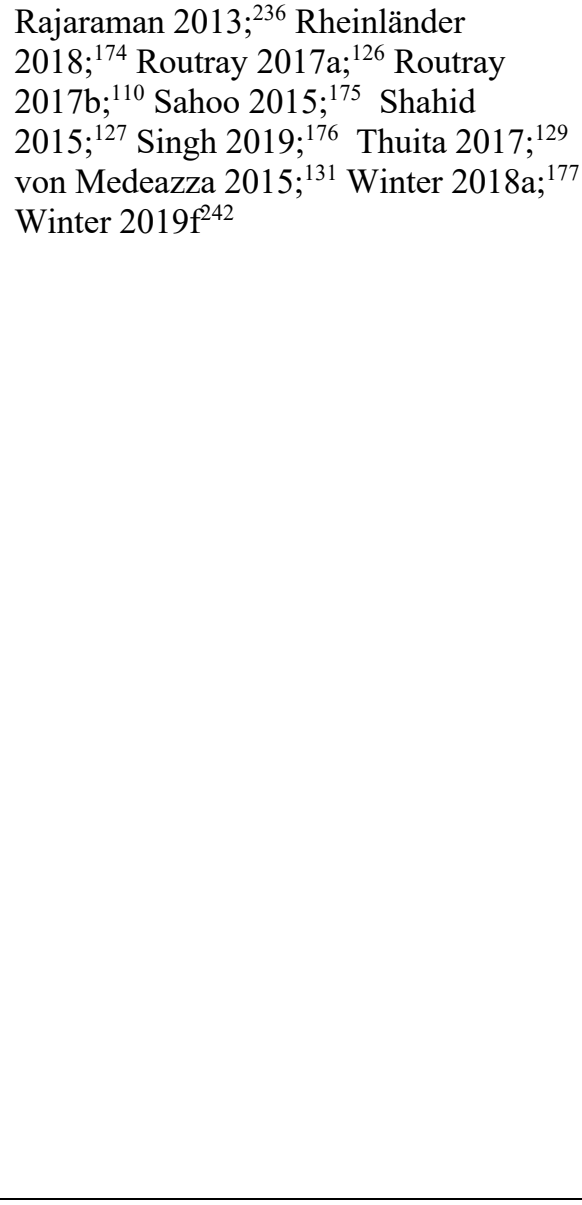 \\
\hline $\begin{array}{l}\text { 3.c } \\
\text { Relations } \\
(\mathbf{N}=\mathbf{1 1 8})\end{array}$ & 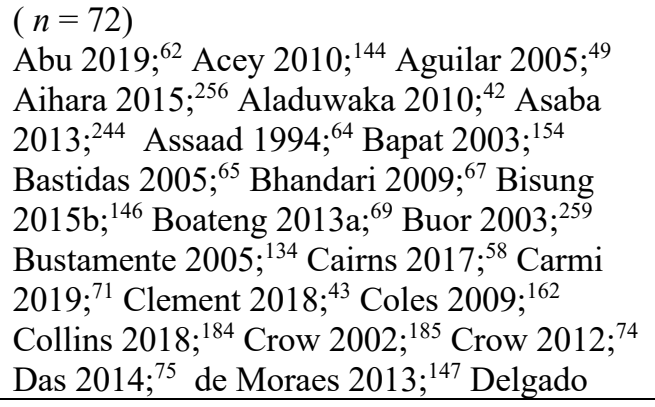 & $\begin{array}{l}(n=12) \\
\text { Ali 2013; }{ }^{102} \text { BeBe } 2015 ;{ }^{103} \text { Belur } 2017 * ; 157 \\
\text { Indarti } 2019 ; ;^{52} \text { Jha } 2012 ; ;^{105} \text { Joshi } 2012 ; ;^{203} \\
\text { Kher } 2015 ;{ }^{230} \text { Nallari } 2015 ; ;^{173} \text { Nerkar } \\
\text { 2013; } ;^{152} \text { Rautanen } 2005 ;{ }^{107} \text { Scott } 2017 a ; ;^{111} \\
\text { Scott } 2017 b^{112}\end{array}$ & 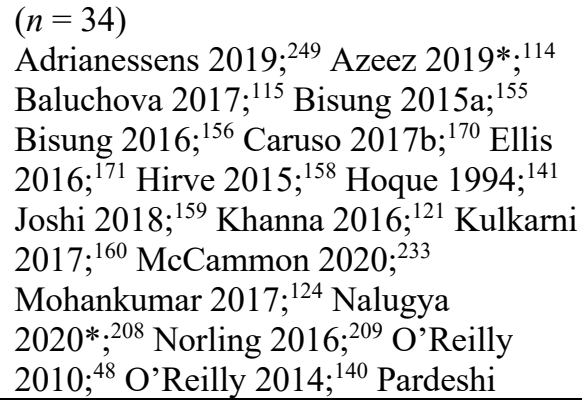 \\
\hline
\end{tabular}




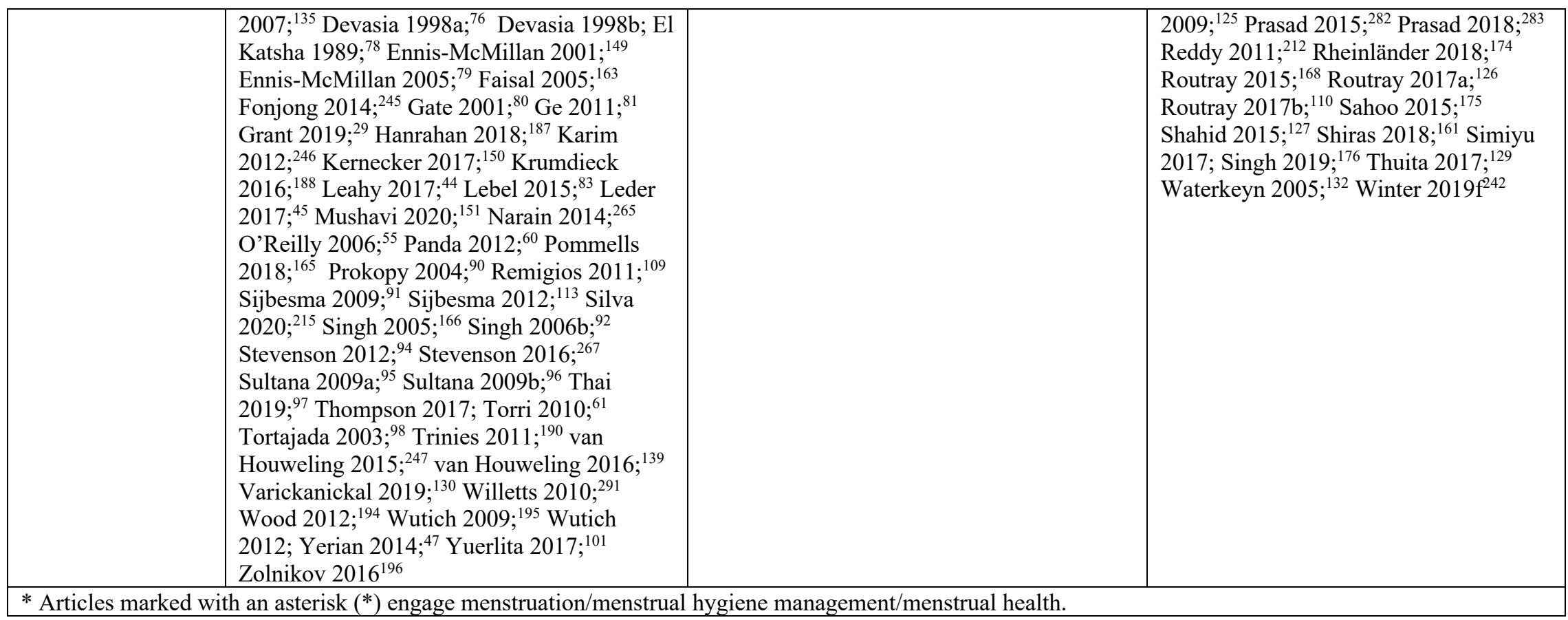




\section{Agency}

As detailed below, women have reported exercising water and sanitation-related agency, including engagement in decision-making inside and outside the household, formal and informal leadership, and collective action. Still, women's freedom of movement has minimally benefited from water and sanitation circumstances.

\section{1.a Decision-Making Household-level Decision-Making}

Women have varied decision-making roles related to household water and sanitation. Women in Guatemalan savings groups reported having at least equal participation in household WASH decisions, with many reporting greater decision-making power than their husbands. ${ }^{59}$ Women in Bangladesh, ${ }^{96}$ Ethiopia, ${ }^{94}$ and India ${ }^{46}$ reported decision-making power over water collection and allocation, though some studies from India found men to make water collection decisions that did not account for women's priorities. ${ }^{87,105} \mathrm{~A}$ water security study from Nepal reported that some women found individual decision-making stressful and that seeking support from in-laws and husbands was culturally valued. ${ }^{45}$ With respect to sanitation, in India, the odds of having a latrine was significantly higher in households where women were the main decision makers ${ }^{122}$ and in Kenya, the likelihood of a household owning an improved sanitation facility was significantly higher when women had at least some input on decisions about major household purchases. ${ }^{120}$

Both the characteristics of women (e.g life stage) and the decisions themselves have influenced women's involvement in WASH-related household decision-making. In Nepal ${ }^{43}$ and India, ${ }^{53,110}$ younger and unmarried or newly married women typically had less decision-making power, and in rural Bangladesh, ${ }^{96}$, older women sometimes had greater decision-making power over household water collection. Women's income-earning has enhanced their ability to make household water and sanitation decisions, particularly pertaining to small purchases or pay-per-use sanitation facilities. ${ }^{29,45,91,110,133}$ When large expenditures are involved, such as for latrine construction, women have been excluded from decision-making, ${ }^{48,55,86,97,105,109,110,117,121,128}$ potentially resulting in latrines that fail to accomodate needs and thus remain unused. ${ }^{48,55,110}$ In Kenya, women reported limited input over home rental decisions, including which WASH services should be available. ${ }^{130}$

\section{Extra-Household Decision-Making}

Women have participated in a range of extra-household water and sanitation decision-making situations. In Indonesia, women exercised independent choice in selecting WASH-related jobs. ${ }^{52}$ In India, women became a part of decision-making processes in village-level sanitation meetings, ${ }^{125}$ water user committees,${ }^{75}$ and other sanitation projects, ${ }^{113}$ and men believed women could speak up in meetings and expressed happiness that they could make joint decisions ${ }^{131}$. Women have voiced opinions about proposed activities and offered suggestions during informal water and sanitation meetings (Egypt), ${ }^{64}$ and both men and women noted that women are likely to speak out in public settings and take action on water-related issues given their role as household water managers (Mexico). ${ }^{79}$ Both men and women in Hmong communities in Vietnam agreed that women were likely to be listened to when they participated in water management meetings. ${ }^{83}$ In Bolivia, although women were rarely able to contribute in water-focused meetings, their contributions often shifted community conversations in important ways and women often had strong influence over water-related decisions, even when men had formal decision-making authority. ${ }^{100}$ 
Women also have been prevented from engaging in extra-household water and sanitation decisionmaking. Women reported being listed as water management group members, but never attending meetings (Bangladesh ${ }^{95}$ ), instructing husbands to relay water concerns to committees (Sri Lanka $^{42}$ ), having husbands or sons attend meetings and make decisions in their place (India ${ }^{92}$ ), and deferring to men to speak during water-related meetings even though they bore water collection responsibility (Kenya ${ }^{62}$ ). In northern Kenya - where women primarily collect water for domestic use and men for livestock - women were not actively involved in decision-making around water source utilization and their needs were not prioritized. ${ }^{47}$ Women play increasingly greater roles in water committees in rural Malawi, but they remain dominated by men in urban areas. ${ }^{72}$

Several factors have influenced women's involvement in extra-household water and sanitation decision-makng. Demographic factors, like class, caste, education, marital status, and age have been found to be influential. ${ }^{45,61,67,70,84,85,89,92,95,101,102,108,111}$ Various social factors constrain women's involvement, like household responsibilities that conflict with meetings; ${ }^{61,62,67,69,75,88,97,101,112,119,179}$ women's ability to attend but not speak or influence decisions, ${ }^{61,65,100-102,112}$ fear, shyness, and lack of confidence compounded by social norms limiting attendance or ability to speak in front of men; ${ }^{47,58,61,62,65,67,69,75,81,83,88,95,97,101,109,112,118,119,126}$ lack of respect or interest in women's opinion; ${ }^{64}$ and taboos governing the discussion of certain topics. ${ }^{109}$ Women's lack of assets, especially land, has prevented entrée into decision-making spheres. ${ }^{88}$

\section{Role of WASH Programs on women's decision-making}

Nongovernmental organizations (NGOs) have promoted women's voices in WASH-related decision-making processes. They have encouraged women to speak up in culturally appropriate ways. ${ }^{12,291}$ Trainings, information, and technical knowledge provided to women have contributed to the improvement of communication between men and women and led to women having a voice in household and community decision-making. ${ }^{44,61,115,291}$ WASH programs have increased trust, acceptance, and respect for women as community decision-makers (India ${ }^{115}$ and Sri Lanka ${ }^{42}$ ), increased women's roles in household decision-making (India ${ }^{125}$ and Vietnam ${ }^{44}$ ), and improved women's reported ability to express themselves $\left(\right.$ Costa Rica $\left.{ }^{49}\right)$.

WASH programs also have discouraged women's participation in decision-making by targeting men $^{88,110}$ or reinforcing gender norms. ${ }^{57,112}$ In India, women were included in public forums because they are responsible for children's health, while men were involved because they could demand improvements and travel outside the village. ${ }^{112}$ Additionally, women in India reported being provided water and sanitation, without consultation, resulting in services not meeting their needs. ${ }^{108}$ In Timor Leste, women's participation in water and sanitation projects has been limited to activities like cleaning or preparing food. ${ }^{57}$

\section{1.b.Leadership}

Women have served as formal and informal leaders in water and sanitation initiatives. Formal positions include leadership on water and sanitation committees; leadership or management of WASH businesses, value chain companies, and organizations; leading community-level projects; and fundraising for and monitoring community-based water and sanitation initiatives. ${ }^{45,52,69,71,75,79,98,106,112,119,125,135,140}$ Women's formal leadership has led to increased confidence among and toward women leaders. ${ }^{42,59,112,132,143,291}$ In rural Vanuatu, water user 
committees with women in key posts met more regularly, functioned better, and collected more revenue than those with only men in these roles. ${ }^{136}$ Still, while quotas have resulted in more women in leadership positions, ${ }^{137}$ women remained underrepresented in committees and leadership. ${ }^{69,88,123}$ Documented informal leadership activities included arbitrating local disputes ${ }^{55}$ disseminating water and sanitation information, ${ }^{140,146}$ motivating family members to use latrines, ${ }^{141}$ and leading protests, like those during the "water wars" in Bolivia. ${ }^{134}$ Select water and sanitation programs in Costa Rica, ${ }^{49}$ Guatemala, ${ }^{59}$ India, ${ }^{12,131}$ Sri Lanka, ${ }^{42}$ and Vietnam ${ }^{44}$ positively influenced the growth of women's leadership and support for women leaders. In India, women's participation in a community-led total sanitation campaign led to the emergence of female leaders who expanded their influence to other villages and activities. ${ }^{131}$

Several factors have influenced women's engagement and acceptance in water and sanitation leadership positions, whether formal or informal. Individual-level factors like women's marital status, religion, educational attainment, knowledge, age and social capital, including political ties and familial support, are influential. ${ }^{45,49,52,65,81,83,85,88,135}$ Barriers included limited confidence speaking in front of men or leading meetings; ${ }^{60,83,112,179}$ constrained time due to responsibilities; ${ }^{83,179}$ and relational factors, like men's level of acceptance of female leaders. ${ }^{42,52,69,97,112,282}$ In Mexico, women gained opportunities to serve as civil officers in municipal systems that govern piped water without opposition because the number of posts increased and men were not displaced. ${ }^{79}$ Even when leaders, women's roles have sometimes been tokenistic, at lower levels than male peers, and not resulting in influential decisionmaking. ${ }^{43,46,47,65,66,69,88,90,95,119,129,137,138,179,282}$ In both Bolivia ${ }^{58}$ and India, ${ }^{58,90,92}$ women in formal leadership positions reported being represented by male relatives and husbands. Men usurping leadership roles in India ${ }^{247}$ have limited initiatives aiming to foster women's leadership.

\section{1.c. Collective Action}

Women have engaged in varied forms of collective action to influence water and sanitation access, conditions, experiences, and opportunities. Women's collective action has led to funding, demand, construction, repair, and maintenance of water services $42,47,59,64,75,77,111,115,149,151,154,155,179,282$ and latrines. ${ }^{15,125,133,154,156,160,161}$ Women have organized to form lending groups to support womenled WASH businesses, ${ }^{52}$ provide community education about water safety, ${ }_{42,47,59,64,75,77,111,115,149,151,154,155,179,282}$ monitor open defecation, ${ }^{131}$ and respond to sanitationrelated harassment. ${ }^{160}$ Indigenous women in Bolivia and the U.S. have collectively defended water access. ${ }^{134,153}$ Women's involvement in WASH-related collective action has led to sustained involvement in water and sanitation issues ${ }^{75,149}$ as well as collective action around non-WASH issues, ${ }^{42,112,131}$ and also has encouraged respect from community members, including men. ${ }^{42,75,152,291}$

Myriad factors influenced collective action. Individual-level factors like class, caste, wealth, marital status, education, and interest in material benefits of participation influenced collective action invovlement. ${ }^{68,75,111}$ Facilitators of collective action included group solidarity, trust, and collective efficacy; ${ }^{44,52,59,75,153,160,291}$ the existence of other women's groups, community groups, and unions; ${ }^{75,85,155,160}$ women's representation in community leadership $;{ }^{59}$ and spaces designated for women. ${ }^{75}$ Barriers to women's involvement in collective action included hostility from men; ${ }^{42}$ norms that limit women speaking in front of men; ${ }^{111,126}$ limitations on women's participation by authority figures; ${ }^{111}$ opportunity costs when women have domestic and income-generating 
responsibilities; ${ }^{62,69,75}$ lack of incentive ${ }^{55,111}$ or trust ${ }^{130}$ limited guidance or training for engaging; ${ }^{126}$ and perceptions that actions are unlikely to have impact. ${ }^{111,155}$

\section{1.d. Freedom of Movement}

Movement restrictions, which are most widely reported in India, influenced women and girls' access to water 87,96,164 and defecation, urination, and menstrual management locations. ${ }^{48,121,160,167,168,170,173,175-177}$ Research in India found that family members (often husbands, fathers, and in-laws) restricted water fetching and sanitation-related movements, most intensely for unmarried daughters ${ }^{160,168,176}$ and recently married and pregnant women, ${ }^{164,168,175}$ (less intensely for women of lower castes ${ }^{121}$ and widows ${ }^{160}$ ). Families have built latrines specifically to restrict movement, ${ }^{48,160}$ though women do not always have access when needed if situated in spaces controlled by men. ${ }^{48}$ In India and Bangladesh, where women's freedom of movement is restricted or being seen in public is considered shameful, women reported difficulty navigating public spaces for water or sanitation needs, experiencing stress, harm to reputations, or risked beatings. ${ }^{87,96,173,175}$ To prevent shaming family members (Bangladesh ${ }^{96}$ ) or suffering beatings by men (India ${ }^{87}$ ), women collected water from closer, polluted sources rather than cleaner sources in male-dominated public spaces.

Women have described benefits of and preference for water and sanitation activities that require leaving the home. In Bangladesh, younger women enjoyed fetching water from distant water sources, providing opportunities to leave home and socialize. ${ }^{96}$ In rural India, some women who owned latrines preferred going for open defecation to visit friends and escape their home, mothersin-law, and chores. ${ }^{168}$

Women's freedom of movement influenced participation in community-level water and sanitation activities. Women in India, ${ }^{75,87} \mathrm{Nepal}^{45}$ and Kenya ${ }^{62}$ reported needing permission from men or elders to participate in meetings outside the home, ${ }^{62,75,87}$ which limited their involvement in water and sanitation committees and access to information, ${ }^{75,87}$ impacted their knowledge about water sources,${ }^{87}$ and constrained water access and decision-making. ${ }^{45,87}$ Restricted movement has limited women's access to training opportunities and therefore engagement in piped water enterprises $\left(\right.$ Cambodia $\left.^{29}\right)$, and has posed barriers to women's WASH businesses (Indonesia ${ }^{52}$ ). Women in India experienced in development projects reported more spatial mobility and were more likely to participate in water committees. ${ }^{75}$ One program (India) intentionally aimed to enhance mobility by engaging women in sanitation promotion outside the home; yet, the very latrines promoted were found to increase women's confinement. ${ }^{48}$

\section{Resources}

As described in the sections that follow, water and sanitation circumstances and conditions contribute to the deprivation of resources, particularly to bodily integrity, which includes health, safety and security, and privacy. Further, women's control over resources, notably financial and productive assets, social capital, and time, influence their access to water and sanitation and, conversely, water and sanitation conditions influence access and control over resources.

\section{2.a. Bodily Integrity}

Bodily integrity includes safety and security, health, and privacy, a subdomain inductively identified. 
Women's and girls' choices about and control over their bodies have been constrained due to water and sanitation conditions. Specifically, women limited bathing, and washing hands, clothes, menstrual materials, and bathrooms ${ }^{62,72,84,86,109,130,151,183,184,186,188,215,218,267}$ restricted food and water to avoid defecation and urination; ${ }^{121,154,160,165,170,178,198,210}$ suppressed defecation and urination urges; $2,48,167,170,174,176,177,200,203,215,221,222,224,227,233,234,236,256$ delayed changing menstrual materials; $;{ }^{210,226,227,233,236}$ and took anti-diarrheal medicines ${ }^{160}$ when lacking sufficient, safe or clean water and sanitation. Water improvements in Ethiopia reportedly decreased women's economization and use of dirty water. ${ }^{267}$

Women's ablity to meet their preferences is fundamental to ensuring bodily integrity. Multiple factors influence this ability, including conditions of water and sanitation facilities. Women and girls have described sanitation conditions as undesirable, dirty, disgusting, and nauseating $99,121,130,154,156,157,159,171,174,203,205,206,208-210,212,213,215,221-223,226,227,230,233,237$ and lacking resources like disposal bins, soap, sufficient water, and buckets for washing or bathing, which are also needed during menstruation. ${ }^{99,130,157,171,176,189,193,201,207,208,212,213,215,232,238-240}$ Women used less preferred locations and sources for sanitation $116,156,159,183,205,211,215,221,226,234,241,242,256$ and water due to cost, distance, or access limitations. $56,72,76,84,151,156,163,166,180,184,185,191,194,196,203,211,215,217$

\section{2.a.i Safety and Security}

General Fears and Perceptions of Safety

General safety concerns were widely noted, $86,105,109,125,129,133,157,163,168,172,174,177,187,188,209,212$ $215,219,224,226,227,237,241,243$ including feeling unsafe collecting water, ${ }^{86,105,163}$ or using sanitation facilities at night, ${ }^{154,157,176,215,241-243}$ and when toilets lack doors, locks, lighting, or are far. ${ }^{157,176,200,209,225-227,238,241}$ Safety issues were described as particularly intense for adolescent girls,

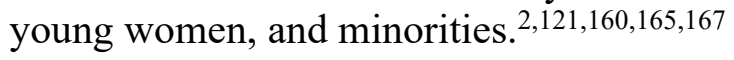

Research describing perceptions of improved safety all focuses on sanitation. ${ }^{125,208,213,243,253}$ Women in Nigeria with lockable latrines were significantly more likely to indicate that their latrine was safe than women without. ${ }^{253}$ Women and girls in Maharashtra, India, particularly when pregnant, menstruating, or adolescent, reported reduced fear when using toilets rather than open defecating. ${ }^{125}$ Women and girls have perceived sanitation facilities to be safer when there was lighting, ${ }^{119,243}$ locks, ${ }^{208}$ a female caretaker, ${ }^{213}$ or an entrance shielded from the men's side of a toilet block. ${ }^{119}$ In Uganda, a majority of female students who used toilets with lighting reported feeling safer, though many still felt unsafe going to the toilets alone because access paths remained unlit. ${ }^{243}$ Respondents in Kenya, ${ }^{133}$ Lebanon, ${ }^{214}$ and Ghana ${ }^{221}$ indicated that sex-separated latrines increase women and girls' safety.

\section{$\underline{\text { Harassment }}$}

General harassment, including taunting, teasing, name calling, and throwing things at women or girls is more frequently observed in sanitation ${ }^{124,154,160,161,167,173,176,249}$ than water research. ${ }^{154,185}$ Sexual harassment, including verbal harassment, peeping, flashing, and male masturbation is also more frequently documented in sanitation ${ }^{157-160,175,176,200,203,212,217,219}$ than water research. ${ }^{130,200,217,245}$ Women doing manual scavenging reported verbal abuse. ${ }^{124}$ 
medRxiv preprint doi: https://doi.org/10.1101/2021.10.26.21265535; this version posted October 28, 2021. The copyright holder for this preprint (which was not certified by peer review) is the author/funder, who has granted medRxiv a license to display the preprint in perpetuity. It is made available under a CC-BY-NC 4.0 International license .

\section{Physical Violence}

All research describing fear or experience of non-partner physical violence focused on sanitation, while all articles focusing on intimate partner physical violence and most focusing on interpersonal conflict focused on water. ${ }^{47,48,62,72,75,87,96,97,109,121,129,130,157,159 \text { - }}$ $161,163,165,167,168,174,175,177,184,187,229,237,241,243,244,246,248,250,252,255$

The majority of non-partner physical violence research focused on women's general fear of physical attack by men or boys, ${ }^{48,72,109,121,129,157,159-161,163,167,168,174,175,177,184,187,237,243,255}$ including "drunkards,"177 "bandits,"161 "idle youth"241 or "thieves"241 when accessing sanitation, with sanitation location emerging as important. Limited research documented actual experiences of physical violence from a non-partner. Research using Kenya Demographic and Health Survey data found women who defecated in the open had $40 \%$ greater odds of having experienced non-partner sexual and/or physical violence in the previous year compared to women who did not. ${ }^{255}$ In urban environments in sub-Saharan Africa, a greater association was found for women using a toilet shared with multiple households and experiencing non-partner violence than for women using private facilities. ${ }^{248}$ Women in India ${ }^{121}$ and Kenya ${ }^{62}$ shared stories of boys attacking and murdering girls who left home for defecation.

Inadequate water provision and collection behaviors were reported to influence intimate partner violence. $61,87,94,97,139,151,165,184,217,246,250,252,291$ Women reported violence from husbands if they did not provide water for bathing needs (Kenya, ${ }^{184}$ Ethiopia, ${ }^{94}$ Vietnam, ${ }^{97}$ Cameroon $^{217}$ ), did not have water in the home (East Africa ${ }^{165}$ ), went to cleaner water sources considered too far (India ${ }^{87}$ ), did not prepare food on time because of water collection duties (Uganda ${ }^{151}$ and Mozambique ${ }^{139}$ ), or attended water-focused community meetings (India ${ }^{61}$ ). Due to an improved water source, a man in Vanuatu reported no longer hitting his wife because she stopped asking for his help to fetch water. $^{291}$

Almost all articles documenting physical violence from interpersonal conflicts focused on water. $^{75,96,184,229,244}$ Women in India experienced intrahousehold conflicts and beatings due to participation in a water supply project: ${ }^{75}$ young women in Bangladesh, especially new brides, suffered verbal and physical abuse from mothers-in-law when they failed to collect water quickly or did not collect enough; ${ }^{96}$ children and women in Uganda reported quarrels, including physical fights, while waiting in long water queues; ${ }^{244}$ and schoolgirls in Kenya reported that the school janitor would beat them if the toilet was unclean. ${ }^{229}$

\section{Sexual Violence}

Fear and experiences of sexual violence were reported by women and girls who had to leave home for water and sanitation needs. ${ }^{56,62,94,109,121,129,139,157,159-161,163,165,167,169,170,172-175,177,184,200,217,219,224-}$ $226,241,244,245,247,251,254-256$

Research from India, ${ }^{167,254}$ Kenya, $^{255}$ and Nigeria ${ }^{56}$ found women openly defecating were particularly vulnerable to non-partner sexual violence compared to those using latrines. Fear of sexual assault was reported to be greatest at night, ${ }^{109,172,224,225,241}$ leading some women to use bags and buckets for sanitation needs. ${ }^{161,241,256}$ In India, those in urban settings reported greater fear of sexual assault when accessing sanitation than those in rural settings. ${ }^{167,175}$ Qualitative research described how men in India hid to watch for, attack, and molest women openly defecting alone, ${ }^{160}$ 
medRxiv preprint doi: https://doi.org/10.1101/2021.10.26.21265535; this version posted October 28, 2021. The copyright holder for this preprint (which was not certified by peer review) is the author/funder, who has granted medRxiv a license to display the preprint in perpetuity.

It is made available under a CC-BY-NC 4.0 International license .

and how a young woman in a Kenyan slum experienced an attempted rape when she walked ten minutes to the latrine. ${ }^{225}$ Some Kenyan women mentioned rape as a stressor (specifically during menstruation, which compels toilet use). ${ }^{241}$

Walking long distances and collecting water from certain sources reportedly exposed women and girls to sexual violence, ${ }^{62,139,165,217,244,245}$ particularly as men studied women's patterns. ${ }^{165}$ In refugee settings in Ethiopia and the Democratic Republic of Congo, caregivers advised girls to not bathe at the river or in community showers to avoid rape. ${ }^{169}$

\section{2.a.ii Health}

Women reported different health concerns, mostly negative, based on life stage and circumstance. Notably, pregnant women expressed health fears related to sanitation-related superstitions (India ${ }^{170,175}$ ), women with trouble controlling urination or defecation stressed about accessing sanitation sites (India ${ }^{2}$, women reliant on bags, buckets, or open defecation had substantially lower odds of reporting good health compared to other women (Kenya ${ }^{242}$ ), and circumcised women who had recently given birth found it difficult and painful to defecate and urinate $\left(\right.$ Kenya $\left.^{129}\right)$.

\section{Bodily Harm}

Women and girls feared, risked, or experienced, varied harms related to their water and sanitation circumstances and activities. ${ }^{48,49,64,76,87,121,127,129,130,144,154-156,158-160,163-165,167,168,170,172,173,175-177,183-}$ $185,187,200,212,217,230,243,244,247,262,263,282$ Many noted exacerbated experiences for women who were pregnant or elderly, had pre-existing conditions, and/or perform activities in harsh weather. ${ }^{121,129,130,155,160,163,165,167,168,170,173,175,185,217}$

Reported risks of and actual harm linked to water and sanitation ranged widely, with reported water fetching related harms in particular resulting in serious and long-term consequences. Specific immediate water fetching harms included general and localized pain; $49,76,87,109,173,184,215,217,230,262$ headaches and head injury; 215 and injury from falls, trucks, and/or car accidents. ${ }^{130,144,154,184,217}$ Fears or experiences of harm from domestic and wild animals and insects were reported for both water collection and sanitation activities. ${ }^{48,121,129,156,158-160,163-}$ 165,170,173,175-177,184,187,200,212,215,243,244,282 Women and girls reported fear and actual experiences of injury at and when accessing sanitation locations, regardless of sanitation type. $121,154,158,160,170,172,175-177,212,243$ Women doing manual scavenging reported backaches (India). ${ }^{127}$

\section{Illness and Infirmity}

Women and girls' experiences of illness and infirmity related to water and sanitation conditions are well documented. $49,51,56,62,67,72,97,104,108,109,121,127,130,140,154,158-160,163,164,170,172,174-177,181,183-$ $185,188,194,200,206,209,211,212,217,225-227,233,242,245,258,259,264,270,271,273,274,276$

Water and sanitation access have been linked to women's reproductive health outcomes. Two global studies (with data from $193^{270}$ and 144 countries $^{272}$ ) and one focused on sub-Saharan Africa $^{273}$ found increased access to improved water and sanitation to be significantly associated with decreased maternal mortality. In India, reproductive tract infections were more common among women who changed their menstrual materials outdoors rather than in a private room or latrine. $^{271}$ 
Water and sanitation access have been linked to women's nutrition and cardiovascular health outcomes. In rural Cambodia, women with nonimproved sanitation facilities had lower body mass index (BMI) and higher prevalence of anemia, ${ }^{276}$ and in urban India there was a positive correlation between women's BMI scores and access to private toilets and a negative correlation between BMI and open defecation. ${ }^{234}$ Higher odds for anemia were observed among women with nonimproved drinking water sources in Uganda, ${ }^{264}$ and women in Kenya consumed poorer quality foods and a less diverse diet as a result of water insecurity. ${ }^{184}$ In Nepal, having intermediate and low water access was associated with higher systolic and diastolic blood pressure levels in women, while men's blood pressure was not statistically different; elevated levels of blood pressure were highest for women with the least water access. ${ }^{258}$

Women qualitatively reported perceived linkages between various illnesses and their water and sanitation environments and experiences. Women reported experiencing or fearing diarrhea, vomiting, dysentery, cholera, hepatitis, schistosomiasis, and skin diseases due to polluted water, ${ }^{51,56,72,97,130,163,164,183,185,200,206,211,217,234,245,259,274}$ and experiencing diarrhea due to limitations on hygiene in times of water scarcity. ${ }^{56,109,188}$ Women in India worried about spreading disease if limited water constrained their ability to wash their hands during menstruation, ${ }^{212}$ and were concerned about fungal diseases when using dirty water inside sanitation facilities. ${ }^{176}$ When interventions improved water availability or treatment, women reported experiencing fewer vaginal infections ${ }^{49}$ and seeing fewer illnesses in their families. ${ }^{67,194}$ Women who withheld food and water or suppressed urination and defecation when lacking access to safe, clean latrines reported experiencing urinary tract infections, headaches, stomach aches, constipation, diarrhea, and other illnesses. ${ }^{121,154,158-160,170,176,200,234}$ In India, women working in manual scavenging reported experiencing sickness, fever, and nausea. ${ }^{127}$

Women and girls identified multiple sanitation-related factors they linked to illness, infection, and disease spread. Factors included dirty public or school toilets, ${ }^{62,130,154,172,177,233}$ open defecation fields, ${ }^{56,175,176,181}$ feces within community spaces, ${ }^{176}$ foul odors from toilets, ${ }^{174}$ urinating on another person's urine, ${ }^{170}$ using shared toilet seats at school, ${ }^{209,227}$ consuming fish from canals where people defecated, ${ }^{140}$ unhygienic defecation practices and insufficient solid waste management, ${ }^{104,108,163,212,225,226}$ and food contamination because of latrine proximity to cooking areas. ${ }^{130}$

$\underline{\text { Mental Health }}$

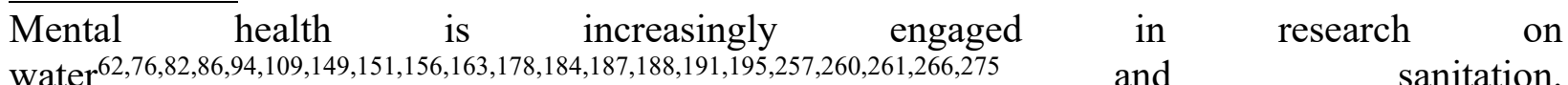
$2,125,154,158,159,161,164,171,174,175,215,269,275$

Water-related stress, anxiety, depression, or fear were reported by women in Ethiopia regarding water-related illnesses; ${ }^{94}$ in Bolivia, ${ }^{218}$ Brazil, $^{215}$ India, ${ }^{266}$ Kenya $^{62,156,184}$ Mexico ${ }^{149}$ and Uganda $^{151,191}$ due to water insecurity; in Kenya ${ }^{184}$ and $\mathrm{Canada}^{187}$ due to interpersonal relations related to water; and in Bangladesh when collecting water after dark. ${ }^{163}$

Women reported myriad sanitation-related stressors, including fear of being attacked by men or ghosts, ${ }^{163,167,170,175,215,224}$ being shamed for using open defecation sites, ${ }^{158}$ suppressing urination or 
defecation, ${ }^{170}$ withholding food and water, ${ }^{170}$ needing help to meet sanitation needs, ${ }^{170}$ being hurried while using shared facilities, ${ }^{154,171,174}$ sanitation-related costs, ${ }^{156,226}$ and lacking privacy or being seen by others, ${ }^{164}$ especially men, ${ }^{170,175}$ while openly defecating. ${ }^{156,158,159,170,175,224,226}$ Women working as manual scavengers in India reported feeling undignified and unworthy. ${ }^{127}$ Women coped with sanitation stressors by seeking social support, withholding food or drink, or changing the timing of sanitation behaviors, though adaptations could also cause stress. ${ }^{154,163,170,175}$

Access to sanitation facilities was associated with mental well-being. Ownership of functional household latrines and enclosed bathing spaces were significantly associated with well-being among women in rural India. ${ }^{2}$ Toilet access in Kenya was associated with better mental health and well-being among women. ${ }^{275}$ Women who received latrines in Mozambique reported that they decreased their stress, ${ }^{161}$ and women in India reported that private latrines helped them to overcome the embarrassment, shame, and anxiety of open defecation. ${ }^{125}$

\section{2.a.iii Privacy}

Women reported practicing hygiene behaviors at nonprivate water sources. Women and girls in Bangladesh, ${ }^{185}$ India, ${ }^{170,175,212}$ Indonesia, ${ }^{101}$ and Mozambique ${ }^{161,247}$ described challenges obtaining privacy at water sources used for bathing, post-defecation cleansing, and washing, particularly during menstruation. In Mozambique, newly constructed handpumps provided women with easier, more reliable water access, but made achieving privacy for bathing and menstrual hygiene more difficult than at sources like rivers. ${ }^{247}$

Sanitation facilities often enable privacy. In India, women with latrines reported a greater sense of privacy, ${ }^{125}$ and adolescent girls and women found latrines particularly useful for maintaining privacy during menstruation and defecation, especially during the rainy season. ${ }^{168,208}$ Women in Nigeria with lockable latrines were significantly more likely to report that their latrine was private $(86 \%$ versus $64 \%) .{ }^{253}$

Privacy is challenging to obtain for those without sanitation facilities and for some using household or shared facilities. In urban India, privacy for open defecation is especially hard to obtain. ${ }^{212}$ Women in Nairobi, Kenya who rely on bags, buckets, or open defecation had lower odds of experiencing privacy. ${ }^{242}$ Household or shared toilets do not always prevent women from being seen or heard while defecating. ${ }^{109,170,172}$ Women reported privacy concerns in shared sanitation facilities in Zimbabwe, ${ }^{109}$ Mozambique, ${ }^{161}$ Kenya, ${ }^{177}$ India, ${ }^{116}$ and South Africa, where limited privacy at community ablution blocks was also noted ${ }^{237}$ Privacy of household and shared latrines is compromised by broken ${ }^{175}$ or missing doors, ${ }^{170,234}$ missing locks, ${ }^{161,177,234,237}$ and poor construction. ${ }^{161,177,226,237}$ Furthermore, women worried about being seen walking to latrines; ${ }^{175,213}$ waiting in queues; ${ }^{116}$ having others hear or smell their activity; ${ }^{161}$ or the proximity of latrines to houses, main roads, or public spaces. ${ }^{55,161,213}$

Privacy concerns vary by gender and life stage. In India, women reported stricter privacy requirements for bathing than men, ${ }^{203}$ particularly among younger ${ }^{212}$ or Muslim women. ${ }^{140}$ In Cameroon $^{217}$ and India, ${ }^{203}$ women reported feeling less free than men to urinate or defecate openly due to privacy. In India, newly married women described stronger requirements for privacy due to reputation concerns, ${ }^{121,168,175}$ and older women reported going where privacy was compromised because they could not suppress urges. ${ }^{159}$ 
Women exercised various coping strategies to adapt to poor privacy conditions. They sought alternative locations by relieving themselves in containers in the home, ${ }^{172,177}$ open defecating near the home ${ }^{177}$ or in sites protected by vegetation, ${ }^{129,156}$ or by walking to farther defecation locations; ${ }^{170}$ suppressed needs by restricting eating and drinking and delaying urination, defecation, ${ }^{48,109,121,163,167,170,174,177,234,236}$ and changing menstrual materials; ${ }^{226}$ created privacy for themselves by constructing or modifying structures for privacy ${ }^{154}$ or wearing skirts or dresses to create coverage; ${ }^{215}$ and responded to breaches in privacy when men passed by standing up (and soiling themselves) while open defecating. ${ }^{121,158,160,170,212}$

Insufficient sanitation privacy posed concerns for women and girls when away from home for work or school. In India, working women voiced concerns over doors without latches or a lack of facilities, resulting in the need to suppress lest they be seen by others, particularly men. ${ }^{159,236}$ Similarly, Indian migrant women workers reported experiencing greater stress when openly defecating without privacy than from the risk of scorpion or snake bites. ${ }^{158}$ Girls in school reported insufficient privacy, particularly during menstruation. ${ }^{99,129,171,174,189,193,197,199,202,206-}$ 208,216,219,233,235,238 Where toilets were lockable and located away from boys' toilets, girls experienced greater privacy. ${ }^{174,193,197,199,202,207,208,235,239}$ Girls have avoided eating and drinking during the school day to avoid using a sanitation facility (Phillippines ${ }^{171}$ ), brought friends with them to the toilets (Philippines, ${ }^{171}$ South Africa, ${ }^{219}$ and Sweden ${ }^{209}$ ), turned on the tap to prevent others hearing them $\left(\right.$ Sweden $\left.^{209}\right)$, or chosen open defecation sites (Ghana ${ }^{174}$ ) to cope with privacy issues.

\section{2.b. Critical Consciousness}

The concept 'critical consciousness' was not explicitly engaged, though many engaged subconstructs, including self-confidence and the identification and questioning of inequalities. Improved self-confidence, including willingness to speak up, was reported regarding women's participation in WASH programs and campaigns in India, ${ }^{75,125,131}$ Sri Lanka, ${ }^{42}$ and Vietnam. ${ }^{44}$ Women in India reported improvements in self-confidence, dignity, and work and life circumstances due to improvements in water supply. ${ }^{115,265}$ In Indonesia, some women reported feeling confident to challenge traditional gender roles and become leaders in the water sector. ${ }^{52}$

Awareness of their unequal position in society was reported to influence how women approached resolving water issues in Sri Lanka ${ }^{42}$ and Mexico, ${ }^{149}$ and sanitation issues in India. ${ }^{131}$ Women in rural India were aware of men's unequal decision-making power, which was reinforced by NGOs; they noted that NGOs only approached male household heads as part of a national campaign to build household latrines. ${ }^{110}$ Women in Kenya raised complaints about service provision to government officials, but leaders ignored them because there are "no consequences for their inaction."130

\section{2.c Assets}

\section{2.c.i Financial and Productive Assets}

Financial and Productive Assets for Water and Sanitation Access and Participation

Access to financial and other assets impacted women's water access. When women lacked control over income and assets, they had limited decision-making power over improving or accessing water sources. ${ }^{51,62,72,104,109,180,185,187,244,278}$ Constrained finances limited women's access to 
preferred water sources, ${ }^{50,72,97,144,156,180,183-185}$ desired water quantity, ${ }^{72,178}$ and water treatment methods. ${ }^{72,97,104,190,279}$ Women reported spending money to access water sources with shorter wait times $^{47,184}$ or higher quality, ${ }^{84,184}$ or to compensate male neighbors, laborers, or drivers for water collection. ${ }^{151,187}$ Water was a major expense for many women. ${ }^{51,72,97,184,186,278}$ In Uganda, women were four times more willing to contribute funds to water provision than men. ${ }^{88}$ In Kenya, purchasing water during the dry season limited money available for food. ${ }^{184}$ In Nigeria, women with water access issues found alternative sources, or purchased, bartered, or obtained water through credit. ${ }^{144}$ Furthermore, limited control over assets like carts, bicycles, and wheelbarrows made water collection more time-consuming, ${ }^{84,109,244}$ or, in sub-Arctic communities where women lack snowmobiles and guns for defense against bears, more dangerous. ${ }^{187}$

Limited income and asset access and control, including over land, constrained women's access to sanitation $^{105,110,111,121,133,154,157,160,172,173,177,203,225,226,256}$ and limited independent decision-making about latrine construction. ${ }^{105,110,121}$ Women reported using public pay-per-use toilets ${ }^{154,157,160,213,225,256}$ and incurring higher costs than men due to more frequent need. ${ }^{172,177,256}$ Limited household income has forced women to prioritize needs like food over sanitation, whether investing in or paying to use toilets. ${ }^{121,133,172}$ Women in Kenya ${ }^{226,256}$ and India ${ }^{173}$ adapted by using prefered pay-per-use locations less often or strategically, like for defecation only. ${ }^{173,226,256}$ Women have faced difficulties accessing government subsidies ${ }^{11,121}$ or loans large enough for latrine construction $^{117}$ and reported willingness to make financial sacrifices, like paying higher rent ${ }^{177}$ or accepting a lower wage job, ${ }^{160,203}$ to gain toilet access. In India, even women with economic and decision-making power could not build latrines without land ownership. ${ }^{10,173,176}$ In Nairobi, women reported that greater financial stability and more control over resources would help them access sanitation. ${ }^{133}$

Finances and assets have influenced women's representation or participation in community water and sanitation initiatives. Women have faced financial or asset-related barriers to participation in community-level initiatives, including a lack of land ownership for water committees (Peru ${ }^{135}$ and Uganda $^{88}$ ), an inability to sustain required monetary contributions for self-help groups (India ${ }^{58}$ ), and a lack of financial incentive and opportunity costs (India ${ }^{55,75,111}$ and Ecuador ${ }^{65}$ ). In India, some families pushed women to attend watershed development meetings because of perceived monetary benefit. $^{58}$

\section{Water and Sanitation Income Generation}

Water and sanitation have increased women's income by providing job opportunities. Specifically, women have engaged in water vending, ${ }^{75}$ meter reading and water tank cleaning, ${ }^{42}$ water management, ${ }^{29,107}$ water filter and toilet pan selling, ${ }^{52}$ and rainwater harvesting container construction. ${ }^{107,147}$ They have also engaged in water-dependent income-generating activities, like horticulture or pottery-making, ${ }^{45,192,247}$ or sanitation-related activities, like toilet cleaning, ${ }^{203}$ latrine construction, ${ }^{107}$ serving as toilet attendants, ${ }^{249}$ or doing scavenging work. ${ }^{124,127,283}$ Finally, water and sanitation improvements have freed up time for other income-generating activities. ${ }^{42,53,91,160,180,196,281}$

Women's income generation has been constrained by poor water access, limited employment opportunities, or by WASH initiatives themselves. Specifically, inadequate water access constrains income generation when time is needed instead for collecting water, or when water 
available is insufficient for income-generating activities. $^{29,42,53,67,72,86,91,152,160,180,184,186,188,192,196,217,230,245,281}$ In some cases, women have not been able to get water and sanitation-related jobs, or have only had access to stigmatized or minimum wage jobs. In Kenya, women wanted to build toilets, but men got the contracts because of beliefs that the work was inappropriate for women, enabling men to earn and control local development. ${ }^{129}$ In India, women working as manual scavengers reported receiving little money, and relying on leftover food and used clothing for survival. ${ }^{127}$ A water project in Sri Lanka engaged women to work for free, but paid men involved to avoid conflict. ${ }^{42}$ Finally, water initiatives have threatened women's incomes; in India, some women refused to support a water expansion project because it would impact their water vending income. ${ }^{75}$

\section{Adverse Effects of Water and Sanitation Conditions on Financial Assets}

Poor WASH conditions have indirect adverse effects on women's financial assets, often by impacting health. Women reported expenses related to health seeking when they or their children contracted WASH-related illnesses (Thailand, ${ }^{179}$ India, ${ }^{234}$ and Kenya ${ }^{226}$ ), increased expenditures on pay-per-use toilets when sick and decreased wages when missing work to care for the sick $\left(\right.$ Kenya $^{225}$ ), and lack of control over financial resources to invest in diarrheal disease prevention and treatment (Pakistan ${ }^{104}$ ). In India, women going for defecation feared being bitten by dogs, which could impact income due to doctor visits, ${ }^{159}$ and those lacking a place to change menstrual pads at work reported lost income from missing or leaving work to address needs. ${ }^{236}$ Conversely, in Costa Rica, a handpump project reduced women's expenditures caring for the sick. ${ }^{49}$

\section{2.c.ii Knowledge and Skills}

Women have specific household-level water and sanitation-related knowledge. ${ }^{104,110,145}$ In Kenya, women's roles as primary water collectors instilled knowledge about water access, quality, and quantity. ${ }^{62}$ In Pakistan, mothers and grandmothers were a source of knowledge and influenced household decision-making about water and hygiene, ${ }^{104}$ while in indigenous communities in Canada and the U.S., older women were responsible for teaching younger generations about waterrelated responsibilities. ${ }^{145,153}$

Women noted various types and sources of knowledge that influenced engagement in communitylevel activities. They reported the importance of knowledge related to village council processes to aquire toilet subsidies, ${ }^{121}$ community meetings and events to enable participation, ${ }^{57,90,95,101}$ community members' needs to evaluate water requests, ${ }^{100}$ and technical and business-related expertise to manage water enterprise businesses. ${ }^{29}$ Perceived limited knowledge has inhibited women's participation in community decision-making bodies, collective action, and WASH businesses, or advantaged more educated women. ${ }^{29,60,62,65,67,68,70,83,88-90}$ Women reported acquiring knowledge from other women at public meetings about water issues (Vietnam ${ }^{97}$ ) and from close friends about WASH activities (Indonesia ${ }^{52}$ ).

Water and sanitation initiatives have enabled women to gain awareness, knowledge, or practical skills, ${ }^{44,49,52,55,60,69,75,80,90,107,125-127,131,141,143,146,243}$ some doing so primarily to support project goals. ${ }^{49,60,125,131}$ Women engaged in a program in Vietnam received education on WASH, technical skills, and women's rights, which contributed to their confidence to speak up and negotiate household and community-level decisions. ${ }^{44}$ Women in Nepal received technical training in water 
and sanitation to enable job opportunities, however not all later found paid work outside the home. $^{107}$

Training initiatives have upheld gender norms. In a project in Ghana, men received skilled technical WASH training, while women were trained in unskilled jobs like cleaners and hygiene officers. ${ }^{69}$ In India, an initiative attempted to exploit women's knowledge of household water management and convince them to donate time and knowledge to the project. ${ }^{55}$

\section{2.c.iii Social Capital}

Women formed and maintained social connections when collecting water $43,64,96,101,139,265$ and relied on social capital from family, friends, and community members for multiple water needs. They leveraged social capital to access water when queues were long or water was scarce, $47,96,100,150,151,165,184,265$ jump water queues, ${ }^{154,165}$ get water from private wells, ${ }^{265}$ haul water using carts, ${ }^{215}$ receive improved home water access, ${ }^{45}$ wait on water deliveries, ${ }^{86}$ or get water during menstruation. ${ }^{164}$ In India, water management was found to be a cooperative task with men collecting water while women made decisions about quantity, quality, and use. ${ }^{166}$ Male partners in Kenya $^{184}$ and Mozambique ${ }^{139}$ helped with the physical labor or cost of water collection in rare circumstances, such as pregnancy, illness, or birth. In Kenya, women faced difficulties collecting water when they lacked childcare assistance. ${ }^{130}$ In Malawi, women were persuaded by friends and relatives to begin and maintain water treatment. ${ }^{194}$

Social capital has facilitated sanitation access. Women and girls have formed and maintained social connections when accessing sanitation locations, ${ }^{116,168,175}$ and sought social support to ensure privacy and safety and to protect reputations when urinating or defecating. ${ }^{159,168,170,173-}$ $176,209,212$ In India, schoolgirls asked friends to clean the school toilets so they could use them without fear of illness, ${ }^{233}$ yet women reported receiving scant sanitation-related cleaning support from men. ${ }^{212}$

Women accessed social networks to address water and sanitation problems. ${ }^{51,65,76,81,121,135,144,179}$ They used social networks to lobby officials to solve water problems (Thailand ${ }^{179}$ ), raise complaints with local authorities about water issues (Ecuador ${ }^{65}$ and Nigeria ${ }^{144}$ ), leverage village council connections to access latrine construction subsidies (India ${ }^{121}$ ), and create strategic alliances with male household members to push their water-related priorities in the community $\left(\right.$ Bangladesh $\left.^{95}\right)$.

Women leveraged social support to assume public roles. Women needed or sought family support to take public water management roles $\left(\right.$ Vietnam $\left.^{83}\right)$, disseminate water and sanitation knowledge as community facilitators (Costa $\mathrm{Rica}^{49}$ ), become masons and water technicians $\left(\mathrm{Nepal}^{107}\right)$, establish water enterprises (Cambodia ${ }^{29}$ ), participate in WASH activities and operate WASH businesses (Indonesia ${ }^{52}$ ), attend trainings on cistern building (Brazil ${ }^{147}$ ), and gain water user association membership (Peru $\left.{ }^{135}\right)$. In Bolivia, a lack of spousal support curtailed women's participation in water and sanitation governance. ${ }^{58}$ Participation in water management projects helped women in Sri Lanka expand their social networks ${ }^{42}$ as did women's participation in waterfocused mobilizations in Bolivia. ${ }^{134}$ Some women in Indonesia chose jobs in the WASH sector and participated in WASH activities because they provide socializing opportunities. ${ }^{52}$ 
medRxiv preprint doi: https://doi.org/10.1101/2021.10.26.21265535; this version posted October 28, 2021. The copyright holder for this preprint (which was not certified by peer review) is the author/funder, who has granted medRxiv a license to display the preprint in perpetuity. It is made available under a CC-BY-NC 4.0 International license .

\section{2.c.iv Time}

Women are the primary water-collectors globally, ${ }^{18,20}$ devoting considerably more time to waterrelated tasks than men. Men were more likely to collect from closer sources, ${ }^{20}$ where queues were shorter ${ }^{139,247}$ or they had priority access, ${ }^{47}$ or with assets like bicycles, motorcycles, wheelbarrows, or donkey carts to assist. ${ }^{84,109,139,244}$ Seasonal changes impacted time spent on water acquisition: during the dry season, women waited for often unpredictable and therefore disruptive water deliveries (Philippines ${ }^{86}$ ); spent extra time collecting water when sources dried up (Ghana ${ }^{183}$ ); slept or cooked at sources when lines were long (Mozambique ${ }^{247}$ ); and walked long distances in the dark (Mozambique ${ }^{139}$ ). Women in Vietnam relied on water sources that became more time consuming to access due to climate-related shortages. ${ }^{97}$ Increasing urban population density in India has exacerbated water scarcity and time required for collection. ${ }^{230}$ Constraints on women's time limit access to safe water or resources needed to treat or boil water. ${ }^{78,104,183,185,194}$ Women also spend considerable time caring for family members ill with water-related diseases. . $^{49,97,163,179,225,226,234,245,291}$

Women expended great amounts of time meeting sanitation needs and fulfilling sanitation-related responsibilities. ${ }^{50,52,107,108,111,113,114,118,119,121,124,127,154,159,160,168,170,171,173,175,176,181,205,212,214,222,225,226,23}$ 4,236,242,251 Women in India, ${ }^{111,181}$ Kenya, $^{242}$ and South Africa ${ }^{251}$ reported long walks to sanitation sites when they lacked private home toilets, and refugee women in Bangladesh ${ }^{205}$ reported waiting in long toilet queues. In urban India, women reported going for sanitation in early morning or late at night to avoid queues or ensure privacy, ${ }^{154,173,176,212,234}$ or open defecated rather than walking to and queuing at latrines. ${ }^{154}$ Time spent on sanitation has caused women to be late for work or suppress needs to avoid being late, ${ }^{154,159}$ work longer days if they needed to leave to use the toilet, ${ }^{236}$ fail to complete household chores, ${ }^{212}$ or be scolded or punished for taking too long. ${ }^{175}$ Women spent time assisting others with sanitation-related needs $\mathrm{s}^{121}$ and cleaning toilets, sometimes rising early to balance domestic duties with wage labor. ${ }^{108,113}$ Women working as manual scavengers in India reported limited control over taking breaks, and not being able to take time off if ill or to participate in festivals, weddings, or other celebrations. ${ }^{124,127}$

Opportunity costs exist related to time. Time devoted to water-related tasks limited women's time for other household chores, ${ }^{29,42,53,67,72,86,91,139,152,160,180,184,186,188,192,196,217,230,245,257,281}$ rest and leisure, ${ }^{76,130,183,184,230,257}$ and income-generating activities. ${ }^{62,108,130,184,230,257}$ Women enlisted daughters to help with water or sanitation-related tasks, ${ }^{62,72,87,108,109,130,151,152,163,173,230,289,290,294}$ or manual scavenging work, ${ }^{124}$ potentially impacting their daughters' education. At schools in Swaziland, girls asked to collect water spent less time in class. ${ }^{206}$ Women's participation was constrained in WASH businesses by restrictions related to overtime work (Indonesia) ${ }^{52}$ and in public life, such as water management, due to the time needed for household chores or incomegenerating activities, especially when participation is unpaid. ${ }^{62,65,67,83,90,92,97,101,118,119}$

When women and girls have reclaimed time related to water and sanitation, they participated in leisure or rest, ${ }^{74,139,168,182,247,281,282}$ productive activities, ${ }^{42,53,91,97,152,160,180,182,192}$ education and vocational training, ${ }^{42}$ or other domestic chores. ${ }^{43,121,139,180,247}$ Time savings have resulted in improved relationships because women were better able to complete chores or spend time with family. ${ }^{94,139,180,196,281,291}$ In Bangladesh, a tube well installation made water collection less time consuming, making older women more willing to help younger women with water collection. ${ }^{163}$ 
medRxiv preprint doi: https://doi.org/10.1101/2021.10.26.21265535; this version posted October 28, 2021. The copyright holder for this preprint

(which was not certified by peer review) is the author/funder, who has granted medRxiv a license to display the preprint in perpetuity.

It is made available under a CC-BY-NC 4.0 International license .

However, interventions have increased time burden; a water intervention in India prompted men, who previously bathed in public ponds, to demand that women fetch water for home bathing. ${ }^{265}$

\section{Institutional Structures}

As outlined below, institutional structures - including formal laws and policies, norms, and relations - influence women's agency and resources related to water and sanitation.

\section{3.a Formal Laws and Policies}

Women have participated in WASH governance to varying extents. In Bangladesh, ${ }^{163}$ Ghana, ${ }^{69}$ India, ${ }^{66,92,131,166}$ Kenya $^{47}$ and Uganda, ${ }^{88}$ governments and organizations that set up community water and sanitation committees have required the inclusion of women ${ }^{47,66,69,88,92,166}$ or encouraged and supported women's participation. ${ }^{131,163}$ In one project in India, rules mandated women be on water committees, but women did not always know they were on them. ${ }^{66}$

Inclusion does not guarantee participation, voice, or decision-making power. Women's participation in WASH-related governance has been constrained by a lack of awareness about the rules (Uganda ${ }^{88}$ ), a lack of transparency or distrust in political institutions (Kenya ${ }^{73}$ ), husbands or sons attending meetings in their place (India ${ }^{92}$ ), and being ignored by men (Kenya ${ }^{47}$ ). Committees with women have divided roles along gendered lines, with men in powerful positions, like president, and women in less powerful positions, like cleaner. ${ }^{69,139}$ Research in Uganda found women constituted less than a third of members and were rarely in leadership positions on water user committees despite guidelines to have women comprise $50 \%$ of membership and serve in influential positions. ${ }^{88}$

WASH policies, and uneven policy awareness, implementation, and enforcement, have posed barriers to women. Female entrepreneurs in Cambodia found certain policies made it hard to run water enterprises. ${ }^{29}$ Even when policies exist to address women's and girls' needs, they are not always known or enforced. In India, both men and women lacked awareness of policies, acts, and regulations that prioritized gender equitable access to resources and participation in a watershed intervention. ${ }^{89}$ A comparative study in Tanzania, Ghana, Cambodia, and Ethiopia, found some countries mandated sex-segregated school toilets, but adherence was inconsistent. ${ }^{239}$ Lack of clear responsibility and accountability has resulted in policy or guidance failure. Women Sanitary Complexes in India were reportedly not maintained according to guidelines due to disagreements over responsibility. ${ }^{125}$ In refugee camps in Lebanon and Myanmar, a lack of detailed guidelines and clarity about responsibility affected government actors' ability to provide sufficient water and sanitation for female refugees, particularly to support menstruation-related needs. ${ }^{214}$

\section{3.b. Norms}

Three themes were widely discussed related to norms: roles and responsibilities, restrictions, and shame and honor.

$\underline{\text { Roles and Responsibilities }}$

Research discussed social norms that govern men's and women's gendered water- and sanitationrelated roles, focusing largely on gendered division of labor and roles in public life. $18,20,45,47,48,52,62,69,74,75,83,87-89,96,97,109-112,117,118,121,126,129,139,151,165,170$ -

$173,176,179,184,187,195,200,206,215,229,231,244,247,259,265,268,282,287,288,290-293$ 
Women and girls are largely responsible for household water collection. . $^{18,20,48,62,74,75,88,89,96,97,109,117,139,151,165,173,179,184,187,195,215,231,247,259,268,282,287,288,290-292}$

Providing sufficient water for the household was described as important to being a good wife; failure to do so has resulted in shame and violence. ${ }^{139,165,259}$ Normative roles extended beyond the home; girls at school in Swaziland were expected to fetch water rather than boys. ${ }^{206}$ Gender intersected with other social identities to result in further marginalization or disadvantage related to roles and expectations. In India, lower caste women were expected to give priority water access to women from upper castes, particularly when water was scarce, ${ }^{265}$ and were reported to lack access to handpumps constructed within upper caste areas, even when tasked with repairing them. ${ }^{92,138}$ In Malawi, women with disabilities experienced difficulty collecting water, though they are often still expected to fulfill this role. ${ }^{268}$

Norms have influenced the extent that men engage in water collection and how they are perceived. ${ }^{96,184,244,265,282}$ Men in Uganda who assisted with water collection were deemed emotionally unstable or bewitched, ${ }^{151,244}$ and boys in India were reportedly embarrassed to be seen helping girls carry water. ${ }^{173}$ In Rwanda, men preferred water collection over other traditionally female tasks, though still viewed it as a woman's task. ${ }^{292}$ Norms of femininity and masculinity were found to be more fluid among lower castes in northwest India, enabling men to help women with water collection more easily than men in upper caste households. ${ }^{265}$ When men or boys do collect water, it has been more acceptable when they consider it 'helping' women ${ }^{247}$ or use technology - like bicycles, wheelbarrows, or motorcycles - while women and girls are expected to carry water. ${ }^{109,151,215,244,247}$ Exceptionally, in Inuit communities, men are primary water collectors. They carry guns for protection against polar bears near water sources - something unacceptable for women to do; women experienced anxiety accessing water when men migrate for work. ${ }^{187}$

Normative expectations affect women's and girls' sanitation-related practices. Rural Indian women reportedly suppressed urination and defecation urges when caregiving and household obligations were pressing ${ }^{170}$ and were often responsible for assisting others, including children, adolescent girls, and elderly family members, with sanitation needs. ${ }^{48,117,121,170,176}$ Women assumed more responsibilities for latrine cleaning than men because cleaning is typically considered women's work. ${ }^{172,293}$

Norms govern public water and sanitation participation. In several countries, it was more acceptable for men to participate in the public sphere and serve in leadership roles, ${ }^{52,62,89,97,109,111,112,118,126,129}$ and to have technological jobs, like as handpump mechanics, while women were discouraged. ${ }^{52,69,247}$ These normative beliefs are sometimes supported by men, women, and NGOs. In Thailand, women believed men were better suited for public leadership roles, and men questioned women's participation and problem-solving capacities related to village water resources. ${ }^{179}$ In sanitation planning initiatives in Kenya, a man justified women's exclusion from participation in the sanitation initiatives stating, women's brains were "like that of a child." 129 NGOs have targeted men as household heads and ignored women in decision-making and public participation. ${ }^{110}$ In rare cases, cultural beliefs facilitated women's public participation; women were described as more trustworthy on water user committees in Uganda and Ghana. ${ }^{69,88}$ 
medRxiv preprint doi: https://doi.org/10.1101/2021.10.26.21265535; this version posted October 28, 2021. The copyright holder for this preprint (which was not certified by peer review) is the author/funder, who has granted medRxiv a license to display the preprint in perpetuity. It is made available under a CC-BY-NC 4.0 International license .

\section{Restrictions}

Normative societal and familial rules have defined the boundaries of acceptable water and sanitation-related behaviors for women. ${ }^{47,48,52,73,75,87-89,96,97,110-112,116,126,160,163-165,167,168,173-}$ 176,183,204,220,247 Norms related to women's movement (discussed in the 'Freedom of Movement' section), asset ownership, and menstrual status have influenced women's water and sanitation access, behaviors, and participation in public life. Specifically, women's restricted access to property in rural India required them to seek permission from husbands or fathers-in-law to access land for latrine construction. ${ }^{110}$ In Nepal, norms preventing women from sharing latrines with men has compelled open defecation. ${ }^{116}$ Women in India reported not being able to use sanitation facilities $^{204}$ or touch water when menstruating due to perceptions that menstruation is polluting. ${ }^{164,167}$

Restrictive social norms regarding women's movement and roles have limited women's attendance and participation in water governance and repair, and latrine construction. In Cambodia ${ }^{29}$ and Indonesia, ${ }^{52}$ female entrepreneurs reported that norms related to women's freedom of movement and household roles made their engagement in piped water enterprises difficult. Even when they had technical skills to repair handpumps, women who lacked privilege and social access in India were not able to physically access handpumps to service them. ${ }^{138}$ In some communities in India, Kenya, and Uganda, women were prevented from speaking or sitting with men in public; ${ }^{47,88,111,126}$ women who did participate in water- and sanitation-related public life could be punished for violating these proscriptions, whether scolded, beaten, gossiped about, or assumed to be neglecting children and household responsibilities. ${ }^{47,73,88,112}$ Research from Kenya found that contracts for latrines and water facilities were almost exclusively awarded to men since technical work was not considered appropriate for women. ${ }^{129}$ In rural India, separate sanitation meetings were sometimes held because men and women could not sit and speak together in meetings, ${ }^{126}$ while in urban India, where norms were less restrictive, women have been able to mobilize and participate in water supply projects. ${ }^{75}$

\section{$\underline{\text { Shame and Honor }}$}

Women and girls have experienced sanitation- and menstruation-related shame; norms related to shame and honor have been leveraged to change water and sanitation conditions and behaviors. $^{48,109,125,126,131,159,160,165,167,168,170,172,174,175,177,199,215,216,236}$

Women and girls voiced shame related to sanitation and menstruation behaviors and experiences. Specifically, shame was reported regarding open defecation, ${ }^{125,159,174,215,236}$ particularly when their bodies may be exposed to males, ${ }^{48,167,168,170,175,236}$ and related to menstruation, including when seen carrying ${ }^{199}$ or washing and drying menstrual materials, ${ }^{170}$ or if menstrual blood was visible on toilets $^{174}$ or hands. ${ }^{216}$ As a result of sanitation- and menstruation-related shame, newly married women in India reported stress about their reputations within the family, while unmarried women and girls worried about their reputations outside the family, family honor, and marriage prospects. ${ }^{160,167,170,175}$ Women have also reported reducing water intake during work hours to avoid the shame of asking employers for sanitation access. ${ }^{159}$ Finally, women and girls in India have experienced shame and stigma when blamed for experiencing sanitation-related sexual assault. ${ }^{160}$

Norms related to shame and honor have been leveraged, perpetuated, and exploited in attempts to improve water and sanitation conditions. ${ }^{48,55,96,126,160}$ Women have convinced husbands to invest 
in tube wells within their compounds to prevent inappropriate movement through public spaces $\left(\right.$ Bangladesh $\left.^{96}\right)$ and to construct latrines to prevent daughters from potentially engaging in clandestine relationships when going for open defecation (India ${ }^{160}$ ). Households in India have built new sanitation facilities to protect the reputations of their daughters and daughters-in-law, ${ }^{160,168}$ with encouragement from national-level sanitation campaigns messages about respecting women and girls' privacy, ${ }^{125,131}$ the impact of women's privacy on family status, ${ }^{48}$ and the shame of women exposing themselves. ${ }^{126}$ Latrines have been marketed in India as means of confining women to the household, thus elevating the public status of the family. ${ }^{48}$

\section{$\underline{\text { Shifting Norms }}$}

Water and sanitation-related norms, including roles, responsibilities, and restrictions, have shifted, but impacts are variable. Water initiatives have increased expectations and work for women: the introduction of piped water resulted in women having to fetch water for their husband's bathing needs (India) ${ }^{265}$ and doing all the clothes washing, instead of sharing responsibility (Vietnam) ${ }^{44}$. Some water and sanitation initiatives have shifted norms and expectations in women's favor. ${ }^{42,111,112,291}$ WASH projects in Vanuatu resulted in men increasingly assisting with responsibilities like cooking and hygiene. ${ }^{291}$ In Sri Lanka, a women's group's successful water project demonstrated women's capacity to conduct public WASH projects. ${ }^{42}$ In India, NGOs used facilitators to challenge norms that limited women's ability to speak in village health committees that address WASH issues. ${ }^{111,112}$ However, initiatives that diverged from normative roles have faced resistance. When a project attempted to put household water connections in women's names, women objected (India). ${ }^{75}$ Men with new homestead water access did not like their increased involvement in what they perceived as women's work (Kenya) ${ }^{74}$ Norm change has emerged from changing circumstances; some displaced Syrian refugee girls did not face the same menstrual restrictions they did back home, though female refugees from Myanmar did not experience any shift. ${ }^{214}$

\section{3.c Relations}

Relations have both facilitated and hindered water-related behaviors and experiences. In India, social networks played an important role in women's decision to purchase new water filters ${ }^{190}$ and aided women's water collection when queues were long. ${ }^{154}$ In Bangladesh, ${ }^{96}$ India, ${ }^{265}$ and Uganda ${ }^{151}$ women relied on social networks to access water, but noted that relationships could be strained or unreliable when water was scarce. Women avoided quarrels at collection sites in Kenya by waking early to get water. ${ }^{62}$

Relations have also facilitated and hindered sanitation-related behaviors and experiences. Women frequently accompanied one another or asked men to accompany them for safety when open defecating, ${ }^{121,159-161,168,173,175,237}$ and to avoid harassment from community members when going to latrines and open defecation sites after dark. ${ }^{121,129,154,168,176,214,224}$ Additionally, women in Kenya reported quarrels over contributions toward sanitation activities and maintenance of shared toilets, ${ }^{156}$ and female toilet attendants in Europe reported poor treatment by patrons who refused payment. ${ }^{249}$ Relations influenced sanitation-related school experiences; girls reported bullying from boys if they were known to have defecated in the school toilet $\left(\right.$ Sweden $\left.^{209}\right)$ and if boys knew girls were menstruating because of which toilets they used (India ${ }^{233}$ ).

\section{Change Agents and Gatekeepers}


Actors with whom women and girls have relationships can serve as change agents, who deviate from the status quo and enhance women and girls' empowerment, or gatekeepers, who maintain the status quo and constrain women and girls' choice and voice.

Few articles discussed change agents. In Nepal, encouragement from mothers-in-law or husbands influenced women's decisions to take leadership positions in water-user groups. ${ }^{45}$ In a few households in rural India, men asked younger women - like daughters-in-law - for input on issues like latrine site selection, though this was uncommon. ${ }^{110}$ In $\mathrm{Cambodia}^{29}$ and Indonesia ${ }^{52}$, familial and organizational support helped women establish and manage WASH enterprises.

Within the home, men were often gatekeepers, holding household decision-making power. Indian women brought up toilet construction, but men dismissed it as an unnecessary expense. ${ }^{121}$ Even higher status women, like mothers-in-law, deferred to husbands or income-earning sons to make latrine construction decisions. ${ }^{110}$ Women in some cases need or value permission from in-laws or husbands to participate in activities outside the home, including water user groups and water management committees ${ }^{45,62,97}$ and have faced discouragement from men when seeking to engage in collective action. ${ }^{52}$

Outside the home, women encountered various gatekeepers. Women are gatekeepers to other women; in India, upper caste women have scolded or punished Dalit women seeking to bathe in the same area. ${ }^{175}$ Men in Sri Lanka expressed hostility to women's leadership in repeated complaints to the police that the women leading a water project had to address. ${ }^{42}$ Women reported that they faced criticism and confusion from local leaders and members of their communities when they sought to engage in WASH-related work (Indonesia). ${ }^{52}$ Students in Uganda who feared using the school toilets reported that male teachers would embarrass and deny them passes to go home when they started their periods. ${ }^{208}$

Influence of water and sanitation on relations

Water and sanitation conditions have strained intra-household relations. Women and men reported getting angry with family members over water issues (Bolivia), ${ }^{195}$ and women reported feeling bad about unreasonable water collection expectations (Uganda) ${ }^{151}$ and disputes occurring when husbands used too much water for bathing or when children spilled water (Kenya). ${ }^{47}$ Husbands became angry, quarrelsome, or physically abusive when women did not complete chores or meals on time due to water collection demands, ${ }^{94,139,151,165}$ when there was not enough water available for bathing and other purposes, ${ }^{94,97,165,184,217}$ or when they were asked to assist with water collection. ${ }^{291}$ In Mozambique, women reported that long absences from home for water collection could lead to conflicts because husbands suspected infidelity. ${ }^{139}$ Dependence on others for water assistance could result in stress and anxiety for women in Mexico ${ }^{149}$ and Inuit communities in Canada. ${ }^{187}$ In India, women reported that their participation in a water project led to intrahousehold conflict; some women reported experiencing beatings when they spoke up at meetings. ${ }^{75}$ In rural India, sanitation-related conflicts varied by life stage. Adolescent girls were scolded by parents for taking too long or talking to boys when going for urination/defecation; newly married women were scolded for not following household sanitation rules; ${ }^{175}$ women with children were scolded for abandoning children to meet sanitation needs; and women across life stages worried about upsetting others if they asked for assistance meeting sanitation needs. ${ }^{224}$ 
Water and sanitation conditions have strained inter-household relations. Disputes with neighbors at water collection locations were widely reported. $47,94,130,151,154,165,175,184,195,244$ Water collection sites could be places of tension and danger, including sexual exploitation, for women and girls in Zimbabwe ${ }^{109}$ and Uganda. ${ }^{151,165}$ In Kenya, disputes arose among women competing for water access, and verbal and physical fights erupted when women collecting payments favored women in the queue. ${ }^{47}$ Inter-household sanitation-related conflicts were reported related to shared toilets, ${ }^{173}$ where women practice open defecation, ${ }^{175,176}$ and accessing sanitation facilities. ${ }^{161}$

Water and sanitation initiatives have both negatively and positively affected relations. Negative effects in India included increased expectations of wives to bring water home, quarrels, and conflicts at water points. ${ }^{265}$ Positive effects included increased respect and support for women by men, changed division of labor, and increased ability of women to negotiate with husbands (Vanuatu ${ }^{291}$ ); reduced conflict between husbands and wives (Mozambique ${ }^{139}$, Kenya, ${ }^{74}$ and Vanuatu ${ }^{291}$ ); improved relationships between men and women (India ${ }^{91}$ ) and in families (Kenya 196 and Vietnam ${ }^{44}$; heightened status of women in and outside the home and positive attitudes and support for women's collective work (India ${ }^{42}$ ); and greater acceptance of women performing WASH roles outside the home (India ${ }^{115}$ ).

\section{Discussion}

We synthesized evidence on water, sanitation, and women and girls' empowerment from 257 peerreviewed empirical research articles, resulting in the most comprehensive synthesis of genderfocused water and sanitation research to date. Our review is more expansive than recent WASH and gender or empowerment-focused reviews that restricted inclusion based on publication date, ${ }^{31}$ only extracted data from titles and abstracts, ${ }^{31}$ or focused more narrowly on the intersection of gender, water, and health ${ }^{32}$ or on identifying the dimensions of empowerment used in WASH research $^{30}$. The majority (86\%) of included research was from Africa and Asia and focused on adults $(69 \%)$. No studies focused primarily on men or transgender or non-binary individuals, revealing patterns of research inequities that should be addressed to include more diverse geographies and populations. Our search and synthesis was grounded in an existing model of empowerment, ${ }^{33}$ which we iteratively expanded based on our review to include 'freedom of movement' within the Agency domain and 'privacy' within the Resources domain. Agency was the least commonly engaged domain among included articles $(122 ; 47 \%)$; the Resources domains was dominant $(241 ; 94 \%)$. This review not only contributes insights to those working in the WASH sector, it also augments understanding of the role of water and sanitation in discourse on empowerment and gender equality more broadly.

Water and sanitation research that engages empowerment and related domains is extensive and growing, yet clear conceptualization of empowerment remains limited. We found that $82 \%$ (211) of included articles were published since 2010, providing evidence that aligns with anecdotal observations that empowerment is increasingly a focus in water and sanitation research. ${ }^{27,31}$ Both the large body of work identified and its growth, which is consistent with growth in the broader field of women's empowerment, ${ }^{295}$ further justify the need to assess learning to date. Importantly, $124(48 \%)$ included articles did not use 'empowerment' or related words (e.g. "empower") in their text, but were included because they specifically reported on empowerment sub-domains (e.g safety, decision-making) aligned with our guiding model. Of the $133(52 \%)$ articles that did use empowerment or related terms in their text, only 17 (13\%; or $7 \%$ of total) provided a definition or 
medRxiv preprint doi: https://doi.org/10.1101/2021.10.26.21265535; this version posted October 28, 2021. The copyright holder for this preprint (which was not certified by peer review) is the author/funder, who has granted medRxiv a license to display the preprint in perpetuity. It is made available under a CC-BY-NC 4.0 International license .

conceptualization of women's empowerment to inform their work. Our assessment aligns with a reflection by Dery et al. (2019) that the definition of empowerment in WASH research lacks clarity. ${ }^{30}$ As this line of research continues, it is essential that researchers use empowerment-related terminology deliberately. Without solid conceptualization, whether by articulating a clear guiding definition or framework a priori, or by eliciting a local understanding of empowerment via the research (See Bisung and Dickin $(2019)^{50}$ ), terms may be misused or become devoid of meaning. ${ }^{296}$ The tool we created and used (Figure 1) can be adopted to assess engagement of empowerment concepts in future research.

We identified only one article that used a quantitative tool to assess women's empowerment related to WASH, the Empowerment in WASH Index. ${ }^{297}$ Additional tools are under development, like the Agency, Resources, and Institutional Structures for Sanitation-related Empowerment (ARISE) Scales, ${ }^{298}$ and the Water, Sanitation, and Hygiene Gender Equality measure (WASH-GEM). ${ }^{299}$ Additionally, in a perspective piece, Kayser et al. (2019) propose four priority areas for assessing gender equality and empowerment related to WASH. ${ }^{24}$ The momentum around measuring empowerment and WASH, while exciting, merits caution. In her critical review of current practices for measuring women's empowerment, Richardson (2018) provides three recommendations to ensure sound measurement: measures should draw on theory; analytic methods should be used to minimize implicit judgement and bias; and comprehensive information should be collected (like data from men or complementary qualitative data). ${ }^{296}$ Yount et al. (2018) note that empowerment measures should rigorously assess validity and reliability. ${ }^{300}$ Furthermore, research on empowerment from other sectors teaches that a multitude of measures can also hinder learning by limiting comparability between studies, ${ }^{301}$ and that tools should be selected intentionally based on context and need. ${ }^{302}$ If WASH-related empowerment is to be monitored at scale, a consensus on indicators and associated measures will be needed eventually. As tools emerge, there will be a need to review and assess the similarities, differences, strengths, weaknesses, specific uses, and gaps to continue strengthening this line of research.

Although existing measurement is limited, this review illuminates how water and sanitation circumstances and conditions have resulted in myriad negative impacts to women's well-being that remain unmonitored and under-evaluated. Illustratively, considerable research shows how compromised water and sanitation environments have contributed to women's risk or experience of harassment or physical and sexual violence; 47,48,56,62,72,75,87,94,96,97,109,121,124,129,130,139,154,157$161,163,165,167-170,172-177,184,185,187,200,203,212,217,219,224-226,229,237,241,243-252,254-256$ compromised mental wellbeing; $2,62,76,82,86,94,109,125,149,151,154,156,158,159,161,163,164,171,174,175,178,184,187,188,191,195,215,257,260,261,266,269,275$ resulted in illness, infirmity, and bodily harm $48,49,51,56,62,64,67,72,76,87,97,104,108,109,121,127,129,130,140,144,154-$ $156,158-160,163-165,167,168,170,172-177,181,183-185,187,188,194,200,206,209,211,212,217,225-227,230,233,242-245,247,258,259,262-$

$264,270,271,273,274,276,282$ or limiting of hygiene, food, and water; $62,72,84,86,109,121,130,151,154,160,165,170,178,183,184,186,188,198,210,215,218,267$ and suppression of urination, defecation and menstrual hygiene needs, ${ }^{2,48,167,170,174,176,177,200,203,210,215,221,222,224,226,227,233,234,236,256 ~}$ among other impacts. However, estimates of the burden of inadequate WASH remain focused on disease outcomes. ${ }^{8}$ Our review shows that the true burden of inadequate WASH on well-being is likely far greater, supporting calls to collect and report sex-disaggregated and gender-specific data that also considers intersectionalities, ${ }^{303,304}$ and to not discount or ignore impacts predominantly or only experienced by women and girls. ${ }^{305}$ Finally, this review confirms the need to set goals for measuring, monitoring, and reporting the specific impacts of WASH on women and girls. ${ }^{22}$ 
Despite the numerous studies that have documented impacts of water and sanitation conditions on women and girls, there has been scant action in response, warranting greater investment in programs and evaluations to create and assess change. For example, the Safety and Security domain is well-researched; $82(32 \%)$ articles document links between WASH and safety and security yet only one study evaluated a program that improved perceived safety. ${ }^{243}$ Furthermore, WASH programs have the potential to catalyze change across domains and be transformative, but only a few studies have documented these linkages and transformative change. Research in Ghana showed how a water project resulted in time savings, which further benefited well-being among women. ${ }^{180} \mathrm{~A}$ water intervention in Kenya also enabled time savings, which led to improved intrafamilial relationships. ${ }^{196}$ WASH programming in Vietnam provided knowledge and skills, which women reported improved their decision-making, public participation, and relations. ${ }^{44}$ Programs aiming to achieve transformative change should be evaluated to deepen the knowledge base on WASH and empowerment. To start, more research on Agency is warranted. Agency is "the heart of empowerment" and transformation, ${ }^{33}$ yet is the domain least studied. Research should aim to understand Agency in the context of WASH, including its relationship with other domains. Finally, political will and investment are necessary to ensure women and girls are prioritized in WASH initiatives. At a minimum, WASH initiatives should engage women meaningfully and not cause harm by bypassing them. ${ }^{88,108,110}$

\section{Strengths and Limitations}

This review has leveraged an existing model of empowerment to review full texts of an extensive volume of research, resulting in the most comprehensive synthesis on gender and water and sanitation to date. This review does not capture studies not available in English and research has continued to emerge since the search, somewhat limiting the comprehensiveness. Additionally, other models of empowerment exist that could have framed the review. Still, this review provides a valuable base and resource from which to develop programming and further research. While this review captures research on menstruation, it only does so in the context of water and sanitation research and cannot be considered a comprehensive review of menstruation and empowerment. Hygiene was not a focus and should be considered in future reviews. Finally, while we intended to register the review, we began extraction to inform other work prior to registering and recent revisions to guidelines now stipulate extraction should not have started prior to registration and thus we were no longer eligible.

\section{Conclusion}

Water and sanitation research specifically engaging women's and girls' empowerment in a welldefined or conceptualized manner is limited. However, a substantial body of research examining domains and sub-domains of empowerment exists that should be leveraged to develop and evaluate programs focused on improving the life outcomes of women and girls. Importantly, the integration of a gender lens into WASH research, and program and policy planning and evaluation, can enable the identification of inequities and potential harms and benefits, ${ }^{303}$ and should be mainstreamed across the WASH sector ${ }^{23}$. Emergent discussions about 'transformative WASH' call for interventions that radically reduce fecal contamination ${ }^{306}$ and chemicals ${ }^{307}$ to impact health. However, our findings underscore that a more comprehensive 'transformative WASH' that includes gender-transformative approaches to challenge and reduce systemic constraints on women's and girls' resources and agency is not only warranted but long overdue. 
medRxiv preprint doi: https://doi.org/10.1101/2021.10.26.21265535; this version posted October 28, 2021. The copyright holder for this preprint

(which was not certified by peer review) is the author/funder, who has granted medRxiv a license to display the preprint in perpetuity.

It is made available under a CC-BY-NC 4.0 International license .

\section{ACKNOWLEDGEMENTS}

We are grateful for the artistic contributions of Fernanda Kuri who assisted the authors in adapting the empowerment conceptual model by Van Eerdewijk et al. (2017) to be specific to this work (Figure 2).

This work was supported by the Bill \& Melinda Gates Foundation (OPP1191625). Under the grant conditions of the Foundation, a Creative Commons Attribution 4.0 Generic License has already been assigned to the Author Accepted Manuscript version that might arise from this submission. 
medRxiv preprint doi: https://doi.org/10.1101/2021.10.26.21265535; this version posted October 28, 2021. The copyright holder for this preprint (which was not certified by peer review) is the author/funder, who has granted medRxiv a license to display the preprint in perpetuity. It is made available under a CC-BY-NC 4.0 International license .

\section{REFERENCES}

1. Bisung E, Elliott SJ. Psychosocial impacts of the lack of access to water and sanitation in low- and middle-income countries: a scoping review. Journal of Water and Health 2016: wh2016158.

2. Caruso BA, Cooper HLF, Haardörfer R, et al. The association between women's sanitation experiences and mental health: A cross-sectional study in Rural, Odisha India. SSMPopulation Health 2018; 5: 257-66.

3. Clasen TF, Alexander KT, Sinclaire D, et al. Interventions to improve water quality for preventing diarrhoea. Cochrane Database of Systematic Reviews; 2015.

4. Dangour AD, Watson L, Cumming O, et al. Interventions to improve water quality and supply, sanitation and hygiene practices, and their effects on the nutritional status of children. Cochrane Database of Systematic Reviews; 2013.

5. Ejemot-Nwadiaro RI, Ehiri JE, Arikpo D, Meremikwu MM, Critchley JA. Hand washing promotion for preventing diarrhoea. Cochrane Database of Systematic Reviews; 2015.

6. Freeman MC, Garn JV, Sclar GD, et al. The impact of sanitation on infectious disease and nutritional status: A systematic review and meta-analysis. International Journal of Hygiene and Environmental Health 2017; 220(6): 928-49.

7. Hutton $\mathrm{G}$, Chase $\mathrm{C}$. The knowledge base for achieving the sustainable development goal targets on water supply, sanitation and hygiene. International Journal of Environmental Health Research and Public Health 2016; 13.

8. Pruss-Uston AJ, Wolf J, Bartram J, et al. Burden of disease from inadequate water, sanitation and hygiene for selected adverse health outcomes: An updated analysis with a focus on low- and middle-income countries. International Journal of Hygiene and Environmental Health 2019; 222: 765-77.

9. Sclar GD, Garn JV, Penakalapati G, et al. Effects of sanitation on cognitive development and school absence: a systematic review. International Journal of Hygiene and Environmental Health 2017; 220: 917-27.

10. Speich B, Croll D, Fürst T, Utzinger J, Keiser J. Effect of sanitation and water treatment on intestinal protozoa infection: A systematic review and meta-analysis. The Lancet Infectious Diseases 2016; 16(1): 87-99.

11. Stelmach RD, Clasen T. Household water quantity and health: A systematic review. International Journal of Environmental Research and Public Health 2015; 12(6): 5954-74.

12. Strunz EC, Addis DG, Stocks ME, Ogden S, Utzinger J, Freeman MC. Water, sanitation, hygiene, and soil-transmitted helminth infection: a systematic review and meta-analysis. PLOS Medicine 2014; 11: e1001620.

13. Wolf J, Hunter PR, Freeman MC, et al. Impact of drinking water, sanitation and handwashing with soap on childhood diarrhoeal disease: updated meta-analysis and metaregression. Tropical medicine \& international health 2018; 23(5): 508-25.

14. Sclar GD, Penakalapati G, Caruso BA, et al. Exploring the relationship between sanitation and mental and social well-being: A systematic review and qualitative synthesis. Social Science \& Medicine 2018; 217: 121-34.

15. United Nations. Sustainable Development Goal 6: Ensure availability and sustainable management of water and sanitation for all. 2016. http://sustainabledevelopment.un.org/sdg6 (accessed 20 August 2020). 
medRxiv preprint doi: https://doi.org/10.1101/2021.10.26.21265535; this version posted October 28, 2021. The copyright holder for this preprint (which was not certified by peer review) is the author/funder, who has granted medRxiv a license to display the preprint in perpetuity. It is made available under a CC-BY-NC 4.0 International license .

16. Joint Monitoring Programme. Progress on household drinking water sanitation, sanitation and hygiene 2000-2017. Special focus on inequalities. New York: JMP, WHO, UNICEF, 2019. 17. Burt Z, Nelson K, Ray I. Toward gender equality through sanitation access: UN WOMEN, 2016.

18. Graham JP, Hirai M, Kim S. An analysis of water collection labor among women and children in 24 sub-Saharan African countries. PloS One 2016; 11(6): e0155981.

19. Ray I. Women, water, and development. Annual Review of Environment and Resources 2007; 32: 421-49.

20. Sorenson SB, Morssink C, Campos PA. Safe access to safe water in low income countries: Water fetching in current times. Social Science \& Medicine 2011; 72(9): 1522-6.

21. Amebelu A, Ban R, Bhagwan J, et al. The Lancet Commission on water, sanitation and hygiene, and health. Lancet 2021.

22. Caruso BA, Sevilimedu V, Fung IC-H, Patkar A, Baker KK. Gender disparities in water, sanitation, and global health. The Lancet 2015; 386: 650-1.

23. Caruso BA, Sinharoy SS. Gender data gaps represent missed opportunities in WASH. The Lancet Global Health 2019; 7(12): e1617.

24. Kayser GL, Rao N, Jose R, Raj A. Water, sanitation and hygiene: Measuring gender equality and empowerment. Bulletin of the World Health Organization 2019; 97: 438-40.

25. Sinharoy SS, Caruso BA. On World Water Day, gender and equality and empowerment require attention. Lancet Planet Health 2019; 3: e202-e03.

26. Carrard N, Crawford J, Halcrow G, Rowland C, Willetts J. A framework for exploring gender equality outcomes from WASH programmes. Waterlines 2013: 315-33.

27. Fisher J, Cavill S, Reed B. Mainstreaming gender in the WASH sector: Dilution or distillation? Gender \& Development 2017; 25(2): 185-204.

28. Gerard K. Rationalizing 'gender-wash': empowerment, efficiency and knowledge construction. Review of International Political Economy 2019; 26: 1022-44.

29. Grant M, Soeters S, Bunthoeun I, Willetts J. Rural piped-water enterprises in Cambodia: A pathway to women's empowerment? Water 2019; 11(12): 2541.

30. Dery F, Bisung E, Dickin S, Dyer M. Understanding empowerment in water, sanitation, and hygiene (WASH): a scoping review. Journal of Water, Sanitation and Hygiene for Development 2020; 10: 5-15.

31. MacArthur J, Carrard N, Willetts J. WASH and gender: a critical review of the literature and implications for gender-transformative WASH research. Journal of Water, Sanitation and Hygiene for Development 2020.

32. Pouramin P, Nagabhatla N, Miletto M. A systematic review of water and gender interlinkages: Assessing the intersection with health. Frontiers in Water 2020; 2: 6.

33. Van Eerdewijk AHJM, Wong F, Vaast C, Newton J, Tyszler M, Pennington A. White paper: A conceptual model on women and girls' empowerment. Amsterdam: Royal Tropical Institute (KIT), 2017.

34. Kabeer N. The conditions and consequences of choice: Reflections on the measurement of women's empowerment. Geneva: United Nations Research Institute for Social Development (UNRISD), 1999.

35. Alsop R, Bertelsen MF, Holland J. Empowerment in practice: From analysis to implementation. Washington DC: World Bank Publications, 2006.

36. Martinez EM, Wu D. Women's Empowerment at CARE. Atlanta, GA: CARE, 2009. 
medRxiv preprint doi: https://doi.org/10.1101/2021.10.26.21265535; this version posted October 28, 2021. The copyright holder for this preprint (which was not certified by peer review) is the author/funder, who has granted medRxiv a license to display the preprint in perpetuity. It is made available under a CC-BY-NC 4.0 International license .

37. Krug EG, Mercy JA, Dahlberg LL, Zwi AB. The world report on violence and health. The Lancet 2002; 360(9339): 1083-8.

38. Carroll C, Booth A, Cooper K. A worked example of" best fit" framework synthesis: a systematic review of views concerning the taking of some potential chemopreventive agents. BMC Medical Research Methodology 2011; 11(1): 1-9.

39. VERBI Software. MAXQDA. 12 ed. Berlin, Germany; 2015.

40. Pluye P, Gagnon M, Griffiths F, Johnson-Lafleur J. A scoring system for appraising mixed methods research, and concomitantly appraising qualitative, quantitative and mixed methods primary studies in mixed studies reviews. International Journal of Nursing Studies 2009; 46(4): 529-46.

41. Hong QN, Pluye P, Fabregues S, et al. Mixed Methods Appraisal Tool (MMAT) Version 2018 User Guide: McGill Department of Family Medicine, 2018.

42. Aladuwaka S, Momsen J. Sustainable development, water resources management and women's empowerment: the Wanaraniya Water Project in Sri Lanka. Gender \& Development 2010; 18(1): 43-58.

43. Clement F, Karki E. When water security programmes seek to empower women-a case study from Western Nepal. In: Fröhlich C, Gioli G, Cremades R, Myrttinen H, eds. Water Security Across the Gender Divide: Springer; 2018: 151-69.

44. Leahy C, Winterford K, Nghiem T, Kelleher J, Leong L, Willetts J. Transforming gender relations through water, sanitation, and hygiene programming and monitoring in Vietnam. Gender \& Development 2017; 25(2): 283-301.

45. Leder S, Clement F, Karki E. Reframing women's empowerment in water security programmes in Western Nepal. Gender \& Development 2017; 25(2): 235-51.

46. Varua ME, Ward J, Maheshwari B, Dave S, Kookana R. Groundwater management and gender inequalities: The case of two watersheds in rural India. Groundwater for Sustainable Development 2018; 6: 93-100.

47. Yerian S, Hennink M, Greene LE, Kiptugen D, Buri J, Freeman MC. The role of women in water management and conflict resolution in Marsabit, Kenya. Environmental Management 2014; 54(6): 1320-30.

48. O'Reilly K. Combining sanitation and women's participation in water supply: An example from Rajasthan. Development in Practice 2010; 20(1): 45-56.

49. Aguilar L. Water as a source of equity and empowerment in Costa Rica. In: Bennett V, Dávila-Poblete S, Rico MN, editors. Opposing Currents The Politics of Water and Gender in Latin America. Pittsburgh: University of Pittsburgh Press; 2005. p. 123-34.

50. Bisung E, Dickin S. Concept mapping: Engaging stakeholders to identify factors that contribute to empowerment in the water and sanitation sector in West Africa. SSM-Population Health 2019; 9: 100490.

51. Gabrielsson S, Ramasar V. Widows: Agents of change in a climate of water uncertainty. Journal of Cleaner Production 2013; 60: 34-42.

52. Indarti N, Rostiani R, Megaw T, Willetts J. Women's involvement in economic opportunities in water, sanitation and hygiene (WASH) in Indonesia: Examining personal experiences and potential for empowerment. Development Studies Research 2019; 6(1): 76-91. 53. James AJ, Verhagen J, Van Wijk C, Nanavaty R, Parikh M, Bhatt M. Transforming time into money using water: A participatory study of economics and gender in rural India. Natural Resources Forum; 2002: Wiley Online Library; 2002. p. 205-17. 
medRxiv preprint doi: https://doi.org/10.1101/2021.10.26.21265535; this version posted October 28, 2021. The copyright holder for this preprint (which was not certified by peer review) is the author/funder, who has granted medRxiv a license to display the preprint in perpetuity. It is made available under a CC-BY-NC 4.0 International license .

54. Mmbengwa VM, Ntili TP, Haines R, Groenewald JA, Van Schalkwyk HD. Analysis of women empowerment in South African water boards: A special reference to historically disadvantaged individuals (HDIs) in South Africa. Gender and Behaviour 2014; 12(2): 6436-48. 55. O'Reilly K. "Traditional" women, "modern" water: Linking gender and commodification in Rajasthan, India. Geoforum 2006; 37(6): 958-72.

56. Oluyemo CA. Women's empowerment as determinant for maintanance and sustainability of portable water and sanitation facilities in Ekiti State, Nigeria. International Journal of Interdisciplinary Social Sciences 2012; 6(4).

57. Tam TNTP. Participation of women in rural water supply and sanitation projects: visible or invisible actors? The case of the sub-district of Maubara (Liquiçá, Timor-Leste). International Journal of Multidisciplinary Thought 2012; 2(4): 149-70.

58. Cairns MR, Workman CL, Tandon I. Gender mainstreaming and water development projects: Analyzing unexpected enviro-social impacts in Bolivia, India, and Lesotho. Gender, Place \& Culture 2017; 24(3): 325-42.

59. DeVries K, Rizo A. Empowerment in action: Savings groups improving community water, sanitation, and hygiene services. Enterprise Development \& Microfinance 2015; 26(1): 34-44.

60. Panda SM, Sannabhadti R. Improving process of natural resources management at the grassroots: The case of the Self Employed Women's Association (SEWA). In: Zwarteveen M, Ahmed S, Guatam SR, eds. Diverting the Flow: Gender Equity and Water in South Asia. New Delhi: Zubaan; 2012: 523-45.

61. Torri MC. Power, structure, gender relations and community-based conservation: The Cawswe Study of the Sariska Region, Rajasthan, India. Journal of International Women's Studies 2010; 11(4): 1-18.

62. Abu TZ, Bisung E, Elliott SJ. What if your husband doesn't feel the pressure? An exploration of women's involvement in WaSH decision making in Nyanchwa, Kenya.

International Journal of Environmental Research and Public Health 2019; 16(10): 1763. 63. Akolgo EA, Ayentimi DT. Community-level mechanisms and strategies for managing sustainable water supply systems: lessons from Bongo district of northern Ghana. Environment, Development and Sustainability 2020; 22(4): 3739-56.

64. Assaad M, El Katsha S, Wins S. Involving women in water and sanitation initiatives; an action/research project in an Egyptian village. Water International 1994; 19(3): 113-20.

65. Bastidas EP. Women and water in the northern Ecuadorean Andes. In: Bennett V, DávilaPoblete S, Rico MN, eds. Opposing Currents The Politics of Water and Gender in Latin America. Pittsburgh: University of Pittsburg Press; 2005: 154-69.

66. Bastola A. Gender and governance: a case of Jalswarajya Project. In: Cronin AA, Mehta PK, Prakash A, eds. Gender Issues in Water and Sanitation Programmes: Lessons from India: SAGE Publications Pvt. Ltd; 2015: 120-38.

67. Bhandari B, Grant M. Strategic gender needs: the missing element in water supply projects of Nepal. Journal of Rural Development (Hyderabad) 2009; 28(2).

68. Bisung E, Elliott SJ, Schuster-Wallace CJ, Karanja DM, Bernard A. Social capital, collective action and access to water in rural Kenya. Social science \& medicine 2014; 119: 14754.

69. Boateng JD, Brown CK, Tenkorang EY. Gender and water management practices in Ghana. Journal of Environment and Earth Science 2013; 3(5): 88-103. 
medRxiv preprint doi: https://doi.org/10.1101/2021.10.26.21265535; this version posted October 28, 2021. The copyright holder for this preprint (which was not certified by peer review) is the author/funder, who has granted medRxiv a license to display the preprint in perpetuity. It is made available under a CC-BY-NC 4.0 International license .

70. Boateng JD, Brown CK, Tenkorang EY. Socio-economic status of women and its influence on their participation in rural water supply projects in Ghana. International Journal of Development and Sustainability 2013; 2(2): 871-90.

71. Carmi N, Alsayegh M, Zoubi M. Empowering women in water diplomacy: A basic mapping of the challenges in Palestine, Lebanon and Jordan. Journal of Hydrology 2019; 569: 330-46.

72. Chipeta L. Water crisis in Blantyre City and its impact on the women: A case of Mbayani and Ntopwa Area. Journal of International Women's Studies 2009; 10(4): 17-33.

73. Coulter JE, Witinok-Huber RA, Bruyere BL, Dorothy Nyingi W. Giving women a voice on decision-making about water: barriers and opportunities in Laikipia, Kenya. Gender, Place \& Culture 2018.

74. Crow B, Swallow B, Asamba I. Community organized household water increases not only rural incomes, but also men's work. World Development 2012; 40(3): 528-41.

75. Das P. Women's participation in community-level water governance in urban India: The gap between motivation and ability. World Development 2014; 64: 206-18.

76. Devasia L. Safe drinking water and its acquisition: Rural women's participation in water management in Maharashtra, India. International Journal of Water Resources Development 1998; 14(4): 537-46.

77. Devasia VV. Tribal women in sustainable development through watershed programmes in Vidarbha. International Journal of Water Resources Development 1998; 14(4): 527-35.

78. El Katsha SE, White AU. Women, water, and sanitation: Household behavioral patterns in two Egyptian villages. Water International 1989; 14(3): 103-11.

79. Ennis-McMillan MC. Women, equity, and household water management in the valley of Mexico. In: Bennett V, Dávila-Poblete S, Rico MN, eds. Opposing currents: The politics of water and gender in Latin America. Pittsburgh: University of Pittsburgh Press; 2005: 137-53.

80. Gate S. Empowerment of women in watershed management: Guraiya panchayat, Madhya Pradesh. Indian Journal of Gender Studies 2001; 8(2): 247-56.

81. Ge J, Resurreccion BP, Elmhirst R. Return migration and the reiteration of gender norms in water management politics: Insights from a Chinese village. Geoforum 2011; 42(2): 133-42.

82. Harris L, Kleiber D, Goldin J, Darkwah A, Morinville C. Intersections of gender and water: Comparative approaches to everyday gendered negotiations of water access in underserved areas of Accra, Ghana and Cape Town, South Africa. Journal of Gender Studies 2017; 26(5): 561-82.

83. Lebel L, Lebel P, Sriyasak P, Ratanawilailak S, Bastakoti RC, Bastakoti GB. Gender relations and water management in different eco-cultural contexts in Northern Thailand.

International Journal of Agricultural Resources, Governance and Ecology 2015; 11(3-4): 22846.

84. Mandara CG, Niehof A, van der Horst HM. Does women's representation in local water management lead to better meeting women's domestic water needs? International Journal of Social Sciences and Humanity Studies 2013; 5(1): 43-62.

85. Mandara CG, Niehof A, van der Horst H. Women and rural water management: Token representatives or paving the way to power? Water Alternatives 2017; 10(1): 116-33.

86. Mason LR. Gender and asset dimensions of seasonal water insecurity in urban Philippines. Weather, Climate, and Society 2012; 4(1): 20-33. 
medRxiv preprint doi: https://doi.org/10.1101/2021.10.26.21265535; this version posted October 28, 2021. The copyright holder for this preprint (which was not certified by peer review) is the author/funder, who has granted medRxiv a license to display the preprint in perpetuity. It is made available under a CC-BY-NC 4.0 International license .

87. Mehta PK, Saxena N. Unleashing the gender differentials in water management: The rural milieu. In: Cronin AA, Mehta PK, Prakash A, eds. Gender Issues in Water and Sanitation Programmes: Lessons from India: SAGE Publications Pvt. Ltd; 2015: 139-54.

88. Naiga R, Penker M, Hogl K. Women's crucial role in collective operation and maintenance of drinking water infrastructure in rural Uganda. Society \& Natural Resources 2017; 30(4): 506-20.

89. Padmaja R, Kasala K, Pramanik S, et al. Gender transformative impacts from watershed interventions: Insights from a mixed methods study in the Bundelkhand region, India. Transactions of the ASABE 2020; 63(1): 153-63.

90. Prokopy LS. Women's participation in rural water supply projects in India: Is it moving beyond tokenism and does it matter? Water Policy 2004; 6(2): 103-16.

91. Sijbesma C, Verhagen J, Nanavaty R, James AJ. Impacts of domestic water supply on gender and income: Results from a participatory study in a drought-prone region in Gujarat, India. Water Policy 2009; 11: 95-105.

92. Singh N. Women's participation in local water governance: Understanding institutional contradictions. Gender, Technology and Development 2006; 10(1): 61-76.

93. Singh S, Bhardwaj N, Kumar B. Role of institutions related to gender mainsreaming in integrated watershed management project. Green Farming 2018; 9(1): 144-7.

94. Stevenson EGJ, Greene LE, Maes KC, et al. Water insecurity in 3 dimensions: An anthropological perspective on water and women's psychosocial distress in Ethiopia. Social Science \& Medicine 2012; 75(2): 392-400.

95. Sultana F. Community and participation in water resources management: Gendering and naturing development debates from Bangladesh. Transactions of the Institute of British Geographers 2009; 34(3): 346-63.

96. Sultana F. Fluid lives: Subjectivities, gender and water in rural Bangladesh. Gender, Place and Culture 2009; 16(4): 427-44.

97. Thai NV, Guevara JR. Women and water management: A policy assessment-A case study in An Giang Province, Mekong Delta, Vietnam. Asia-Pacific Journal of Rural Development 2019; 29(1): 77-97.

98. Tortajada C. Professional women and water management: Case study from Morocco: A Water Forum contribution. Water International 2003; 28(4): 532-9.

99. Trinies V, Caruso BA, Sogoré A, Toubkiss J, Freeman MC. Uncovering the challenges to menstrual hygiene management in schools in Mali. Waterlines 2015; 34(1): 31-40.

100. Wutich A. Gender, water scarcity, and the management of sustainability tradeoffs in Cochabamba, Bolivia. In: Cruz-Torres ML, McElwee P, eds. Gender and Sustainability: Lessons from Asia and Latin America: University of Arizona Press; 2012: 97-120.

101. Yuerlita. Women's participation in a rural water supply and sanitation project: A case study in Jorong Kampung Baru, Solok, West Sumatra, Indonesia. In: Febriamansyah R, Yonariza, Ullah R, Shivakoti GP, eds. The Reciprocal Relationship between Governance of Natural Resources and Socio-Ecological Systems Dynamics in West Sumatra, Indonesia: Elsevier; 2017: 89-102.

102. Ali R. Women's participation in the water, sanitation and hygiene program at community level in Bangladesh. Journal of Third World Studies 2013; 30(1): 193-208.

103. BeBe K, Bing W. Outsourcing and local public administration: Water and sanitation services delivery and women participation in urban areas. Journal of Public Administration and Governance 2015; 5(4): 112-32. 
medRxiv preprint doi: https://doi.org/10.1101/2021.10.26.21265535; this version posted October 28, 2021. The copyright holder for this preprint (which was not certified by peer review) is the author/funder, who has granted medRxiv a license to display the preprint in perpetuity. It is made available under a CC-BY-NC 4.0 International license .

104. Halvorson SJ. Women's management of the household health environment: Responding to childhood diarrhea in the Northern Areas, Pakistan. Health \& Place 2004; 10(1): 43-58.

105. Jha N. Reducing a community's water and sanitation burden: Insights from Maharashtra. In: Zwarteveen M, Ahmed S, eds. Diverting the Flow: Gender Equity and Water in South Asia. New Delhi: Zubaan; 2012: 203-39.

106. Makoni FS, Manase G, Ndamba J. Patterns of domestic water use in rural areas of Zimbabwe, gender roles and realities. Physics and Chemistry of the Earth, Parts $A / B / C 2004$; 29(15-18): 1291-4.

107. Rautanen S, Baaniya U. Technical work of women in Nepal's rural water supply and sanitation. Water International 2008; 33(2): 202-13.

108. Reddy BS. Appropriate sanitation: Perceptions and experiences amongst a heterogeneous group of the urban poor. ICF AI Journal of Public Administration 2008; 4(3): 52-68.

109. Remigios MV. Women-water-sanitation: The case of Rimuka high-density suburb in Kadoma, Zimbabwe. Agenda: Empowering Women for Gender Equity 2011; 25(2): 113-21. 110. Routray P, Torondel B, Clasen T, Schmidt W. Women's role in sanitation decision making in rural coastal Odisha, India. PloS One 2017; 12(5): e0178042.

111. Scott K, George AS, Harvey SA, et al. Beyond form and functioning: Understanding how contextual factors influence village health committees in northern India. PLoS One 2017; 12(8): e0182982.

112. Scott K, George AS, Harvey SA, Mondal S, Patel G, Sheikh K. Negotiating power relations, gender equality, and collective agency: Are village health committees transformative social spaces in northern India? International Journal for Equity in Health 2017; 16(84).

113. Sijbesma C, Mathew K, Nishshanka R, et al. Adopting a gender approach in a water and sanitation project: The case of the 4WS Project in coastal communities in South Asia. In: Zwarteveen M, Ahmed S, Gautam SR, eds. Diverting the Flow: Gender Equity and Water in South Asia. New Delhi: Zubaan; 2012.

114. Azeez AEP, Negi DP, Mishra A. Women's experiences of defecating in the open: A qualitative study. Indian Journal of Gender Studies 2019; 26(1-2): 160-70.

115. Baluchova B, Mamova A. The role of implementation and communication of MANTRA Water, sanitation and hygiene program in improving public health in Odisha state (India). Neuroendocrinology Letters 2017; 38(Suppl 1): 35-9.

116. Bhatt N, Budhathoki SS, Lucero-Prisno DEI, et al. What motivates open defecation? A qualitative study from a rural setting in Nepal. PloS one 2019; 14(7): e0219246.

117. Czerniewska A, Muangi WC, Aunger R, Massa K, Curtis V. Theory-driven formative research to inform the design of a national sanitation campaign in Tanzania. PloS one 2019; 14(8): e0221445.

118. Dwipayanti NMU, Rutherford S, Chu C. Cultural determinants of sanitation uptake and sustainability: local values and traditional roles in rural Bali, Indonesia. Journal of Water, Sanitation and Hygiene for Development 2019; 9(3): 438-49.

119. Elledge M, Parker A, Toolaram A, Stoner B. A gender lens into sanitation technology innovation. Journal of Management in Engineering 2020; 36(4): 06020002.

120. Hirai M, Graham JP, Sandberg J. Understanding women's decision making power and its link to improved household sanitation: The case of Kenya. Journal of Water, Sanitation and Hygiene for Development 2016; 6(1): 151-60.

121. Khanna T, Das M. Why gender matters in the solution towards safe sanitation?

Reflections from rural India. Global Public Health 2016; 11(10): 1185-201. 
medRxiv preprint doi: https://doi.org/10.1101/2021.10.26.21265535; this version posted October 28, 2021. The copyright holder for this preprint (which was not certified by peer review) is the author/funder, who has granted medRxiv a license to display the preprint in perpetuity. It is made available under a CC-BY-NC 4.0 International license .

122. Lee YJ. Informing women and improving sanitation: Evidence from rural India. Journal of Rural Studies 2017; 55: 203-15.

123. Mannan F. Are organizations accountable? Disconnect between gender and sanitation in Bangladesh. Environment and Urbanization Asia 2018; 9(1): 101-6.

124. Mohankumar A. Narrating the Stench Testimonies of Women Engaged in Manual Scavenging in Udaipur, Rajasthan. Indian Journal of Dalit and Tribal Social Work 2015; 3(2): 45-68.

125. Pardeshi G. Women in total sanitation campaign: a case study from Yavatmal district, Maharashtra, India. Journal of Human Ecology 2009; 25(2): 79-85.

126. Routray P, Torondel B, Jenkins MW, Clasen T, Schmidt W. Processes and challenges of community mobilisation for latrine promotion under Nirmal Bharat Abhiyan in rural Odisha, India. BMC Public Health 2017; 17: 453.

127. Shahid M. Manual scavenging: Issues of caste, culture and violence. Social Change 2015; 45(2): 242-55.

128. Simiyu S, Swilling M, Cairncross S. Decision-making on shared sanitation in the informal settlements of Kisumu, Kenya. International Journal of Environmental Health Research 2017; 27(5): 377-93.

129. Thuita W, Conn C, Wilson K. The role of marginalised women in sanitation initiatives:

Somali women in northern Kenya. Development in Practice 2017; 27(1): 16-25.

130. Varickanickal J, Bisung E, Elliott SJ. Water risk perceptions across the life-course of women in Kenya. Health Promotion International 2019.

131. von Medeazza G, Jain M, Tiwari A, Shukla JP, Kumar N. Women-led total sanitation:

Saving lives and dignity. In: Cronin AA, Mehta PK, Prakash A, eds. Gender Issues in Water and Sanitation Programmes: Lessons from India: SAGE Publications Pvt. Ltd.; 2015: 231-49.

132. Waterkeyn J, Cairncross S. Creating demand for sanitation and hygiene through Community Health Clubs: A cost-effective intervention in two districts in Zimbabwe. Social Science \& Medicine 2005; 61(9): 1958-70.

133. Winter SC, Barchi F, Dzombo MN. Not just any toilet-women's solutions to sanitation in informal settlements in Nairobi. Development in Practice 2019; 29(1): 15-25.

134. Bustamente RR, Peredo E, Udaeta ME. Women in the "water war" in the Cochabamba Valleys. Opposing Currents The Politics of Water and Gender in Latin America. Pittsburgh: University of Pittsburgh Press; 2005: 72-89.

135. Delgado JV, Zwarteveen M. The public and private domain of the everyday politics of water: the constructions of gender and water power in the Andes of Perú. International Feminist Journal of Politics 2007; 9(4): 503-11.

136. Mommen B, Humphries-Waa K, Gwavuya S. Does women's participation in water committees affect management and water system performance in rural Vanuatu. Waterlines 2017; 36(3): 216-32.

137. Sam J, Todd SK. Women as hand pump technicians: Empowering women and enhancing participation in rural water supply projects. Development in Practice 2020; 30(3).

138. Singh N. The changing role of women in water management: Myths and realities. In:

Kalnická Z, ed. Water \& Women in Past, Present, and Future; 2006: 94-113.

139. Van Houweling E. "A good wife brings her husband bath water": Gender roles and water practices in Nampula, Mozambique. Society \& Natural Resources 2016; 29(9): 1065-78.

140. O'Reilly K, Louis E. The toilet tripod: Understanding successful sanitation in rural India. Health \& place 2014; 29: 43-51. 
medRxiv preprint doi: https://doi.org/10.1101/2021.10.26.21265535; this version posted October 28, 2021. The copyright holder for this preprint (which was not certified by peer review) is the author/funder, who has granted medRxiv a license to display the preprint in perpetuity. It is made available under a CC-BY-NC 4.0 International license .

141. Hoque BA, Aziz KM, Hasan KZ, Sack RB. Women's involvement in a rural Bangladesh water and sanitation project. The Southeast Asian Journal of Tropical Medicine and Public Health 1994; 25(1): 67-73.

142. Pardeshi G, Shirke A, Jagtap M. SWOT analysis of total sanitation campaign in Yavatmal district of Maharashtra. Indian Journal of Community Medicine 2008; 33(4): 255-9. 143. Smith MA, Garbharran H, Edwards MJ, O'Hara-Murdock P. Health promotion and disease prevention through sanitation education in South African Zulu and Xhosa women. Journal of Transcultural Nursing 2004; 15(1): 62-8.

144. Acey C. Gender and community mobilisation for urban water infrastructure investment in southern Nigeria. Gender \& Development 2010; 18(1): 11-26.

145. Anderson K, Clow B, Haworth-Brockman M. Carriers of water: Aboriginal women's experiences, relationships, and reflections. Journal of Cleaner Production 2013; 60: 11-7.

146. Bisung E, Elliott SJ, Abudho B, Karanja DM, Schuster-Wallace CJ. Using photovoice as a community based participatory research tool for changing water, sanitation, and hygiene behaviours in Usoma, Kenya. BioMed Research International 2015; 2015.

147. de Moraes AFJ, Rocha C. Gendered waters: the participation of women in the 'One Million Cisterns' rainwater harvesting program in the Brazilian Semi-Arid region. Journal of Cleaner Production 2013; 60: 163-9.

148. Enabor B. Integrated water management by urban poor women: A Nigerian slum experience. International Journal of Water Resources Development 1998; 14(4): 505-12.

149. Ennis-McMillan MC. Suffering from water: social origins of bodily distress in a Mexican community. Medical Anthropology Quarterly 2001; 15(3): 368-90.

150. Kernecker M, Vogl CR, Meléndez AA. Women's local knowledge of water resources and adaptation to landscape change in the mountains of Veracruz, Mexico. Ecology and Society 2017; 22(4).

151. Mushavi RC, Burns BFO, Kakuhikire B, et al. "When you have no water, it means you have no peace": A mixed-methods, whole-population study of water insecurity and depression in rural Uganda. Social Science \& Medicine 2020; 245: 112561.

152. Nerkar SS, Tamhankar AJ, Johansson E, Lundborg CS. Improvement in health and empowerment of families as a result of watershed management in a tribal area in India-a qualitative study. BMC International Health and Human Rights 2013; 13(42).

153. Privott M. An ethos of responsibility and indigenous women water protectors in the \#NoDAPL movement. American Indian Quarterly 2019; 43(1): 74-100.

154. Bapat M, Agarwal I. Our needs, our priorities; women and men from the slums in Mumbai and Pune talk about their needs for water and sanitation. Environment and Urbanization 2003; 15(2): 71-86.

155. Bisung E, Elliott SJ, Abudho B, Schuster-Wallace CJ, Karanja DM. Dreaming of toilets: Using photovoice to explore knowledge, attitudes and practices around water-health linkages in rural Kenya. Health \& Place 2015; 31: 208-15.

156. Bisung E, Elliott SJ. 'Everyone is exhausted and frustrated': Exploring psychosocial impacts of the lack of access to safe water and adequate sanitation in Usoma, Kenya. Journal of Water, Sanitation and Hygiene for Development 2016; 6(2): 205-14.

157. Belur J, Parikh P, Daruwalla N, Joshi R, Fernandes R. Perceptions of gender-based violence around public toilets in Mumbai slums. International Journal of Comparative and Applied Criminal Justice 2017; 41(1-2): 63-78. 
medRxiv preprint doi: https://doi.org/10.1101/2021.10.26.21265535; this version posted October 28, 2021. The copyright holder for this preprint (which was not certified by peer review) is the author/funder, who has granted medRxiv a license to display the preprint in perpetuity. It is made available under a CC-BY-NC 4.0 International license .

158. Hirve S, Lele P, Sundaram N, et al. Psychosocial stress associated with sanitation practices: Experiences of women in a rural community in India. Journal of Water, Sanitation and Hygiene for Development 2015; 5(1): 115-26.

159. Joshi N. Low-income women's right to sanitation services in city public spaces: A study of waste picker women in Pune. Environment and Urbanization 2018; 30(1): 249-64.

160. Kulkarni S, O’Reilly K, Bhat S. No relief: Lived experiences of inadequate sanitation access of poor urban women in India. Gender \& Development 2017; 25(2): 167-83.

161. Shiras T, Cumming O, Brown J, Muneme B, Nala R, Dreibelbis R. Shared latrines in Maputo, Mozambique: Exploring emotional well-being and psychosocial stress. $B M C$ International Health and Human Rights 2018; 18(30).

162. Coles A. Domestic water provision and gender roles in drylands. Hagar Studies in Culture, Policy and Identities 2009; 9(1): 175-91.

163. Faisal IM, Kabir MR. An analysis of gender-water nexus in rural Bangladesh. Journal of Developing Societies 2005; 21(1-2): 175-94.

164. MacRae ER, Clasen T, Dasmohapatra M, Caruso BA. 'It's like a burden on the head': Redefining adequate menstrual hygiene management throughout women's varied life stages in Odisha, India. PloS one 2019; 14(8): e0220114.

165. Pommells M, Schuster-Wallace C, Watt S, Mulawa Z. Gender violence as a water, sanitation, and hygiene risk: Uncovering violence against women and girls as it pertains to poor WaSH access. Violence Against Women 2018; 24(15): 1851-62.

166. Singh N, Jacks G, Bhattacharya P. Women and community water supply programmes: An analysis from a socio-cultural perspective. Natural Resources Forum 2005; 29(3): 213-23. 167. Hulland KRS, Chase RP, Caruso BA, et al. Sanitation, stress, and life stage: A systematic data collection study among women in Odisha, India. PloS One 2015; 10(11): e 0141883.

168. Routray P, Schmidt W, Boisson S, Clasen T, Jenkins MW. Socio-cultural and behavioural factors constraining latrine adoption in rural coastal Odisha: An exploratory qualitative study. BMC Public Health 2015; 15: 880.

169. Sommer M, Munoz-Laboy M, Wilkinson Salamea E, et al. How narratives of fear shape girls' participation in community life in two conflict-affected populations. Violence Against Women 2018; 24(5): 565-85.

170. Caruso BA, Clasen TF, Hadley C, et al. Understanding and defining sanitation insecurity: Women's gendered experiences of urination, defecation and menstruation in rural Odisha, India. BMJ Global Health 2017; 2(4): e000414.

171. Ellis A, Haver J, Villasenor J, et al. WASH challenges to girls' menstrual hygiene management in Metro Manila, Masbate, and South Central Mindanao, Philippines. Waterlines 2016; 35(3): 306-23.

172. Kwiringira J, Atekyereza P, Niwagaba C, Günther I. Gender variations in access, choice to use and cleaning of shared latrines; experiences from Kampala Slums, Uganda. BMC Public Health 2014; 14(1): 1180.

173. Nallari A. "All we want are toilets inside our homes!" The critical role of sanitation in the lives of urban poor adolescent girls in Bengaluru, India. Environment and Urbanization 2015; 27(1): 73-88.

174. Rheinländer T, Gyapong M, Akpakli DE, Konradsen F. Secrets, shame and discipline: School girls' experiences of sanitation and menstrual hygiene management in a peri-urban community in Ghana. Health Care for Women International 2019; 40(1): 13-32. 
medRxiv preprint doi: https://doi.org/10.1101/2021.10.26.21265535; this version posted October 28, 2021. The copyright holder for this preprint (which was not certified by peer review) is the author/funder, who has granted medRxiv a license to display the preprint in perpetuity. It is made available under a CC-BY-NC 4.0 International license .

175. Sahoo KC, Hulland KRS, Caruso BA, et al. Sanitation-related psychosocial stress: a grounded theory study of women across the life-course in Odisha, India. Social Science \& Medicine 2015; 139: 80-9.

176. Singh KK, Mishra P. Understanding women's access to sanitation: A study of the slums in Delhi. Journal of Social Inclusion Studies 2019; 5(2): 200-9.

177. Winter SC, Barchi F, Dzombo MN. Drivers of women's sanitation practices in informal settlements in sub-Saharan Africa: A qualitative study in Mathare Valley, Kenya. International Journal of Environmental Health Research 2018; 28(6): 609-25.

178. Aihara Y, Shrestha S, Sharma J. Household water insecurity, depression and quality of life among postnatal women living in urban Nepal. Journal of Water and Health 2016; 14(2): 317-24.

179. Andajani S, Chirawatkul S, Saito E. Gender and water in Northeast Thailand: inequalities and women's realities. Journal of International Women's Studies 2015; 16(2): 200-12.

180. Arku FS. Time savings from easy access to clean water: Implications for rural men's and women's well-being. Progress in Development Studies 2010; 10(3): 233-46.

181. Baker KK, Padhi B, Torondel B, et al. From menarche to menopause: A populationbased assessment of water, sanitation, and hygiene risk factors for reproductive tract infection symptoms over life stages in rural girls and women in India. PloS One 2017; 12(12): e0188234.

182. Bisung E, Elliott SJ. Improvement in access to safe water, household water insecurity, and time savings: A cross-sectional retrospective study in Kenya. Social Science \& Medicine 2018; 200: 1-8.

183. Chew JF, Corlin L, Ona F, et al. Water source preferences and water quality perceptions among women in the eastern region, Ghana: a grounded theory study. International Journal of Environmental Research and Public Health 2019; 16(20): 3835.

184. Collins SM, Mbullo Owuor P, Miller JD, et al. "I know how stressful it is to lack water!' Exploring the lived experiences of household water insecurity among pregnant and postpartum women in western Kenya. Global Public Health 2019; 14(5): 649-62.

185. Crow B, Sultana F. Gender, class, and access to water: Three cases in a poor and crowded delta. Society \& Natural Resources 2002; 15(8): 709-24.

186. Crow B, Odaba E. Access to water in a Nairobi slum: Women's work and institutional learning. Water International 2010; 35(6): 733-47.

187. Hanrahan M, Mercer N. Gender and water insecurity in a subarctic Indigenous community. The Canadian Geographer 2019; 63(2): 211-24.

188. Krumdieck NR, Collins SM, Wekesa P, et al. Household water insecurity is associated with a range of negative consequences among pregnant Kenyan women of mixed HIV status. Journal of Water and Health 2016; 14(6): 1028-31.

189. Malhotra A, Goli S, Coates S, Mosquera-Vasquez M. Factors associated with knowledge, attitudes, and hygiene practices during menstruation among adolescent girls in Uttar Pradesh. Waterlines 2016; 35(3): 277-305.

190. Trinies V, Freeman MC, Hennink M, Clasen T. The role of social networks on the uptake of household water filters by women in self-help groups in rural India. Journal of Water, Sanitation and Hygiene for Development 2011; 1(4): 224-32.

191. Tsai AC, Kakuhikire B, Mushavi R, et al. Population-based study of intra-household gender differences in water insecurity: Reliability and validity of a survey instrument for use in rural Uganda. Journal of Water and Health 2016; 14(2): 280-92. 
medRxiv preprint doi: https://doi.org/10.1101/2021.10.26.21265535; this version posted October 28, 2021. The copyright holder for this preprint (which was not certified by peer review) is the author/funder, who has granted medRxiv a license to display the preprint in perpetuity. It is made available under a CC-BY-NC 4.0 International license .

192. Van Houweling E, Hall R, Diop AS, Davis J, Seiss M. The role of productive water use in women's livelihoods. Evidence from rural Senegal. Water Alternatives 2012; 5(3): 658.

193. Wall LL, Teklay K, Desta A, Belay S. Tending the 'monthly flower:'a qualitative study of menstrual beliefs in Tigray, Ethiopia. BMC Women's Health 2018; 18(1): 183.

194. Wood S, Foster J, Kols A. Understanding why women adopt and sustain home water treatment: insights from the Malawi antenatal care program. Social Science \& Medicine 2012; 75(4): 634-42.

195. Wutich A. Intrahousehold disparities in women and men's experiences of water insecurity and emotional distress in urban Bolivia. Medical Anthropology Quarterly 2009; 23(4): 436-54.

196. Zolnikov TR, Salafia EB. Improved relationships in eastern Kenya from water interventions and access to water. Health Psychology 2016; 35(3): 273.

197. Boosey R, Prestwich G, Deave T. Menstrual hygiene management amongst schoolgirls in the Rukungiri district of Uganda and the impact on their education: a cross-sectional study. Pan African Medical Journal 2014; 19(253).

198. Bora S, Chatterjee A, Rani P, Chakrabarti D. On-the-job stress: Interventions to improve the occupational well-being of policewomen in Assam, India. Journal of International Women's Studies 2016; 18(1): 260-72.

199. Connolly S, Sommer M. Cambodian girls' recommendations for facilitating menstrual hygiene management in school. Journal of Water, Sanitation and Hygiene for Development 2013; 3(4): 612-22.

200. Datta A, Ahmed N. Intimate infrastructures: The rubrics of gendered safety and urban violence in Kerala, India. Geoforum 2020; 110: 67-76.

201. Hall NL. Women and girls in remote Indigenous Australian communities: Cultural, financial and knowledge barriers to menstrual hygiene management. Australian Indigenous Health Bulletin 2018; 18(2).

202. Jewitt S, Ryley H. It's a girl thing: Menstruation, school attendance, spatial mobility and wider gender inequalities in Kenya. Geoforum 2014; 56: 137-47.

203. Joshi D, Fawcett B, Mannan F. Sanitation for the urban poor: Gender matters. In:

Zwarteveen M, Ahmed S, eds. Diverting the Flow: Gender Equity and Water in South Asia. New Delhi: Zubaan; 2012: 175-202.

204. Joshy N, Prakash K, Ramdey K. Social taboos and menstrual practices in the Pindar Valley. Indian Journal of Gender Studies 2019; 26(1-2): 79-95.

205. Karin S. Status of Rohingya refugees in Bangladesh: A comparative study with emphasis on aspects of women and girls in camps of Kutupalong, Cox's Bazar, Bangladesh. Open Access Library Journal 2020; 7(01): e5831.

206. Mbatha T. Addressing girls' challenges of water and sanitation in a rural schooling context in Swaziland. Agenda 2011; 25(2): 35-42.

207. McMahon SA, Winch PP, Caruso BA, et al. 'The girl with her period is the one to hang her head' Reflections on menstrual management among schoolgirls in rural Kenya. $B M C$

International Health and Human Rights 2011; 11(7).

208. Nalugya R, Tanton C, Hytti L, et al. Assessing the effectiveness of a comprehensive menstrual health intervention program in Ugandan schools (MENISCUS): Process evaluation of a pilot intervention study. Pilot and Feasibility Studies 2020; 6(51): 1-15.

209. Norling M, Stenzelius K, Ekman N, Wennick A. High school students' experiences in school toilets or restrooms. The Journal of School Nursing 2016; 32(3): 164-71. 
medRxiv preprint doi: https://doi.org/10.1101/2021.10.26.21265535; this version posted October 28, 2021. The copyright holder for this preprint (which was not certified by peer review) is the author/funder, who has granted medRxiv a license to display the preprint in perpetuity. It is made available under a CC-BY-NC 4.0 International license .

210. Rajagopal S, Mathur K. 'Breaking the silence around menstruation': Experiences of adolescent girls in an urban setting in India. Gender \& Development 2017; 25(2): 303-17.

211. Rajbangshi PR, Nambiar D. "Who will stand up for us?" the social determinants of health of women tea plantation workers in India. International Journal for Equity in Health 2020; 19(29).

212. Reddy BS, Snehalatha M. Sanitation and personal hygiene: what does it mean to poor and vulnerable women? Indian Journal of Gender Studies 2011; 18(3): 381-404.

213. Reddy YM, Raghavan S, Vedala SC. A narrative exposition on public toilet usage by women: A study from Warangal. Indian Journal of Gender Studies 2019; 26(1-2): 108-37. 214. Schmitt ML, Clatworthy D, Ratnayake R, et al. Understanding the menstrual hygiene management challenges facing displaced girls and women: Findings from qualitative assessments in Myanmar and Lebanon. Conflict and Health 2017; 11(19).

215. Silva BB, Sales B, Lanza AC, Heller L, Rezende S. Water and sanitation are not genderneutral: Human rights in rural Brazilian communities. Water Policy 2020; 22: 102-20.

216. Sommer M. Where the education system and women's bodies collide: The social and health impact of girls' experiences of menstruation and schooling in Tanzania. Journal of Adolescence 2010; 33(4): 521-9.

217. Thompson JA, Gaskin SJ, Agbor M. Embodied intersections: Gender, water and sanitation in Cameroon. Agenda 2017; 31(1): 140-55.

218. Wutich A, Ragsdale K. Water insecurity and emotional distress: Coping with supply, access, and seasonal variability of water in a Bolivian squatter settlement. Social Science \& Medicine 2008; 67(12): 2116-25.

219. Abrahams N, Mathews S, Ramela P. Intersections of 'sanitation, sexual coercion and girls' safety in schools'. Tropical Medicine \& International Health 2006; 11(5): 751-6.

220. Alam M, Luby SP, Halder AK, et al. Menstrual hygiene management among Bangladeshi adolescent schoolgirls and risk factors affecting school absence: Results from a cross-sectional survey. BMJ Open 2017; 7(7): e015508.

221. Anyarayor BK, Alhassan A, Faisal AM. Access to improved sanitation facilities and female school attendance: a study of Savelugu Municipality of Ghana. Journal of Arts and Humanities 2019; 9(1): 56-67.

222. Camenga DR, Brady SS, Hardacker CT, et al. US adolescent and adult women's experiences accessing and using toilets in schools, workplaces, and public spaces: A multi-site focus group study to inform future research in bladder health. International Journal of Environmental Research and Public Health 2019; 16(18): 3338.

223. Carolini GY. Framing water, sanitation, and hygiene needs among female-headed households in periurban Maputo, Mozambique. American Journal of Public Health 2012; 102(2): 256-61.

224. Caruso BA, Clasen T, Yount KM, Cooper HLF, Hadley C, Haardörfer R. Assessing women's negative sanitation experiences and concerns: the development of a novel sanitation insecurity measure. International Journal of Environmental Research and Public Health 2017; 14(7): 755 .

225. Corburn J, Hildebrand C. Slum sanitation and the social determinants of women's health in Nairobi, Kenya. Journal of Environmental and Public health 2015; 2015.

226. Corburn J, Karanja I. Informal settlements and a relational view of health in Nairobi, Kenya: Sanitation, gender and dignity. Health Promotion International 2016; 31(2): 258-69. 
medRxiv preprint doi: https://doi.org/10.1101/2021.10.26.21265535; this version posted October 28, 2021. The copyright holder for this preprint (which was not certified by peer review) is the author/funder, who has granted medRxiv a license to display the preprint in perpetuity. It is made available under a CC-BY-NC 4.0 International license .

227. Coswosk ÉD, Neves-Silva P, Modena CM, Heller L. Having a toilet is not enough: the limitations in fulfilling the human rights to water and sanitation in a municipal school in Bahia, Brazil. BMC Public Health 2019; 19(1): 137.

228. Dudeja P, Sindhu A, Shankar P, Gadekar T. A cross-sectional study to assess awareness about menstruation in adolescent girls of an urban slum in western Maharashtra. International Journal of Adolescent Medicine and Health 2016; 30(4).

229. Girod C, Ellis A, Andes KL, Freeman MC, Caruso BA. Physical, social, and political inequities constraining girls' menstrual management at schools in informal settlements of Nairobi, Kenya. Journal of Urban Health 2017; 94(6): 835-46.

230. Kher J, Aggarwal S, Punhani G. Vulnerability of poor urban women to climate-linked water insecurities at the household level: A case study of slums in Delhi. Indian Journal of Gender Studies 2015; 22(1): 15-40.

231. Kookana RS, Maheshwari B, Dillon P, et al. Groundwater scarcity impact on inclusiveness and women empowerment: Insights from school absenteeism of female students in two watersheds in India. International Journal of Inclusive Education 2016; 20(11): 1155-71. 232. Krusz E, Hall N, Barrington DJ, et al. Menstrual health and hygiene among Indigenous Australian girls and women: Barriers and opportunities. BMC Women's Health 2019; 19.

233. McCammon E, Bansal S, Hebert LE, Yan S, Menendez A, Gilliam M. Exploring young women's menstruation-related challenges in Uttar Pradesh, India, using the socio-ecological framework. Sexual and Reproductive Health Matters 2020; 28(1): 1-12.

234. Nagpal A, Hassan M, Siddiqui MA, et al. Missing basics: A study on sanitation and women's health in urban slums in Lucknow, India. GeoJournal 2019: 1-13.

235. Ngila WM, Role E, Makewa LN. Safety, sexual harassment, sanitary facilities, and household chores as threats to girl child in mixed secondary schools. Journal of International Forum of Researchers in Education (JIFORE) 2014; 1(1): 36-53.

236. Rajaraman D, Travasso SM, Heymann SJ. A qualitative study of access to sanitation amongst low-income working women in Bangalore, India. Journal of Water, Sanitation and Hygiene for Development 2013; 3(3): 432-40.

237. Scorgie F, Foster J, Stadler J, et al. "Bitten by shyness": Menstrual hygiene management, sanitation, and the quest for privacy in South Africa. Medical Anthropology 2016; 35(2): 161-76. 238. Senior E. We love our school toilets: Involving primary school students in improving their school toilets. Global Health Promotion 2014; 21(1): 23-8.

239. Sommer M, Ackatia-Armah N, Connolly S, Smiles D. A comparison of the menstruation and education experiences of girls in Tanzania, Ghana, Cambodia and Ethiopia. Compare: A Journal of Comparative and International Education 2015; 45(4): 589-609.

240. Whale K, Cramer H, Joinson C. Left behind and left out: The impact of the school environment on young people with continence problems. British Journal of Health Psychology 2018; 23(2): 253-77.

241. Winter SC, Barchi F, Dzombo MN. Neighborhood disorganization and women's sanitation utilization practices in Mathare Valley, Kenya. Environment and Behavior 2019; 51(5): 530-60.

242. Winter SC, Dreibelbis R, Barchi F. Women's sanitation practices in informal settlements: A multi-level analysis of factors influencing utilisation in Nairobi, Kenya. Global Public Health 2019; 14(5): 663-74. 
medRxiv preprint doi: https://doi.org/10.1101/2021.10.26.21265535; this version posted October 28, 2021. The copyright holder for this preprint (which was not certified by peer review) is the author/funder, who has granted medRxiv a license to display the preprint in perpetuity. It is made available under a CC-BY-NC 4.0 International license .

243. You J, Staddon C, Cook A, et al. Multidimensional Benefits of Improved Sanitation: Evaluating 'PEE POWER ${ }^{\circledR}$ 'in Kisoro, Uganda. International Journal of Environmental Research and Public Health 2020; 17(7): 2175.

244. Asaba RB, Fagan H, Kabonesa C, Mugumya F. Beyond distance and time: Gender and the burden of water collection in rural Uganda. wH2O: Journal of Gender and Water 2013; 2(1): 31-8.

245. Fonjong LN, Ngekwi MA. Challenges of water crisis on women's socio-economic activities in the Buea Municipality, Cameroon. Journal of Geography and Geology 2014; 6(4): 122.

246. Karim KMR, Emmelin M, Resurreccion BP, Wamala S. Water development projects and marital violence: Experiences from rural Bangladesh. Health Care for Women International 2012; 33(3): 200-16.

247. Van Houweling E. Gendered water spaces: A study of the transition from wells to handpumps in Mozambique. Gender, Place \& Culture 2015; 22(10): 1391-407.

248. Barchi F, Winter SC. Non-partner violence in Sub-Saharan Africa and the built environment: a multicountry analysis of the effects of sanitation, water access, and urban settings. Violence Against Women 2020; 26(10): 1101-19.

249. Adriaenssens S, Hendrickx J. "Bad jobs": a case study of toilet attendants. Employee Relations: The International Journal 2019; 41(3): 489-505.

250. Bangdiwala SI, Ramiro L, Sadowski LS, Bordin IAS, Hunter W, Shankar V. Intimate partner violence and the role of socioeconomic indicators in WorldSAFE communities in Chile, Egypt, India and the Philippines. Injury Control and Safety Promotion 2004; 11(2): 101-9. 251. Gonsalves GS, Kaplan EH, Paltiel AD. Reducing sexual violence by increasing the supply of toilets in Khayelitsha, South Africa: a mathematical model. PLoS One 2015; 10(4): e0122244.

252. Hassan F, Sadowski LS, Bangdiwala SI, et al. Physical intimate partner violence in Chile, Egypt, India and the Philippines. Injury Control and Safety Promotion 2004; 11(2): 111-6. 253. Hennegan J, Zimmerman L, Shannon AK, et al. The relationship between household sanitation and women's experience of menstrual hygiene: Findings from a cross-sectional survey in Kaduna State, Nigeria. International Journal of Environmental Research and Public Health 2018; 15(5): 905.

254. Jadhav A, Weitzman A, Smith-Greenaway E. Household sanitation facilities and women's risk of non-partner sexual violence in India. BMC Public Health 2016; 16(1): 1139. 255. Winter SC, Barchi F. Access to sanitation and violence against women: Evidence from Demographic Health Survey (DHS) data in Kenya. International Journal of Environmental Health Research 2015; 26(3): 291-305.

256. Winter SC, Dreibelbis R, Dzombo MN, Barchi F. A mixed-methods study of women's sanitation utilization in informal settlements in Kenya. PloS One 2019; 14(3): e0214114.

257. Aihara Y, Shrestha S, Kazama F, Nishida K. Validation of household water insecurity scale in urban Nepal. Water Policy 2015; 17(6): 1019-32.

258. Brewis A, Choudhary N, Wutich A. Low water access as a gendered physiological stressor: Blood pressure evidence from Nepal. American Journal of Human Biology 2019; 31(3): e23234.

259. Buor D. Water needs and women's health in the Kumasi metropolitan area, Ghana. Health \& Place 2004; 10(1): 85-103. 
medRxiv preprint doi: https://doi.org/10.1101/2021.10.26.21265535; this version posted October 28, 2021. The copyright holder for this preprint (which was not certified by peer review) is the author/funder, who has granted medRxiv a license to display the preprint in perpetuity. It is made available under a CC-BY-NC 4.0 International license .

260. Cooper-Vince CE, Kakuhikire B, Vorechovska D, et al. Household water insecurity, missed schooling, and the mediating role of caregiver depression in rural Uganda. Global Mental Health 2017; 4: e15.

261. Cooper-Vince CE, Arachy H, Kakuhikire B, et al. Water insecurity and gendered risk for depression in rural Uganda: A hotspot analysis. BMC Public Health 2018; 18(1): 1143.

262. Geere J, Bartram J, Bates L, et al. Carrying water may be a major contributor to disability from musculoskeletal disorders in low income countries: A cross-sectional survey in South Africa, Ghana and Vietnam. Journal of Global Health 2018; 8(1).

263. Mehretu A, Mutambirwa C. Gender differences in time and energy costs of distance for regular domestic chores in rural Zimbabwe: A case study in the Chiduku Communal Area. World Development 1992; 20(11): 1675-83.

264. Nankinga O, Aguta D. Determinants of Anemia among women in Uganda: Further analysis of the Uganda demographic and health surveys. BMC Public Health 2019; 19: 1757. 265. Narain V. Shifting the focus from women to gender relations: Assessing the impacts of water supply interventions in the Morni-Shiwalik hills of northwest India. Mountain Research and Development 2014; 34(3): 208-13.

266. Siddiqui RN, Pandey J. Coping with environmental stressors by urban slum dwellers. Environment and Behavior 2003; 35(5): 589-604.

267. Stevenson EGJ, Ambelu A, Caruso BA, Tesfaye Y, Freeman MC. Community water improvement, household water insecurity, and women's psychological distress: An intervention and control study in Ethiopia. PloS One 2016; 11(4): e0153432.

268. White S, Kuper H, Itimu-Phiri A, Holm R, Biran A. A qualitative study of barriers to accessing water, sanitation and hygiene for disabled people in Malawi. PloS One 2016; 11(5): e0155043.

269. Winter SC, Obara LM, McMahon S. Intimate partner violence: A key correlate of women's physical and mental health in informal settlements in Nairobi, Kenya. PloS One 2020; 15(4): e0230894.

270. Cheng JJ, Schuster-Wallace CJ, Watt S, Newbold BK, Mente A. An ecological quantification of the relationships between water, sanitation and infant, child, and maternal mortality. Environmental Health 2012; 11(1): 4.

271. Das P, Baker KK, Dutta A, et al. Menstrual hygiene practices, WASH access and the risk of urogenital infection in women from Odisha, India. PloS One 2015; 10(6): e0130777.

272. Klugman J, Li L, Barker KM, Parsons J, Dale K. How are the domains of women's inclusion, justice, and security associated with maternal and infant mortality across countries? Insights from the Women, Peace, and Security Index. SSM-Population Health 2019; 9: 100486. 273. Sommer JM, Shandra JM, Restivo M, Coburn C. Water, sanitation, and health in sub-Saharan Africa: A cross-national analysis of maternal and neo-natal mortality. Human Ecology Review 2015; 22(1): 129-52.

274. Winter SC, Dzombo MN, Barchi F. Exploring the complex relationship between women's sanitation practices and household diarrhea in the slums of Nairobi: a cross-sectional study. BMC Infectious Diseases 2019; 19(1): 242.

275. Winter SC, Obara LM, Barchi F. Environmental correlates of health-related quality of life among women living in informal settlements in Kenya. International Journal of Environmental Research and Public Health 2019; 16(20): 3948.

276. Janmohamed A, Karakochuk CD, McLean J, Green TJ. Improved sanitation facilities are associated with higher body mass index and higher hemoglobin concentration among rural 
medRxiv preprint doi: https://doi.org/10.1101/2021.10.26.21265535; this version posted October 28, 2021. The copyright holder for this preprint (which was not certified by peer review) is the author/funder, who has granted medRxiv a license to display the preprint in perpetuity. It is made available under a CC-BY-NC 4.0 International license .

Cambodian women in the first trimester of pregnancy. American Journal of Tropical Medicine and Hygiene 2016; 95(5): 1211-5.

277. Tegegne TK, Sisay MM. Menstrual hygiene management and school absenteeism among female adolescent students in Northeast Ethiopia. BMC Public Health 2014; 14(1): 1118.

278. Boateng GO, Collins SM, Mbullo P, et al. A novel household water insecurity scale: Procedures and psychometric analysis among postpartum women in western Kenya. PloS one 2018; 13(6): e0198591.

279. Daniel D, Diener A, Pande S, et al. Understanding the effect of socio-economic characteristics and psychosocial factors on household water treatment practices in rural Nepal using Bayesian Belief Networks. International Journal of Hygiene and Environmental Health 2019; 222(5): 847-55.

280. Fiasorgbor DA. Water and sanitation situation in Nima and Teshie, Greater Accra region of Ghana. Journal of Toxicology and Environmental Health Sciences 2013; 5(2): 23-8.

281. Ilahi N, Grimard F. Public infrastructure and private costs: Water supply and time allocation of women in rural Pakistan. Economic Development and Cultural Change 2000; 49(1): 45-75.

282. Prasad S, Acharya S, Basu S. Leadership and participation: Role of gender. In: Cronin AA, Mehta PK, Prakash A, eds. Gender Issues in Water and Sanitation Programmes: Lessons from India: SAGE Publications Pvt. Ltd.; 2015: 190-208.

283. Prasad CSS, Ray I. 'When you start doing this work, it is hard to eat dal': Life and work of manual scavengers. Economic and Political Weekly 2018; 53(32): 25-7.

284. Kodjebacheva GD, Lapeyrouse LM, Rahrig J, Walker L, Campbell K. Strategies to promote safe water drinking identified by and for women of reproductive age. American Journal of Health Promotion 2019; 33(5): 756-9.

285. Leventhal KS, DeMaria LM, Gillham JE, Andrew G, Peabody J, Leventhal SM. A psychosocial resilience curriculum provides the "missing piece" to boost adolescent physical health: A randomized controlled trial of Girls First in India. Social Science \& Medicine 2016; 161: $37-46$.

286. Dreibelbis R, Greene LE, Freeman MC, Saboori S, Chase RP, Rheingans R. Water, sanitation, and primary school attendance: A multi-level assessment of determinants of household-reported absence in Kenya. International Journal of Educational Development 2013; 33(5): 457-65.

287. Arku FS, Arku C. I cannot drink water on an empty stomach: A gender perspective on living with drought. Gender \& Development 2010; 18(1): 115-24.

288. Irianti S, Prasetyoputra P. The struggle for water in Indonesia: The role of women and children as household water fetcher. Journal of Water, Sanitation and Hygiene for Development 2019; 9(3): 540-8.

289. Porter G, Hampshire K, Abane A, et al. Mobility, education and livelihood trajectories for young people in rural Ghana: a gender perspective. Children's Geographies 2011; 9(3-4): 395-410.

290. Ramanaik S, Collumbien M, Prakash R, et al. Education, poverty and" purity" in the context of adolescent girls' secondary school retention and dropout: A qualitative study from Karnataka, southern India. PLoS One 2018; 13(9): e0202470.

291. Willetts J, Halcrow G, Carrard N, Rowland C, Crawford J. Addressing two critical MDGs together: Gender in water, sanitation and hygiene initiative. Pacific Economic Bulletin 2010; 25(1): 162-76. 
medRxiv preprint doi: https://doi.org/10.1101/2021.10.26.21265535; this version posted October 28, 2021. The copyright holder for this preprint (which was not certified by peer review) is the author/funder, who has granted medRxiv a license to display the preprint in perpetuity. It is made available under a CC-BY-NC 4.0 International license .

292. McLean L, Heise LL, Stern EA. Shifting and transforming gender-inequitable beliefs, behaviours and norms in intimate partnerships: The Indashyikirwa couples programme in Rwanda. Culture, Health \& Sexuality 2019: 1-18.

293. Aluko OO, Oloruntoba EO, Chukwunenye UA, Henry EU, Ojogun E. The dynamics and determinants of household shared sanitation cleanliness in a heterogeneous urban settlement in Southwest Nigeria. Public Health 2018; 165: 125-35.

294. Agesa RU, Agesa J. Time spent on household chores (fetching water) and the alternatives forgone for women in sub-Saharan Africa: evidence from Kenya. The Journal of Developing Areas 2019; 53(2).

295. Priya P, Venkatesh A, Shukla A. Two decades of theorising and measuring women's empowerment: Literature review and future research agenda. Women's Studies International Forum 2021; 87: 102495.

296. Richardson RA. Measuring women's empowerment: A critical review of current practices and recommendations for researchers. Social Indicators Research 2018; 137(2): 53957.

297. Dickin S, Bisung E, Nansi J, Charles K. Empowerment in water, sanitation and hygiene index. World Development 2021; 137: 105158.

298. Sinharoy S, Conrad A, Patrick M, McManus S, Caruso B. Development and validation protocol for an instrument to measure women's empowerment in urban sanitation across countries: The Agency, Resources, and Institutional Structures for Sanitation-related Empowerment (ARISE) Scales. medRxiv; 2021.

299. Water for Women. The water, sanitation and hygiene gender equality measure. In: Futures UIfS, editor.; 2020.

300. Yount KM, Peterman A, Cheong YF. Measuring women's empowerment: a need for context and caution. The Lancet Global Health 2018; 6(1): e29.

301. Pratley P. Associations between quantitative measures of women's empowerment and access to care and health status for mothers and their children: a systematic review of evidence from the developing world. Social Science \& Medicine 2016; 169: 119-31.

302. Santoso MV, Kerr RB, Hoddinott J, Garigipati P, Olmos S, Young SL. Role of women's empowerment in child nutrition outcomes: A systematic review. Advances in Nutrition 2019; 10(6): 1138-51.

303. Lawry LL, Lugo-Robles R, McIver V. Improvements to a framework for gender and emerging infectious diseases. Bulletin of the World Health Organization 2021; 99(9): 682. 304. Hawkes S, Haseen F, Aounallah-Skhiri H. Measurement and meaning: reporting sex in health research. The Lancet 2019; 393(10171): 497-9.

305. Caruso BA, Sommer M, Phillips-Howard PA. All of women's health needs are worthy of attention. The Lancet 2019; 393(10186): 2119.

306. Pickering AJ, Null C, Winch PJ, et al. The WASH Benefits and SHINE trials: interpretation of WASH intervention effects on linear growth and diarrhoea. The Lancet Global Health 2019; 7(8): e1139-e46.

307. Kearns J. Moving towards transformational WASH. The Lancet Global Health 2019; 7(11): e1493. 